\title{
TECHNOLOGIES TO ENHANCE THE OPERATION OF EXISTING NATURAL GAS COMPRESSION INFRASTRUCTURE - MANIFOLD DESIGN FOR CONTROLLING ENGINE AIR BALANCE
}

\author{
Prepared by \\ Gary D. Bourn \\ Ford A. Phillips \\ Ralph E. Harris
}

TOPICAL REPORT

Reporting Period Start Date: 10/01/05

Reporting Period End Date: 12/31/05

DOE Award No. DE-FC26-02NT41646

SwRI Project No. 03.10622

Prepared for

Mr. Richard Baker

U.S. Department of Energy

National Energy Technology Laboratory

3610 Collins Ferry Road, P.O. Box 880

Morgantown, WV 26507-0880

December 2005

SOUTHWEST RESEARCH INSTITUTE 


\title{
TECHNOLOGIES TO ENHANCE THE OPERATION OF EXISTING NATURAL GAS COMPRESSION INFRASTRUCTURE - MANIFOLD DESIGN FOR CONTROLLING ENGINE AIR BALANCE
}

\author{
Prepared by \\ Gary D. Bourn \\ Ford A. Phillips \\ Ralph E. Harris \\ TOPICAL REPORT \\ Reporting Period Start Date: 10/01/05 \\ Reporting Period End Date: 12/31/05 \\ DOE Award No. DE-FC26-02NT41646 \\ SwRI Project No. 03.10622 \\ Prepared for \\ Mr. Richard Baker \\ U.S. Department of Energy \\ National Energy Technology Laboratory
}

December 2005

Approved:

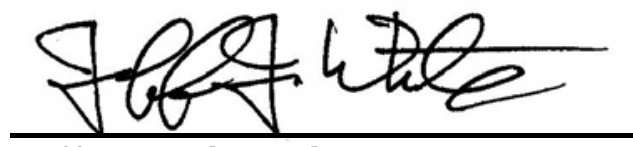

Jeff J. White, Director - Development

Department of Engine \& Emissions Research 


\section{DISCLAIMER}

This report was prepared as an account of work sponsored by an agency of the United States Government. Neither the United States nor any agency thereof, nor any of their employees, makes any warranty, express or implied, or assumes any legal liability or responsibility for the accuracy, completeness, or usefulness of any information, apparatus, product, or process disclosed, or represents that its use would not infringe privately owned rights. Reference herein to any specific commercial product, process, or service by trade name, trademark, manufacturer, or otherwise does not necessarily constitute or imply its endorsement, recommendation, or favoring by the United States Government or any agency thereof. The views and opinions of authors expressed herein do not necessarily state or reflect those of the United States Government or any agency thereof. 


\begin{abstract}
This document provides results and conclusions for Task 15.0 - Detailed Analysis of Air Balance \& Conceptual Design of Improved Air Manifolds in the "Technologies to Enhance the Operation of Existing Natural Gas Compression Infrastructure” project. SwRI ${ }^{\circledR}$ is conducting this project for DOE in conjunction with Pipeline Research Council International, Gas Machinery Research Council, El Paso Pipeline, Cooper Compression, and Southern Star, under DOE contract number DE-FC26-02NT41646. The objective of Task 15.0 was to investigate the perceived imbalance in airflow between power cylinders in two-stroke integral compressor engines and develop solutions via manifold redesign.
\end{abstract}




\section{EXECUTIVE SUMMARY}

This document provides results and conclusions for Task 15.0 - Detailed Analysis of Air Balance \& Conceptual Design of Improved Air Manifolds in the "Technologies to Enhance the Operation of Existing Natural Gas Compression Infrastructure” project. SwRI ${ }^{\circledR}$ is conducting this project for DOE in conjunction with Pipeline Research Council International, Gas Machinery Research Council, El Paso Pipeline, Cooper Compression, and Southern Star, under DOE contract number DE-FC26-02NT41646. The objective of Task 15.0 was to investigate the perceived imbalance in airflow between power cylinders in two-stroke integral compressor engines and develop solutions via manifold redesign.

The gas transmission industry operates over 4,000 integral engine compressors, the majority being two-stroke, with a median age of 45 years and a median size of 2000 horsepower. Field testing in the overall project and in other related projects has shown many of the integral engines to have inconsistent performance between cylinders on a given unit. This inconsistency has been exhibited by the tendency of one or two of the cylinders in a given unit to be more prone to either misfire or knock (detonation) than the other cylinders. Dynamic cylinder pressure measurements have shown a spread in not only peak firing pressure but also the pressure during the compression stroke. This spread in compression pressure and the tendency for misfire or detonation in one or two cylinders indicates the air/fuel ratio between cylinders is varied. A variance, or spread, in air/fuel ratio would lead to higher emissions and fuel consumption than could be achieved with balanced cylinder performance. The field data further suggests that an imbalance in cylinder airflow is a culprit leading to the variation in air/fuel ratio.

A laboratory GMVH-6 engine owned by Cooper Compression and installed in a test facility at Southwest Research Institute was used for testing and the Virtual 2-Stroke ${ }^{\circledR}$ software produced by Optimum Power Technology was used for simulation and design. Initial difficulties were experienced with validation of the one-dimensional GMVH-6 simulation model, which led to the disassembly of the engine for geometric analysis. Results of the geometric analysis and simulations on the affects of geometric variation showed that a large percentage (50 to 60 percent) of the spread in compression pressure is due to component geometry variation. Additional simulations with identical cylinder geometry, using mean values from measurements, showed only a difference in compression between banks due to articulation. These simulation results indicate that either the original manifold designs are not causing flow imbalances or that the simulation model is not providing accurate predictions. Additional testing is planned in Task 16.0 to aid quantification of model predictions.

Several conceptual manifold designs and retro-fits to the existing manifolds were developed. Development of these designs was driven by results from GMVH-6 engine test results which show the perceived air imbalance to not be as great as originally presumed. Therefore, two concepts were determined to offer potential for air balance improvement and be insensitive to random geometric variations. The first concept was a side branch absorber retro-fit to the exhaust manifold, which was shown analytically to reduce exhaust pulsations for improved cylinder isolation. The second concept was an intake manifold modification or redesign that would improve flow to each cylinder. Testing and demonstration of these concepts is planned for Task 16.0. 


\section{TABLE OF CONTENTS}

Section

Page

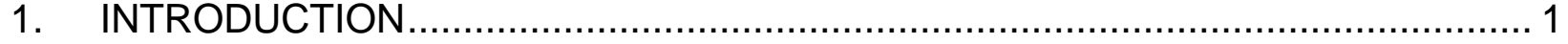

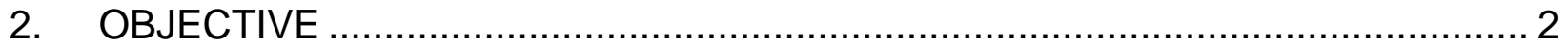

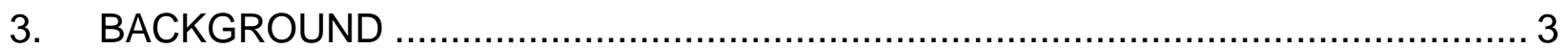

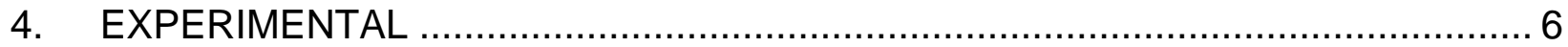

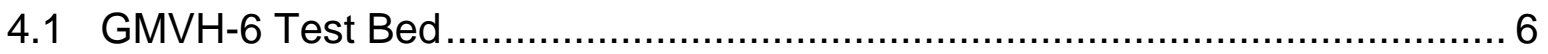

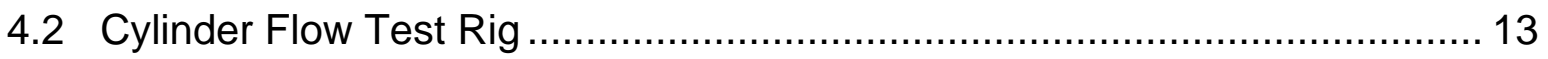

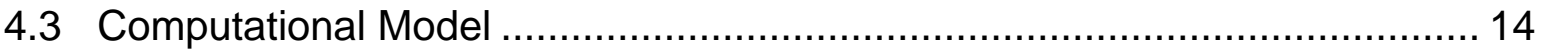

5. RESULTS AND DISCUSSION: ENGINE MEASUREMENT AND TESTING ........ 15

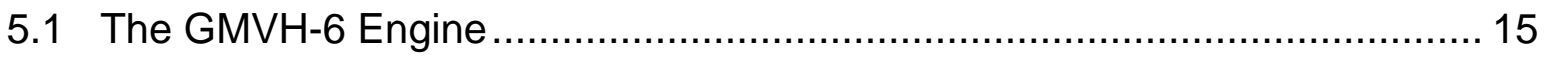

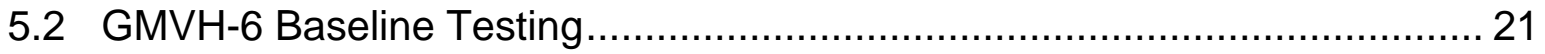

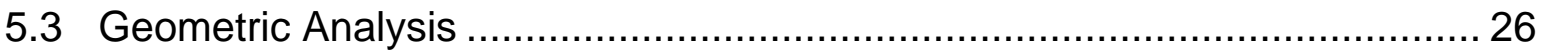

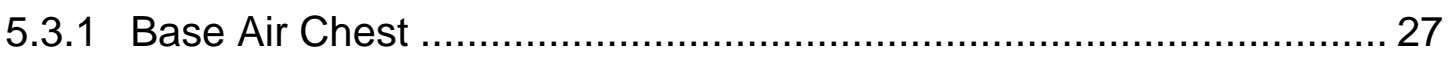

5.3.2 Cylinder Castings and Port Shape ........................................ 28

5.3.3 Cylinder Inlet Airbox ..................................................... 29

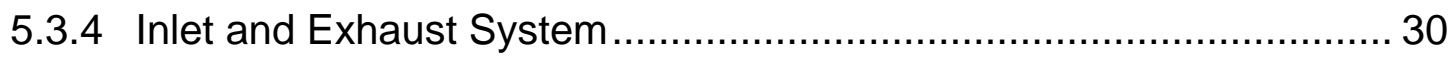

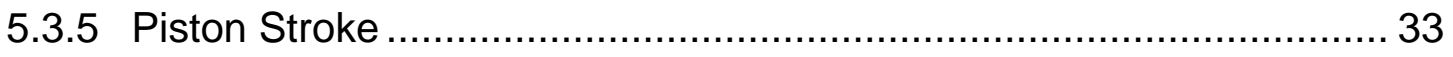

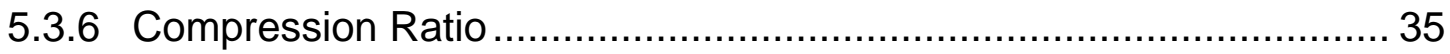

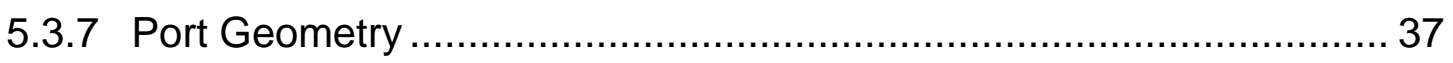

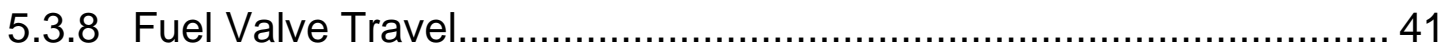

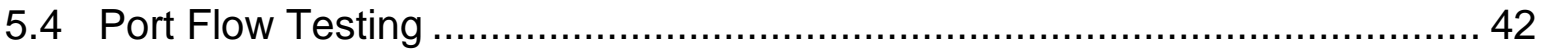

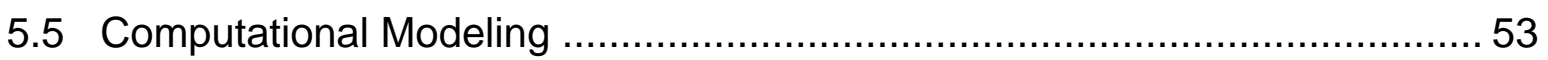

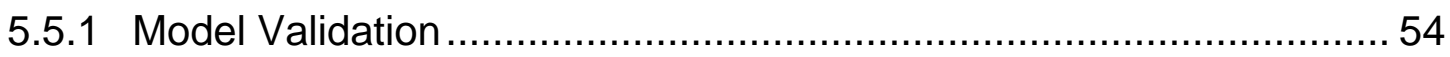

5.5 .2 Identical Cylinder Model ................................................ 58

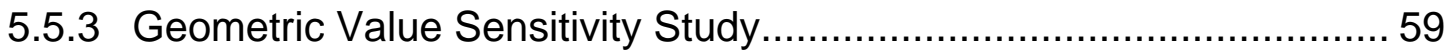

5.6 GMVH-6 Component Swap Testing ........................................... 61

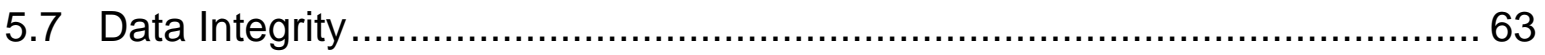

6. RESULTS AND DISCUSSION: CONCEPTUAL MANIFOLD DESIGNS ............. 64

6.1 Individual Tuned Expansion Chamber Concept ................................ 65

6.2 Multi-Cylinder Coupling Tuned Manifold Concept .............................. 67

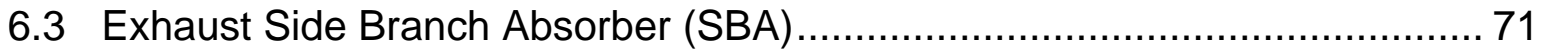

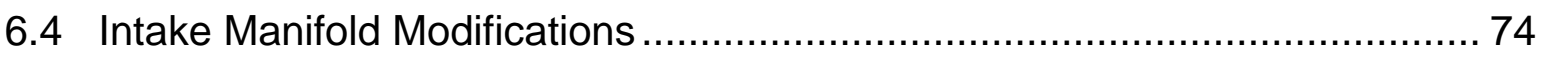

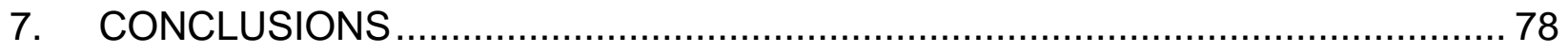

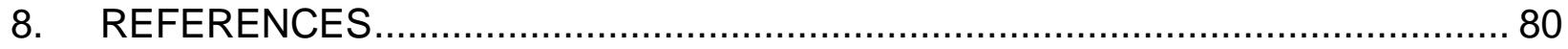




\section{LIST OF FIGURES}

Section

Page

Figure 3-1. GMVH-6 Cylinder Pressure Traces..................................................... 4

Figure 3-2. Typical Lean-Burn Engine Operating Map Showing Effects of Spread Equivalence Ratio ……................................................................. 5

Figure 4-1. Photograph of GMVH-6 Laboratory Research Engine ............................... 6

Figure 4-2. Photograph of Dynamic Pressure Sensor Installation for Engine Cylinder .... 9

Figure 4-3. Photograph of Dynamic Exhaust Pressure Sensor in Exhaust Runner.......... 9

Figure 4-4. Comparison of Dynamic Exhaust Pressure Sensor to Kistler Piezo-

Resistive Sensor at End of Measurement Channel in Exhaust Runner.......... 10

Figure 4-5. Comparison of FFT-Filtered Dynamic Exhaust Pressure Sensor to Flush-

Mounted Kistler Piezo-Resistive Sensor in Exhaust Runner ........................ 10

Figure 4-6. Photograph of Dynamic Exhaust Pressure Sensor in Exhaust Manifold ........ 11

Figure 4-7. Photograph of Dynamic Intake Pressure Sensor in Intake Manifold ............... 11

Figure 4-8. Photographs of GMVH Cylinder Flow Bench ............................................ 13

Figure 4-9. Virtual Two-Stroke Computational Model Schematic of GMVH-6 ................. 14

Figure 5-1. Cross Section of a Cooper-Bessemer GMVH Integral Compressor Engine .. 15

Figure 5-2. Kinematic Model Illustration of GMVH-6 Articulation.................................... 16

Figure 5-3. Kinematic Model Results of Left and Right Bank Piston Travel versus Crank

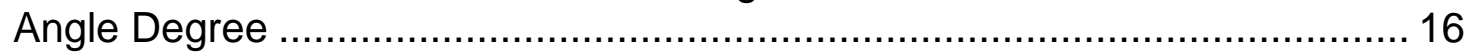

Figure 5-4. Nominal Exhaust Port Timings for Left and Right Banks ........................... 17

Figure 5-5. Nominal Intake Port Timings for Left and Right Banks.............................. 17

Figure 5-6. GMVH Cylinder Pressure versus Crank Angle - Scavenging and Fuel Admission Events Noted ........................................................................ 19

Figure 5-7. GMVH Cylinder Pressure versus Cylinder Volume on Logarithmic Scale Scavenging and Fuel Admission Events Noted .......................................... 19

Figure 5-8. Top-View Schematic of GMVH-6 Engine ................................................ 20

Figure 5-9. Comparison of Cylinder to Cylinder Compression Pressure $\left(20^{\circ} \mathrm{BTDC}\right)$ at All Operating Conditions ...................................................................... 21

Figure 5-10. Open Chamber Fuel Efficiency versus Engine Speed at Constant $\mathrm{NO}_{\mathbf{x}} \ldots \ldots . .22$

Figure 5-11. Open Chamber Fuel Efficiency versus Engine Load and Ignition Timing at Constant $\mathrm{NO}_{\mathrm{x}}$

Figure 5-12. Prechamber Fuel Efficiency versus Engine Load, Speed, and Ignition

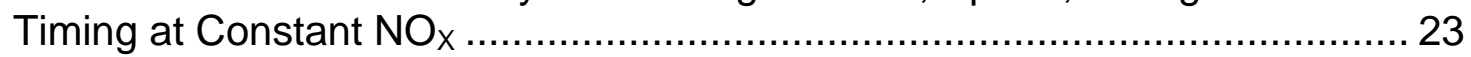

Figure 5-13. Prechamber and Open Chamber NOx - Efficiency Trade-Off ...................... 24

Figure 5-14. Cylinder 1L Pressure Comparison for Prechamber and Open Chamber ...... 24

Figure 5-15. Cylinder 1L Apparent Heat Release Rate Comparison for Prechamber and Open Chamber 25

Figure 5-16. Cylinder 1L Cumulative Heat Release Comparison for Prechamber and Open Chamber..................................................................................... 25

Figure 5-17. CAD Model of Base Air Chest (air volume shown as solid)....................... 27 Figure 5-18. Photograph of GMVH Base with Cylinder Removed - Air Chest Ports

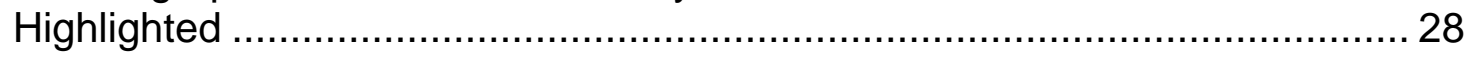

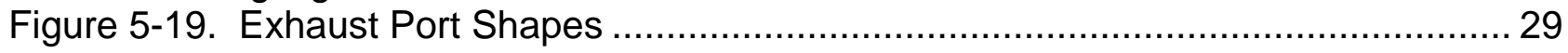


Figure 5-20. Cylinder Inlet Volume Measurements .................................................. 30

Figure 5-21. GMVH Cross Section with Inlet (blue) and Exhaust (red) Highlights............ 31

Figure 5-22. Photographs of External Inlet Air System.............................................. 32

Figure 5-23. Photographs of External Exhaust System............................................ 32

Figure 5-24. Photographs of Internal Geometry of Exhaust Manifold.............................. 33

Figure 5-25. Measured Left Bank Piston Motions versus Calculated Motion .................... 34

Figure 5-26. Measured Right Bank Piston Motions versus Calculated Motion .................. 34

Figure 5-27. Measured Piston Stroke per Cylinder Compared to Drawing Mean Values. 35

Figure 5-28. Measured Distances from Cylinder Top to Exhaust Port Top ..................... 36

Figure 5-29. Calculated TDC Clearance Volumes and Effective Compression Ratios for

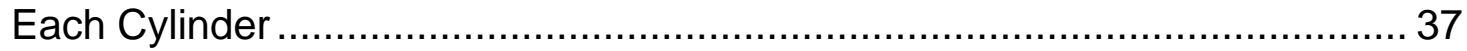

Figure 5-30. Calculated Exhaust Port Opening Timings for Each Cylinder ..................... 38

Figure 5-31. Calculated Exhaust Port Closing Timings for Each Cylinder ........................38

Figure 5-32. Calculated Exhaust Port Areas for Each Cylinder ..................................... 39

Figure 5-33. Calculated Intake Port Open Timings for Each Cylinder ........................... 40

Figure 5-34. Calculated Intake Port Closing Timings for Each Cylinder .........................40 40

Figure 5-35. Calculated Intake Port Areas for Each Cylinder .................................... 41

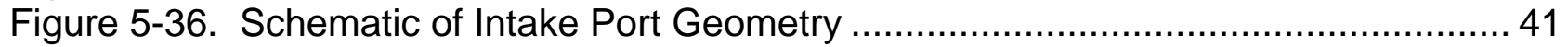

Figure 5-37. Measured Fuel Valve Travel ........................................................ 42

Figure 5-38. Cylinder 1L Intake - Mass Flow versus Piston Travel from BDC .................. 43

Figure 5-39. Cylinder 1L Intake - Mass Flow versus Plenum Pressure .......................... 44

Figure 5-40. Cylinder 1L Exhaust - Mass Flow versus Piston Travel from BDC .............. 45

Figure 5-41. Cylinder 1L Exhaust - Mass Flow versus Plenum Pressure ....................... 45

Figure 5-42. Comparison of Intake Mass Flow versus Area Ratio (Pressure Ratio=1.05) 46

Figure 5-43. Comparison of Exhaust Mass Flow versus Area Ratio (Pressure

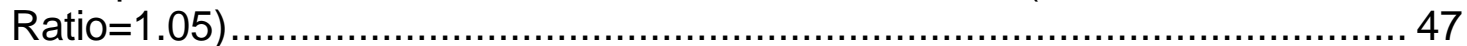

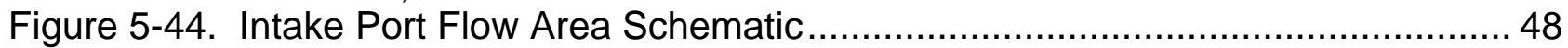

Figure 5-45. Exhaust Port Flow Area Schematic..................................................... 48

Figure 5-46. Cylinder 1L Intake Discharge Coefficient versus Area Ratio at Tested

Pressure Ratios............................................................................... 49

Figure 5-47. Cylinder 1L Exhaust Discharge Coefficient versus Area Ratio at Tested

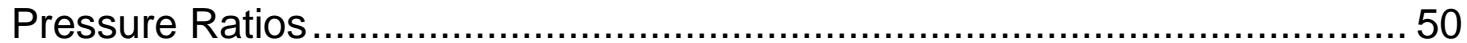

Figure 5-48. Intake Discharge Coefficient versus Area Ratio for Tested Cylinders

(Pressure Ratio=1.05) ...................................................................... 50

Figure 5-49. Intake Discharge Coefficient versus Area Ratio for Tested Cylinders

(Pressure Ratio=1.2) ...................................................................... 51

Figure 5-50. Exhaust Discharge Coefficient versus Area Ratio for Tested Cylinders

(Pressure Ratio=1.05) ......................................................................... 51

Figure 5-51. Exhaust Discharge Coefficient versus Area Ratio for Tested Cylinders

(Pressure Ratio=1.2) .................................................................. 52

Figure 5-52. Model Generated Exhaust Discharge Coefficients................................. 52

Figure 5-53. Model Generated Intake Discharge Coefficients .................................... 53

Figure 5-54. Initial Simulation to Measurement Comparison - Cylinder 1L Pressure ...... 55

Figure 5-55. Initial Simulation to Measurement Comparison - Intake Manifold Pressure 55

Figure 5-56. Initial Simulation to Measurement Comparison - Exhaust Manifold

Pressure. 56 
Figure 5-57. Revised Simulation to Measurement Comparison - Cylinder Pressure ....... 57

Figure 5-58. Revised Simulation to Measurement Comparison - Inlet, Exhaust, and Cylinder Pressure ............................................................................ 57

Figure 5-59. Identical Cylinder Simulation to Measurement Comparison - Cylinder

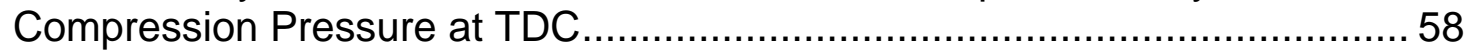

Figure 5-60. Simulation Predictions of Compression Pressure with Variation in Port

Opening Height (Timing) .............................................................. 60

Figure 5-61. Simulation Predictions of Compression Pressure with Variation in Port

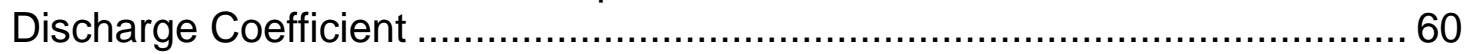

Figure 5-62. Simulation Predictions of Compression Pressure with Variation in Compression Ratio

Figure 5-63. 100-Cycle Average Cylinder Pressures at $20^{\circ}$ BTDC versus Air Manifold Pressure - Post Power Assembly Swap

Figure 5-64. Cylinder Pressures at $20^{\circ}$ BTDC for Air Manifold Pressure of $20 \mathrm{inHg}-$ Before and After Power Assembly Swap.......................................... 63

Figure 6-1. Flowchart of Current Conceptual Manifold Designs 65

Figure 6-2. Photographs of Expansion Chambers (Motorcycle Application at Left \& AJAX ${ }^{\mathrm{TM}}$ Application on Right ${ }^{[4]}$ ) 66

Figure 6-3. Design Parameters of an Individual Expansion Chamber Manifold ............... 66

Figure 6-4. Multi-Cylinder Coupling Tuned Manifold Concept ..............................6 68

Figure 6-5. Phasing and Coupling of Cylinders on the GMVH-6 Engine ......................69

Figure 6-6. Dimensions for Optimized Multi-Cylinder Coupled Exhaust Manifold Concept 70 Figure 6-7. Dynamic Pressure Data Recorded on Cylinder 1L of the GMVH-6 Engine.... 71 Figure 6-8. Frequency Analysis of Recorded Engine Data for Left Bank Cylinders ......... 72 Figure 6-9. Conceptual Exhaust SBA Design for GMVH-6.................................. 73

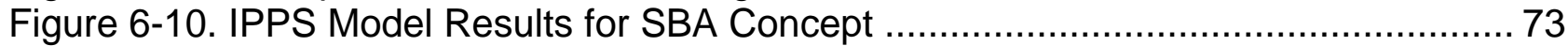

Figure 6-11. Simulated Mass Air Flow from Base Plenum, Intake Manifold, and Through the Intake Ports.... 75

Figure 6-12. Photograph and Sketch of Intake Manifold Showing Region of Concern for Flow Disturbance and Restriction. 76 


\section{LIST OF TABLES}

Section

Page

Table 4-1. Time-Averaged and Crank-Angle Resolved Measurements on GMVH.......... 8

Table 4-2. Static Measurements on Each Cylinder of GMVH..................................... 12

Table 4-3. GMVH Cylinder Flow Bench Measurements .............................................. 14 


\section{INTRODUCTION}

This document provides results and conclusions for Task 15.0 - Detailed Analysis of Air Balance \& Conceptual Design of Improved Air Manifolds in the "Technologies to Enhance the Operation of Existing Natural Gas Compression Infrastructure” project. SwRI is conducting this project for DOE in conjunction with the Pipeline Research Council International, Gas Machinery Research Council, El Paso Pipeline, Cooper Compression, and Southern Star, under DOE contract number DE-FC26-02NT41646. 


\section{OBJECTIVE}

The overall project objective is to develop and substantiate methods for operating integral engine/compressors in gas pipeline service, which reduce fuel consumption, increase capacity, and enhance mechanical integrity. The objective of Task 15.0 was to investigate the perceived imbalance in airflow between power cylinders in two-stroke integral compressor engines and develop solutions via manifold redesign. 


\section{BACKGROUND}

The United States gas transmission industry operates over 4,000 integral engine compressors, the majority being two-stroke, with a median age of 45 years and a median size of 2000 horsepower. Although the use of centrifugal compressors in the U.S. pipeline industry has grown, these integral reciprocating units still represent over $70 \%$ of the fleet in numbers and over one-half of the installed power. These engines are no longer produced, but to replace these units with currently available technology would incur a large cost and disruption to service with insufficient improvement in overall performance of the pipeline system to justify this cost and disruption. For these reasons, wholesale replacement remains unlikely (although selective replacement driven by factors such as environmental regulations can be expected). Growth to a 30-TCF-plus gas market in the U.S., anticipated over the next 10 to 20 years, must come on the backs of the existing compression infrastructure. Therefore, it is critical that mechanical integrity of the aging integral compressor engine fleet be maintained while enhancing capacity, efficiency, and emissions under all loads. The industry needs demonstrated technology options and operating methods, which will cost-effectively meet these goals.

Integral gas compression engines have historically exhibited poor performance and high emissions, due in part to poor combustion stability and consistency between cylinders. The end results are misfires and partial burns that lead to increased fuel usage and exhaust emissions. Field testing in this and other projects has shown many of the integral engines to have inconsistent performance between cylinders on a given unit. This inconsistency has been exhibited by the tendency of one or two of the cylinders in a given unit to be more prone to either misfire or knock (detonation) than the other cylinders. Dynamic cylinder pressure measurements have shown a spread in peak firing pressure and the pressure during the compression stroke. This spread in compression pressure and the tendency for misfire or detonation in one or two cylinders indicated that the air/fuel ratio between cylinders is varied. A variance, or spread, in air/fuel ratio would lead to excessive emissions and fuel consumption.

Data from Cooper Compression's laboratory GMVH-6 engine located at SwRI showed a similar spread in compression pressure to that measured in several field engines. Data from the GMVH-6 showing the compression pressure spread is depicted in Figure 3-1. The cylinder pressure data shown in this figure was acquired with flush mounted piezo-electric transducers which have been calibrated frequently and switched to ensure the affect is not due to sensor variation. The spread in compression pressure is consistent over the entire operating range of the engine.

It was theorized that the spread in compression pressures in the various engines tested was caused in large part to dynamics in either or both of the intake or exhaust manifolds. This theory was qualitatively based on measurements of high amplitude pressure pulsations in the manifolds and the tendency of the low compression pressure cylinder to be located at the first junction of the intake manifold, nearest the turbocharger outlet. If this theory was correct, then redesigning the manifolds based on actual fluid dynamics of the particular engine should alleviate the spread and create balanced trapped mass between cylinders.

Other factors that could cause this spread in compression pressure relate to cylinder geometry. The geometric parameters include mechanical compression ratio, port flow coefficients, and port timings. The uncertainty was to what magnitude each of these parameters 
contributes to the spread, what is the likely variation existing in field engines, and whether or not these factors dominate over fluid dynamics affects.

If the cause is due to flow and trapped mass variations, then power output will also vary between cylinders. Furthermore, balancing peak firing pressures by adjusting individual cylinder fuel flow would also create a spread in trapped air/fuel ratio (trapped equivalence ratio). A spread in cylinder equivalence ratio would lead to several undesirable results, including lower efficiency, higher $\mathrm{NO}_{\mathrm{X}}$ production, increased crankshaft stress, increased vibration, and reduced detonation (knock) and misfire margins. An illustration of some of these adverse affects is provided in Figure 3-2. In this graph, the operating boundaries of a typical lean-burn engine at constant speed and load are shown by the knock, misfire, peak pressure limit, and pre-turbine exhaust temperature lines. Within this boundary is the spark timing/trapped equivalence ratio operating region. Constant $\mathrm{NO}_{\mathrm{X}}$ is typically a straight line, while peak efficiency is typically an island near the corner of the knock and misfire lines (i.e. advanced timing and lean fuel-air equivalence ratio). If the cylinder-to-cylinder equivalence ratio has a large spread, then the mean operating point must be at a lower efficiency to allow for suitable margins between misfire and knock. Since $\mathrm{NO}_{\mathrm{X}}$ is typically an exponential function of trapped equivalence ratio, at constant ignition timing, the total engine-out $\mathrm{NO}_{\mathrm{X}}$ will be higher due to a greater contribution from the rich cylinders. Therefore, either the ignition timing would need to be retarded, or the mean equivalence ratio reduced (more lean) to maintain a given global $\mathrm{NO}_{\mathrm{X}}$ level. Unfortunately, this will reduce efficiency even further.

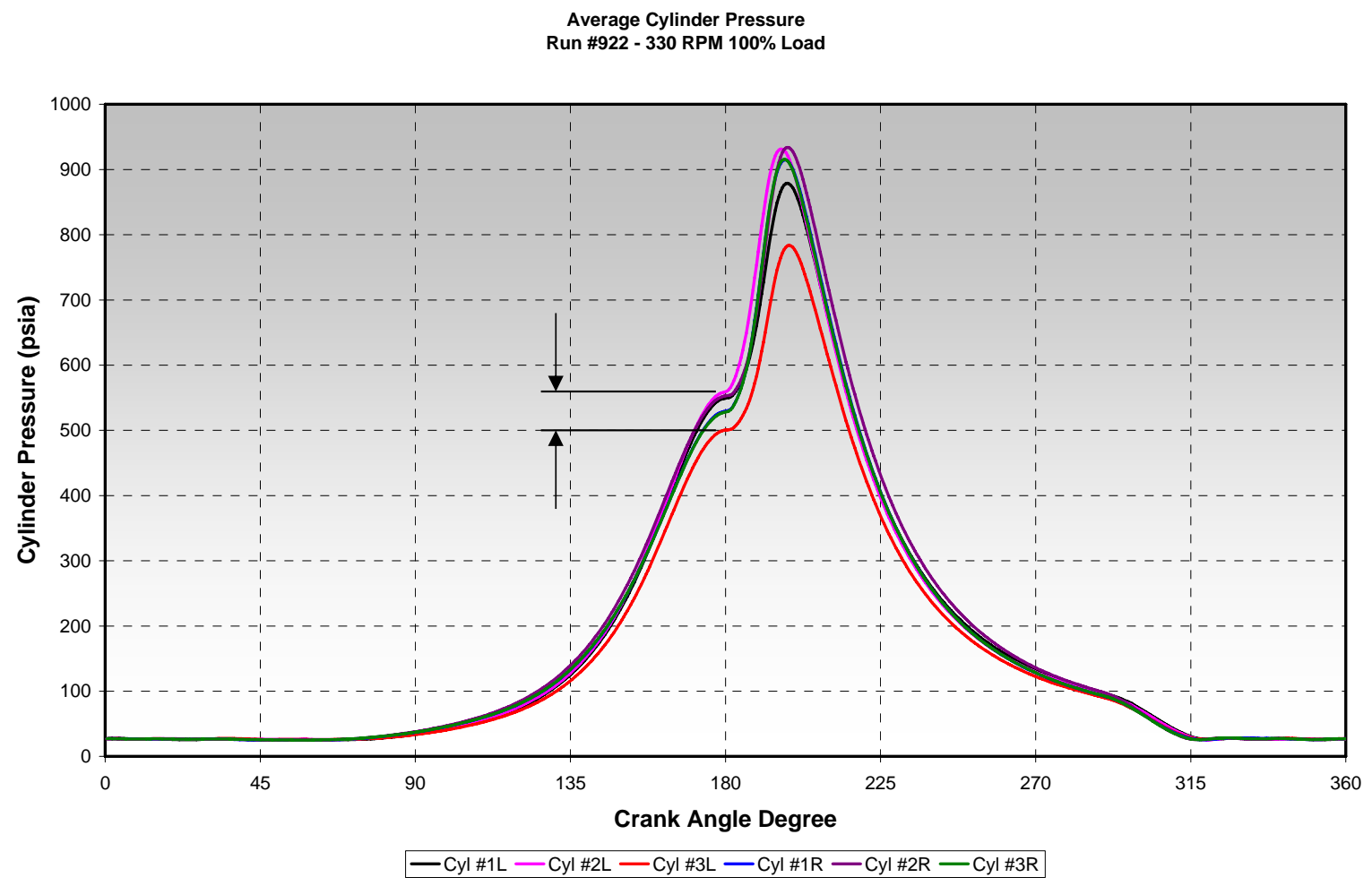

Figure 3-1. GMVH-6 Cylinder Pressure Traces 


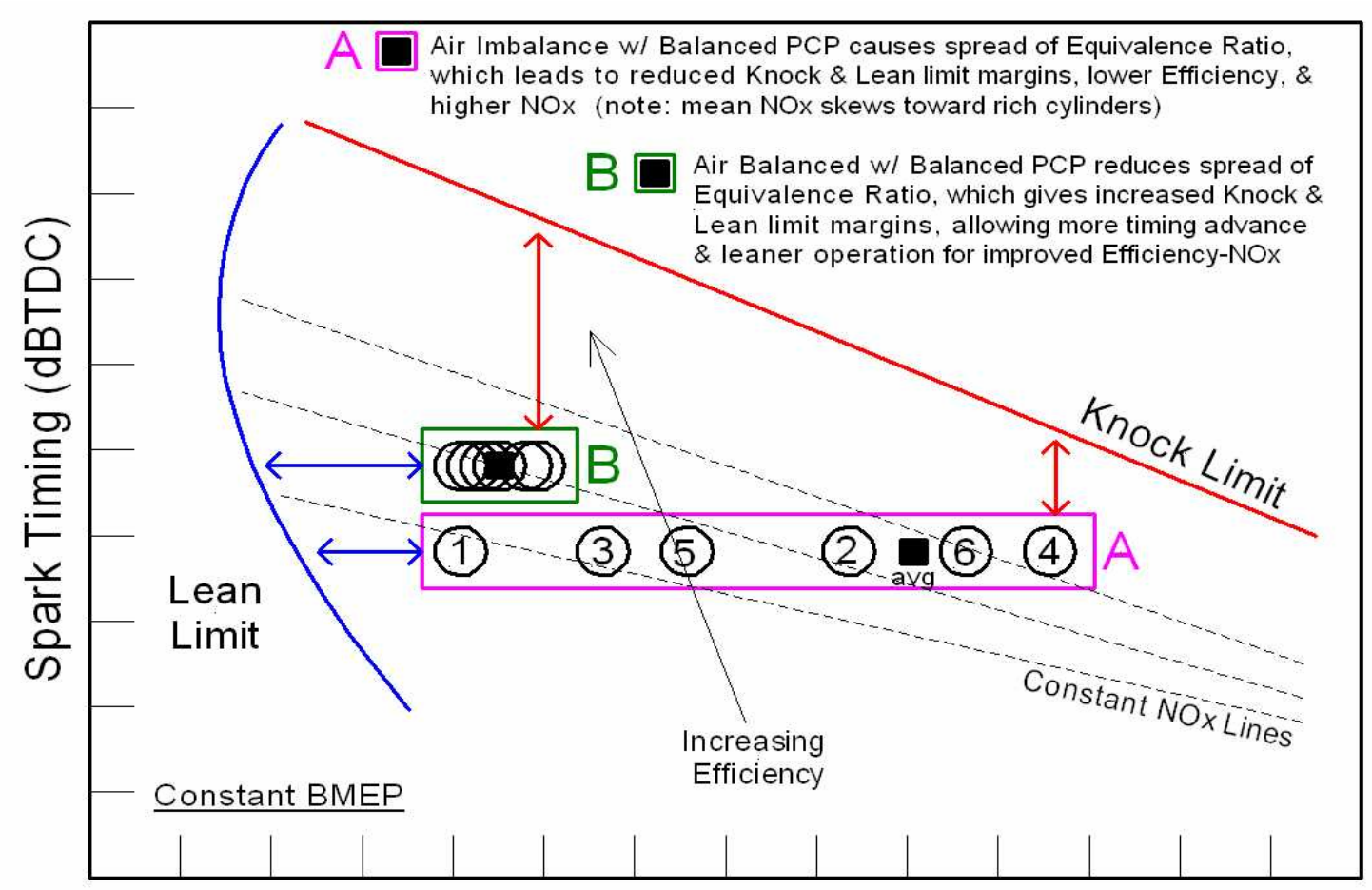

Fuel-Air Equivalence Ratio

Figure 3-2. Typical Lean-Burn Engine Operating Map Showing Effects of Spread Equivalence Ratio 


\section{EXPERIMENTAL}

\subsection{GMVH-6 TEST BED}

The test bed for the work in Task 15.0 was a Cooper-Bessemer GMVH six-cylinder turbocharged integral compressor engine. This engine belongs to Cooper Compression and is installed at Southwest Research Institute $\left(\mathrm{SwRI}^{\mathbb{B}}\right)$ for research and product development to support the gas transmission industry. The compressors have been removed and a dynamometer has been connected to the flywheel to apply load. The remainder of the engine setup, including the foundation, was designed to mimic a typical compressor station installation as much as possible. A photograph of the test engine installation is provided in Figure 4-1.

The GMVH-6 research engine has standard mechanical fuel valves and a pneumatically controlled fuel regulator. The governor has been removed, and the dynamometer controller is setup to maintain engine speed. Load is controlled by adjusting the fuel header pressure with a PID controller. Cooper configured the engine in a standard Cleanburn ${ }^{\mathrm{TM}}$ configuration with JetCell igniters prior to installation. Testing in open-chamber configuration was accomplished by replacing the Jet-Cells with spark plug adapters. An Altronic CPU-2000 was used for ignition, and Altronic software was installed on the data acquisition computer to command spark timing.

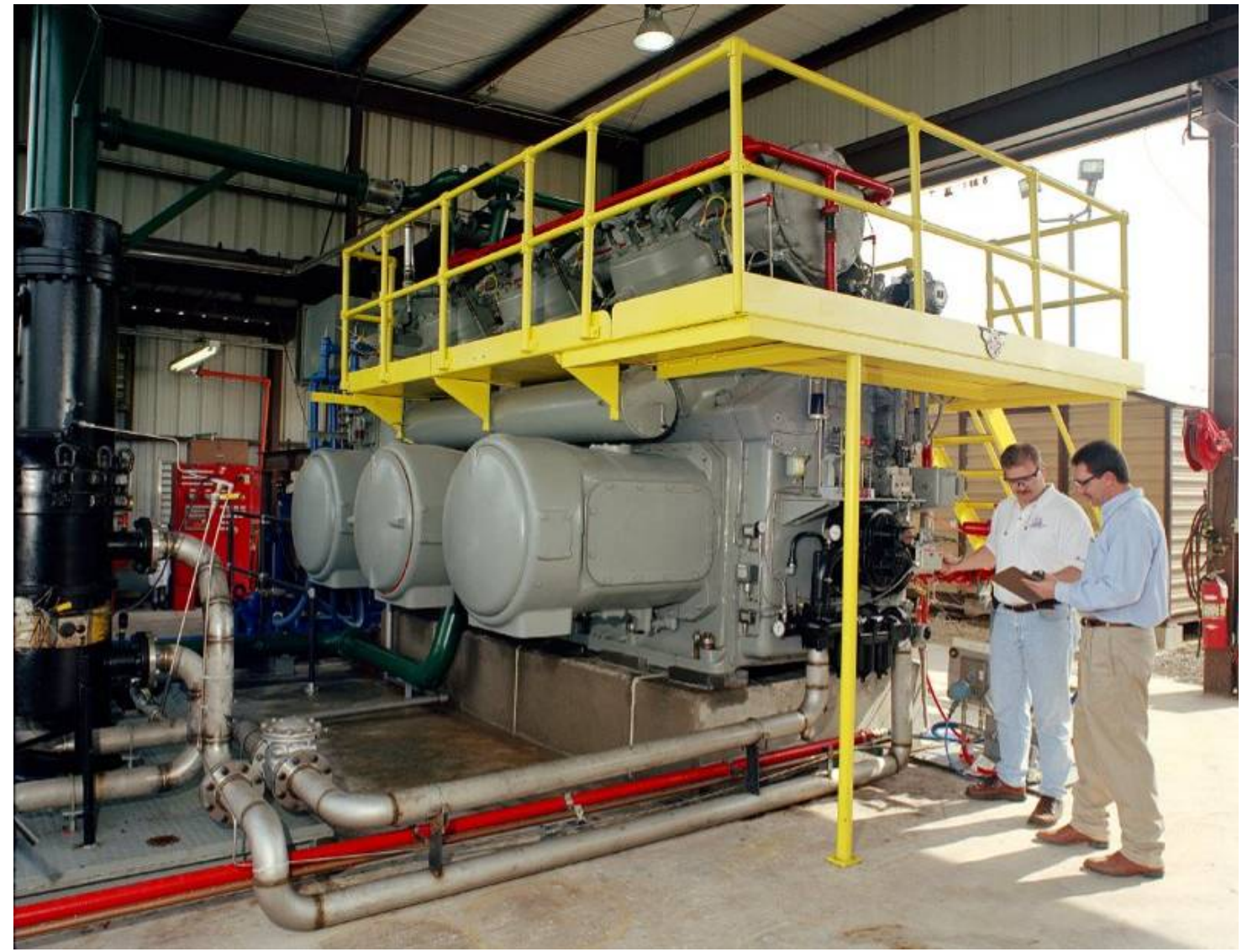

Figure 4-1. Photograph of GMVH-6 Laboratory Research Engine

The GMVH engine was highly instrumented prior to utilization for the air balance investigation. The instrumentation package included a variety of pressure, temperature, frequency, flow, and crankshaft position sensors. Each cylinder was instrumented with flush 
mount Kistler piezo-electric dynamic pressure sensors through modified start-valve dummy plugs as shown in Figure 4-2. An emissions bench featuring compliance grade analyzers for THC, $\mathrm{CO}, \mathrm{NO}_{\mathrm{X}}, \mathrm{CO}_{2}$, and $\mathrm{O}_{2}$ was utilized for all emissions measurements. Additionally, a ThermoNicolet FTIR was available for hydrocarbon speciation. Additional dynamic pressure measurements were required for proper simulation with the computational model within the air balance tasks. The additional instrumentation is as follows:

- Dynamic Pressure in Exhaust Manifold Runners - Prior to the air balance investigation, only Cylinder 1L was instrumented for dynamic exhaust pressure. Additional dynamic pressure sensors were added to the remaining five cylinders to capture the dynamic pressure pulsations of the exhaust from each cylinder's ports. These sensors are of a thin-film strain gage type, typically used for absolute pressure measurement of manifold pressure in automotive electronic engine control systems. Special heat exchangers were constructed to cool the exhaust gas slightly to minimize damage of these sensors. Each sensor was calibrated and a comparison test to a Kistler piezo-resistive sensor was performed on the running engine to validate transient response. A photograph of the exhaust manifold runner dynamic pressure transducer is depicted in Figure 4-3. A graph showing the comparison of signals from the Kistler piezo-resistive and dynamic exhaust runner pressure sensors is shown if Figure 4-4. These measurements were taken at the end of the measurement channel. An FFT filter was developed to remove the channel resonance and provide a comparison to the FFT-filtered signal from the dynamic exhaust runner pressure sensor to a flush-mounted Kistler piezo-resistive sensor is shown in Figure 4-5 as final validation of the sensor and filter performance.

- Dynamic Pressure in Exhaust Manifold Plenum - A new sensor was installed in the exhaust manifold plenum near the turbocharger. This measurement is required to capture the dynamic pressure pulsations in the exhaust manifold plenum and provide data to characterize the dynamic flow through the exhaust manifold. A Kistler piezo-resistive absolute pressure transducer was utilized for this measurement. This sensor was calibrated via a deadweight tester. A photograph of the exhaust manifold dynamic pressure sensor as installed for testing is provided in Figure 4-6.

- Dynamic Pressure in Inlet Manifold Plenums - Prior to the air balance investigation, only the left inlet manifold was instrumented for dynamic inlet plenum pressure. An additional dynamic pressure sensor was added to the right inlet manifold plenum to capture the dynamic pressure pulsations of the exhaust from each cylinder's ports. These sensors are of a thinfilm strain gage type, like those utilized in the exhaust manifold runners. A photograph of the left bank inlet manifold dynamic pressure sensor as installed for testing is provided in Figure 4-7.

The complete instrumentation package on the laboratory GMVH-6 engine is listed in Table 4-1. 
Table 4-1. Time-Averaged and Crank-Angle Resolved Measurements on GMVH

\begin{tabular}{|l|l|}
\hline Time-Averaged Measurements & Oil Pressure \\
\hline Engine Speed & Turbocharger Oil Pressure \\
\hline Turbocharger Shaft Speed & Coolant Inlet \& Outlet Pressure \\
\hline Turbocharger Wastegate Position & Pre-Turbine Pressure \\
\hline Engine Torque & Stack Pressure \\
\hline Total Fuel Flow & Compressor Inlet Temperature \\
\hline Pre-Chamber Fuel Flow & Compressor Left \& Right Outlet Temperatures \\
\hline Fuel Gas Composition & Inlet Manifold Left \& Right Temperatures \\
\hline Fuel Gas Heating Value & Fuel Header Temperature \\
\hline Total Air Flow & Pre-Chamber Header Temperature \\
\hline Barometric Pressure & Individual Cyl. Exhaust Runner Temperatures \\
\hline Ambient Temperature & Pre-Turbine Temperature \\
\hline Ambient Humidity & Post-Turbine Temperature \\
\hline Exhaust NOx Concentration & I/C Inlet Left \& Right Water Temperatures \\
\hline Exhaust CO Concentration & I/C Outlet Left \& Right Water Temperatures \\
\hline Exhaust HC Concentration & Oil Sump Temperature \\
\hline Exhaust CO2 Concentration & Oil Inlet Temperature \\
\hline Exhaust O2 Concentration & Turbocharger Oil Inlet Temperature \\
\hline Exhaust Equivalence Ratio & Coolant Inlet \& Outlet Temperatures \\
\hline Inlet Manifold Left \& Right Pressures & Individual Cyl. Head Temperatures \\
\hline Fuel Header Pressure & Dynomometer Inlet \& Outlet Temperatures \\
\hline Pre-Chamber Header Pressure & Cylinder 1L Exhaust Runner Pressure \\
\hline Crank-Angle Resolved (Dynamic) Measurements \\
\hline Cylinder 1L Firing Pressure & Cylinder 2L Exhaust Runner Pressure \\
\hline Cylinder 2L Firing Pressure & Cylinder 3L Exhaust Runner Pressure \\
\hline Cylinder 3L Firing Pressure & Cylinder 1R Exhaust Runner Pressure \\
\hline Cylinder 1R Firing Pressure & Cylinder 2R Exhaust Runner Pressure \\
\hline Cylinder 2R Firing Pressure & Cylinder 3R Exhaust Runner Pressure \\
\hline Cylinder 3R Firing Pressure & Right Inlet Manifold Plenum Pressure \\
\hline Left Inlet Manifold Plenum Pressure & Exhaust Manifold Plenum Pressure \\
\hline Cylinder 1L Pre-Chamber Firing Pressure & \\
\hline
\end{tabular}




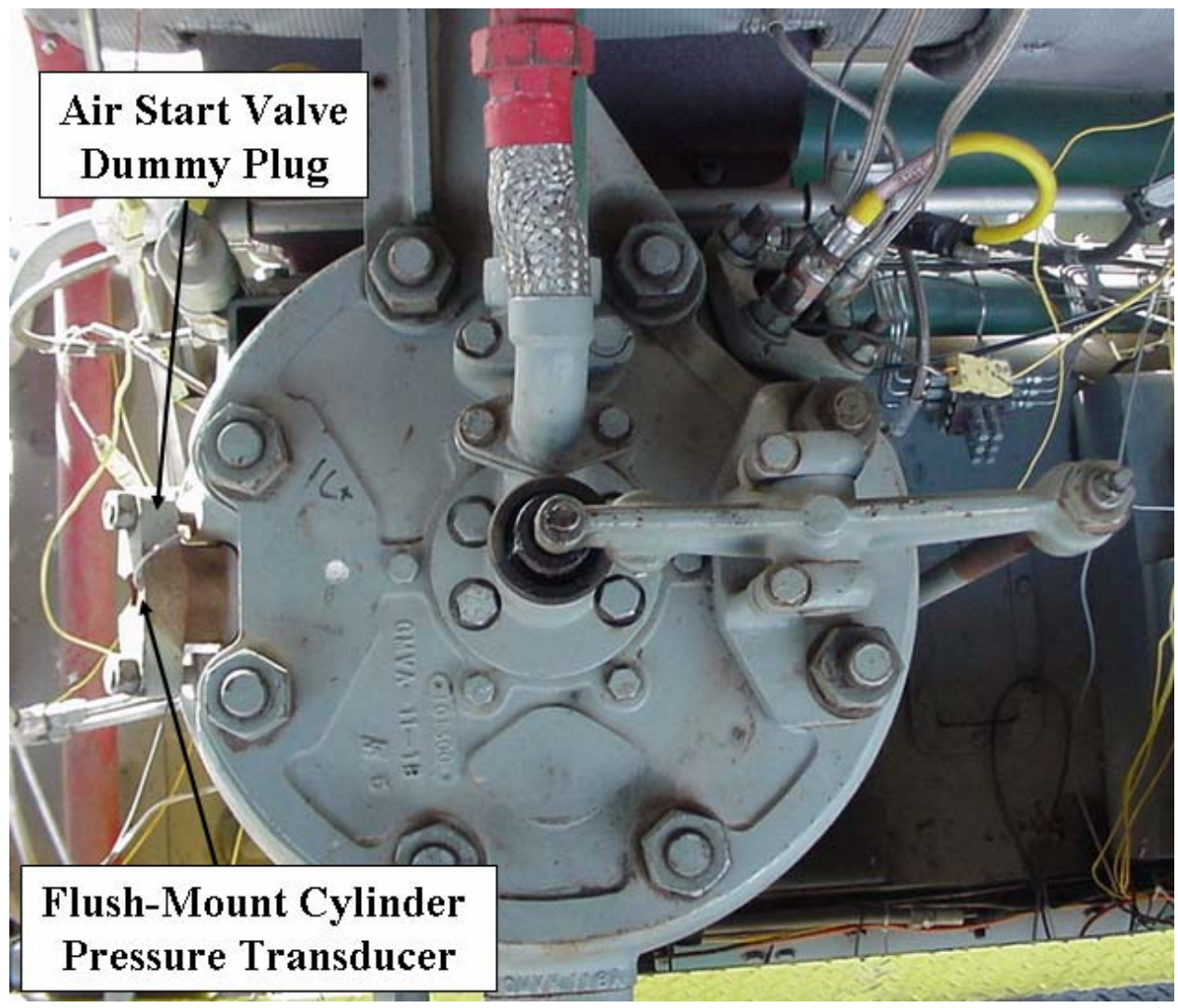

Figure 4-2. Photograph of Dynamic Pressure Sensor Installation for Engine Cylinder

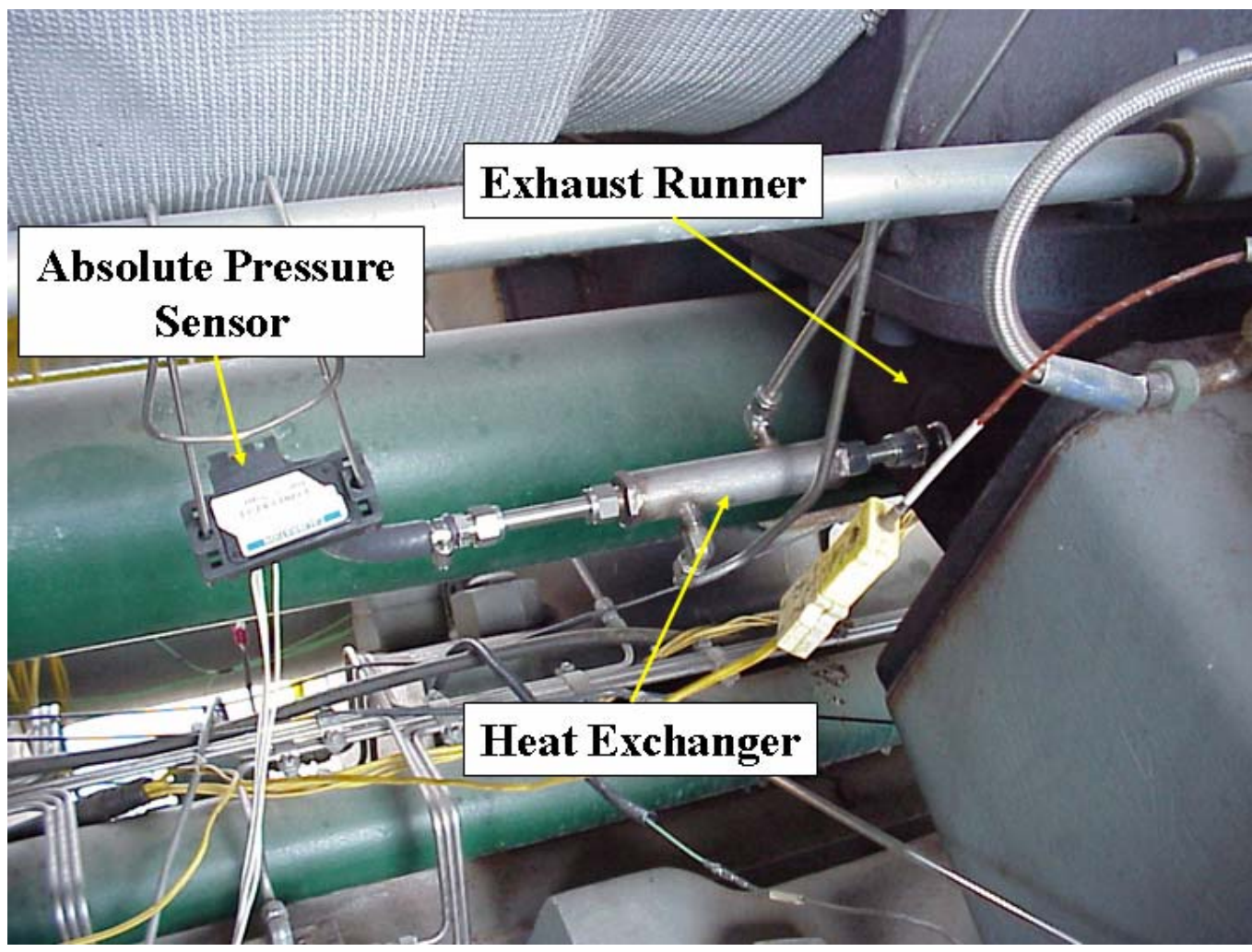

Figure 4-3. Photograph of Dynamic Exhaust Pressure Sensor in Exhaust Runner 


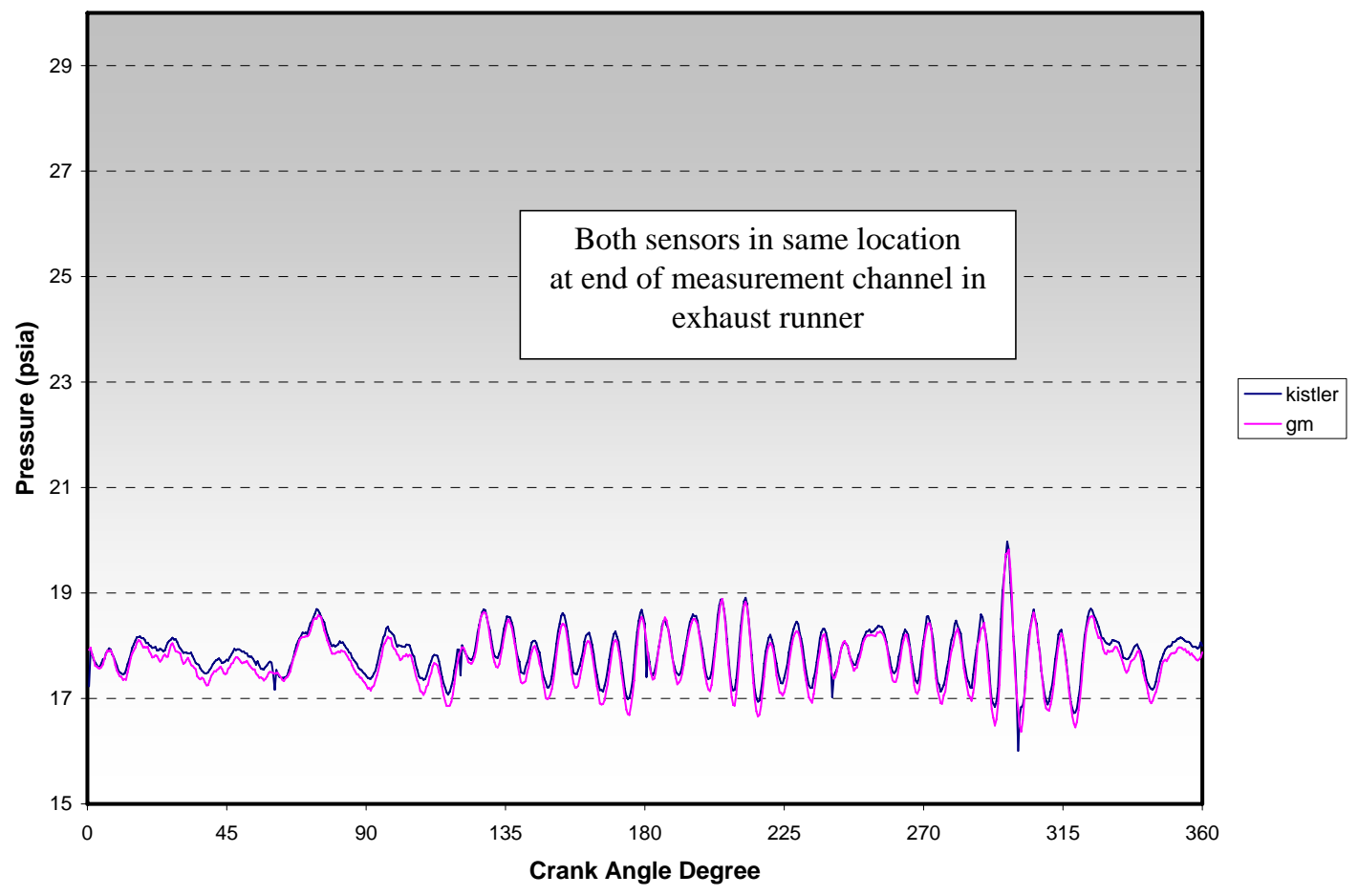

Figure 4-4. Comparison of Dynamic Exhaust Pressure Sensor to Kistler Piezo-Resistive Sensor at End of Measurement Channel in Exhaust Runner

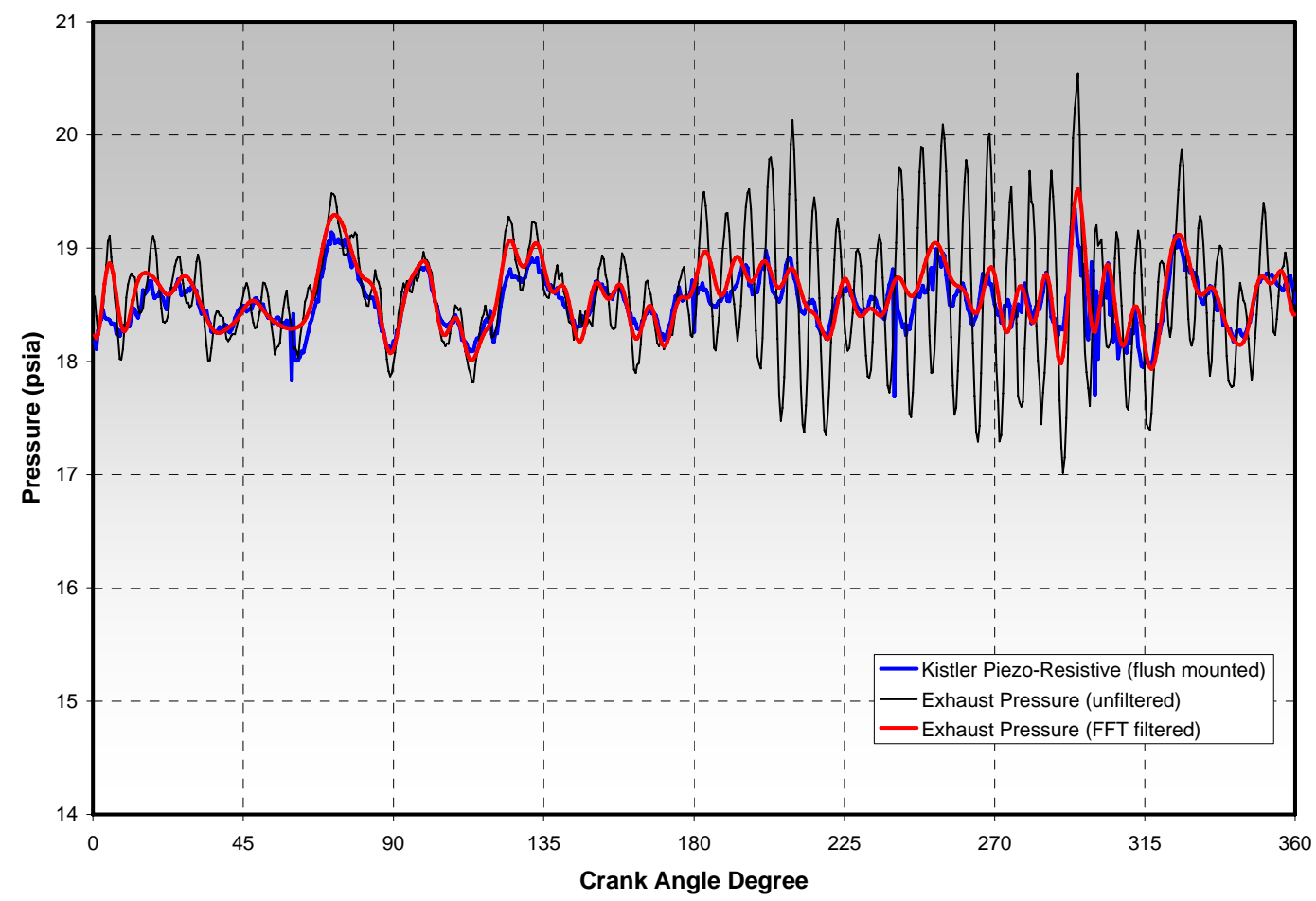

Figure 4-5. Comparison of FFT-Filtered Dynamic Exhaust Pressure Sensor to Flush-Mounted Kistler Piezo-Resistive Sensor in Exhaust Runner 


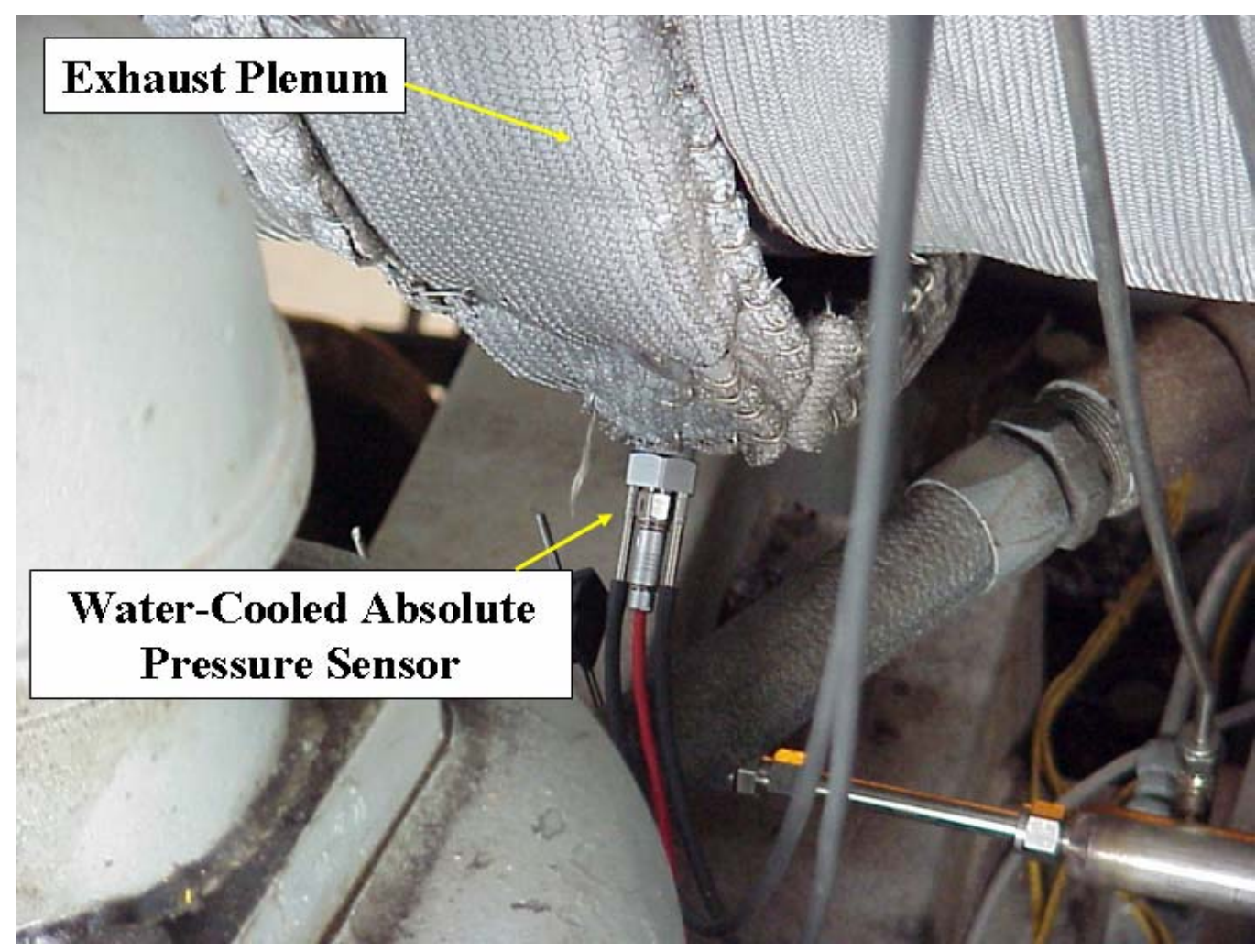

Figure 4-6. Photograph of Dynamic Exhaust Pressure Sensor in Exhaust Manifold

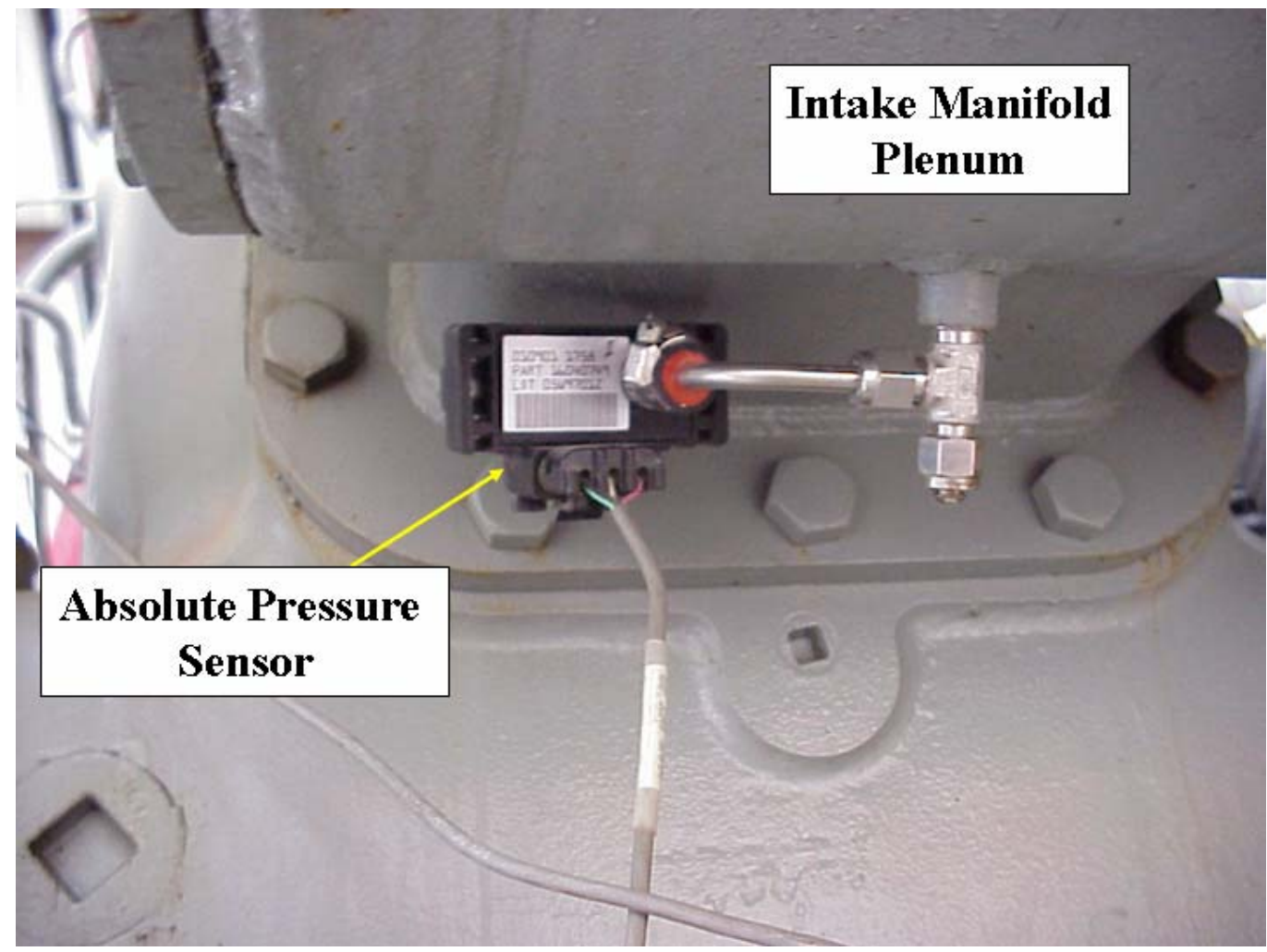

Figure 4-7. Photograph of Dynamic Intake Pressure Sensor in Intake Manifold 
In addition to the many measurements for engine performance and emissions, several static measurements were made of the engine geometry. These geometric measurements have been determined to be of critical importance for proper simulation of the engine. The key geometric parameters are compression ratio, port timing, and port area for each cylinder of the test engine. In order to conduct the many detailed measurements, the engine was disassembled. A list of the many static measurements taken on each cylinder is provided in Table 4.2. From these measurements several calculated parameters were derived and discussed in the next section.

Table 4-2. Static Measurements on Each Cylinder of GMVH

\begin{tabular}{|c|c|}
\hline Piston Stroke (BDC to TDC) & Cylinder Bore ( 1" from top) \\
\hline Connecting Rod C-C (cyl 1L only) & Piston TDC Height (from cylinder top) \\
\hline Pre-Chamber Volume & Piston Top Ring Land Diameter \\
\hline Cylinder Inlet Volume (inc.ports) & Piston Top Ring Land Height \\
\hline Cylinder Intake Flange Width & Piston Dome Angle \\
\hline Cylinder Intake Flange Height & Piston Dome Height from edge \\
\hline Cylinder Exhaust Flange Width & Piston Bowl Depth \\
\hline Cylinder Exhaust Flange Height & Piston Bowl Volume (inc puller-hole) \\
\hline Cylinder Head Volume & Piston Pin Center to Crown Height \\
\hline Cylinder Head Gasket Step & Top Int Port to Gasket Step - A \\
\hline Cylinder Head Gasket Thickness & Top Int Port to Gasket Step - B \\
\hline Exhaust Port "Shape" - A & Top Int Port to Gasket Step - C \\
\hline Exhaust Port "Shape" - B & Top Int Port to Gasket Step - D \\
\hline Exhaust Port "Shape" - C & Top Int Port to Gasket Step - E \\
\hline Exhaust Port "Shape" - D & Top Int Port to Gasket Step - F \\
\hline Exhaust Port "Shape" - E & Top Int Port to Gasket Step - G \\
\hline Top Exh Port to Gasket Step - A & Top Int Port to Gasket Step - H \\
\hline Top Exh Port to Gasket Step - B & Intake Port to Edge Width - A \\
\hline Top Exh Port to Gasket Step - C & Intake Port to Edge Width - B \\
\hline Top Exh Port to Gasket Step - D & Intake Port to Edge Width - C \\
\hline Top Exh Port to Gasket Step - E & Intake Port to Edge Width - D \\
\hline Exhaust Port Edge Width - A & Intake Port to Edge Width - E \\
\hline Exhaust Port Edge Width - B & Intake Port to Edge Width - F \\
\hline Exhaust Port Edge Width - C & Intake Port to Edge Width - G \\
\hline Exhaust Port Edge Width - D & Intake Port to Edge Width - $\mathrm{H}$ \\
\hline Exhaust Port Edge Width - E & Intake Port Edge Height - A \\
\hline Exhaust Port Min Width - A & Intake Port Edge Height - B \\
\hline Exhaust Port Min Width - B & Intake Port Edge Height - C \\
\hline Exhaust Port Min Width - C & Intake Port Edge Height - D \\
\hline Exhaust Port Min Width - D & Intake Port Edge Height - E \\
\hline Exhaust Port Min Width - E & Intake Port Edge Height - F \\
\hline Exhaust Port Edge Height - $\mathrm{A}$ & Intake Port Edge Height - G \\
\hline Exhaust Port Edge Height - B & Intake Port Edge Height - H \\
\hline Exhaust Port Edge Height - $\mathrm{C}$ & Intake Port Angle - A \\
\hline Exhaust Port Edge Height - D & Intake Port Angle - B \\
\hline Exhaust Port Edge Height - E & Intake Port Angle - C \\
\hline Exhaust Port Min Height - $\mathrm{A}$ & Intake Port Angle - D \\
\hline Exhaust Port Min Height - B & Intake Port Angle - E \\
\hline Exhaust Port Min Height - C & Intake Port Angle - F \\
\hline Exhaust Port Min Height - D & Intake Port Angle - G \\
\hline Exhaust Port Min Height - E & Intake Port Angle - $\mathrm{H}$ \\
\hline
\end{tabular}




\subsection{CYLINDER FLOW TEST RIG}

Cylinders 1L and 3L, representing a high and low compression pressure on a given bank, were removed from the base and flow tested. During disassembly it was found that Cylinder $1 \mathrm{R}$ had a different exhaust port shape from the other cylinders, and was removed to be flow tested as well. The flow testing was conducted to measure the discharge coefficient of both intake and exhaust ports versus open area. Accurate discharge coefficients were required for simulation. In addition, a review of allowable port shape on the manufacturing drawings gave concern that variance in port shape from cylinder to cylinder could be a large contributor to flow imbalance. The effects of port shape also needed to be characterized and accounted for in the simulations.

A flow test rig was assembled specifically for this effort. This test rig featured a compressed air storage and regulation system, meter run, data acquisition, and cylinder stand. Photographs of the flow bench rig are shown together in Figure 4-8. The compressed air system featured $3-1,050$ gallon cylinders, charged to 250 psig. The outlet of the compressed air cylinders was connected to a regulator and control valve for setting the desired pressure versus mass flow of air into the flow bench. The meter run was fabricated from Schedule 40 PVC pipe and featured an ASME nozzle for flow measurement. Two sizes of flow nozzles, 2 and 4 inch, were interchangeably used for low and high flows. Mass flow was calculated from the volumetric flow measurements using standard equations given in ASME codes. The cylinder stand was fabricated to hold and seal the cylinder during testing. An adjusting screw protruded from the bottom of the stand to allow for adjustment of piston height to achieve the desired port open fraction. A vernier scale mounted on the bottom of the stand was used for measuring piston travel. A fixture was later fabricated to mount on the cylinder studs to lock the piston and prevent lifting due to air pressure leaking past the rings and under the piston. The data acquisition system acquired data at a rate of $6 \mathrm{~Hz}$ and included the measurements given in Table 4-3.

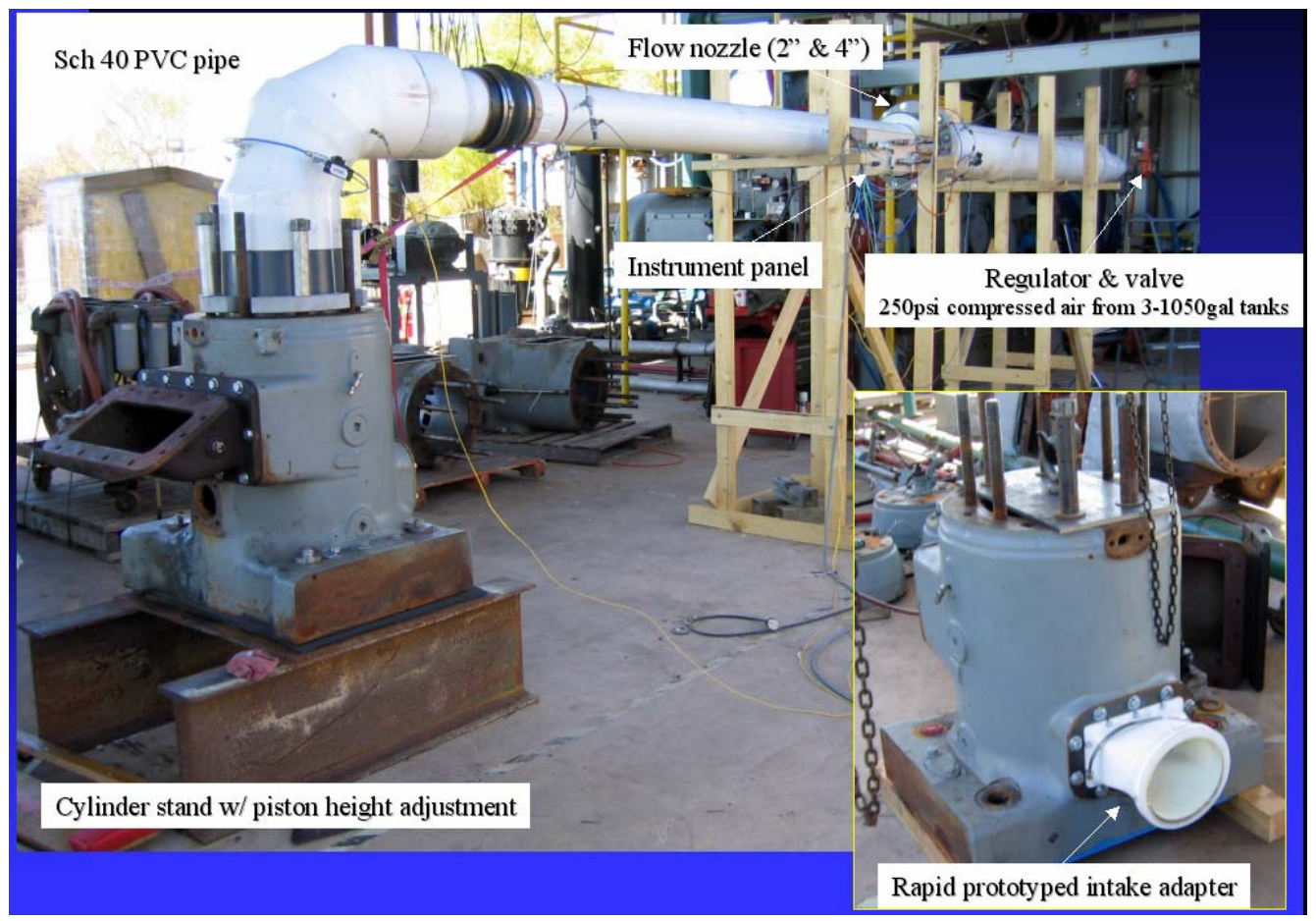

Figure 4-8. Photographs of GMVH Cylinder Flow Bench 
Table 4-3. GMVH Cylinder Flow Bench Measurements

\begin{tabular}{|l|l|}
\hline Supply Static Pressure (upstream) & Ambient Pressure \\
\hline Supply Temperature (upstream) & Ambient Temperature \\
\hline 4" Nozzle delta-Pressure & Ambient Dewpoint Temperature \\
\hline 2" Nozzle delta-Pressure & Air Tank Pressure \\
\hline Plenum Static Pressure (downstream) & Piston Travel from BDC \\
\hline Plenum Temperature (downstream) & \\
\hline
\end{tabular}

\subsection{COMPUTATIONAL MODEL}

The computational modeling for the air balance investigation was performed with software purchased on this project from Optimum Power Technology. The particular software package is titled Automated Design with Virtual 2-Stroke (C. This software is written specifically for modeling of two-stroke engines and is a one-dimensional cycle-simulation model that focuses on the fluid dynamics in an internal combustion engine.

A model of the GMVH engine was configured using the dimensions both provided by Cooper Compression and obtained through direct measurement. Being a one-dimensional computational model, many of the complex three-dimensional geometries were simplified to representative pipes, plenums, junctions, and orifices. A schematic of the computational model of the GMVH-6 engine is provided in Figure 4-9.

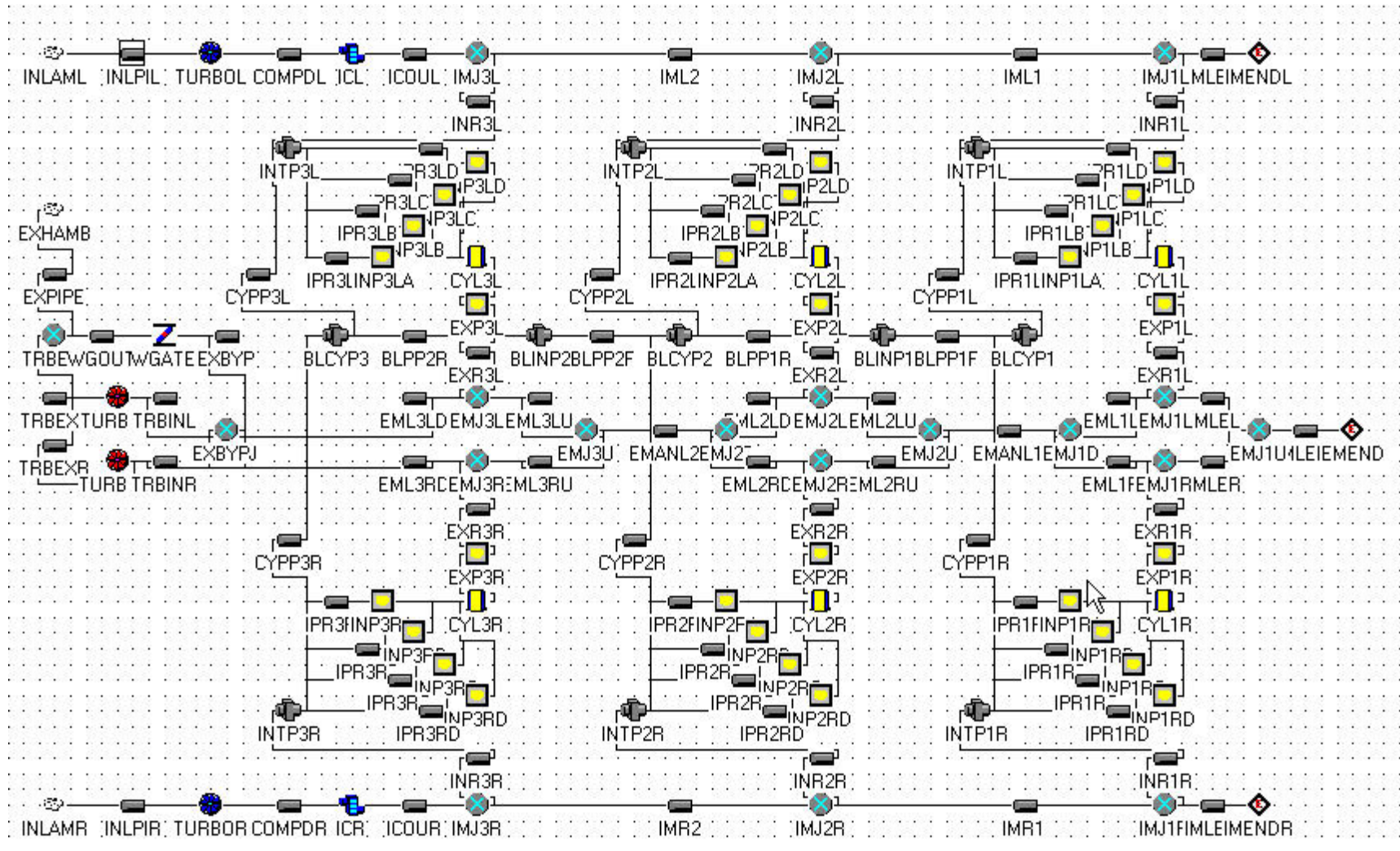

Figure 4-9. Virtual Two-Stroke Computational Model Schematic of GMVH-6 


\section{RESULTS AND DISCUSSION: ENGINE MEASUREMENT AND TESTING}

\subsection{THE GMVH-6 ENGINE}

The GMVH-6 integral compressor engine is a turbocharged two-stroke engine. This engine is loop scavenged, Schnurle type, with inlet and exhaust ports fixed in the cylinder liner. Port opening and closing is therefore governed by piston motion. A cross-sectional view of the GMVH engine is provided in Figure 5-1. The power cylinders are arranged in a Vee, with the compressor cylinders horizontal to the crankshaft centerline. The compressors are integrated into the engine design and driven by the master connecting rod. The power cylinder pistons are connected to the slave rods in an articulated rod configuration. Rotations of the slave rod hinge pins are elliptical rather than circular (as with traditional slider-crank configurations in typical engines). Figure 5-2 shows the articulating motion of the hinge pins. The resulting piston motions differ slightly between left and right banks, as shown in Figure 5-3, creating slight differences in port timings. The exhaust port timings based on nominal dimensions are shown in Figure 5-4. Due to articulation and the different piston motion between banks, the nominal exhaust port closing (EPC) timing varies between banks by 6.5 crank angle degrees. However, the exhaust port opening (EPO) timings vary between banks by only 1.5 crank angle degrees. The intake port timings based on nominal dimensions are shown in Figure 5-5. The variance between banks on the intake port closing (IPC) and intake port opening (IPO) timings is 7.5 and 3.0 crank angle degrees, respectively.

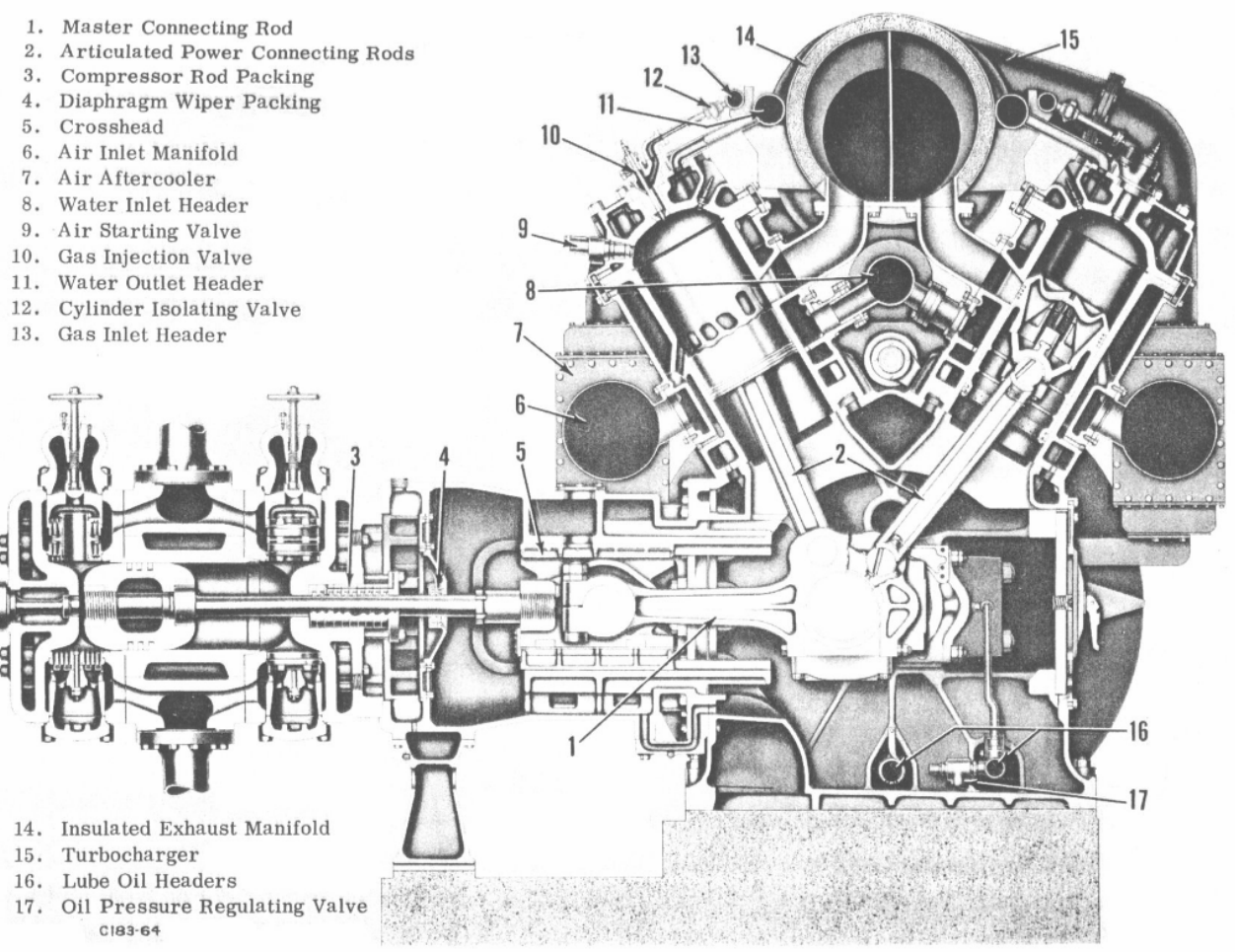

Figure 5-1. Cross Section of a Cooper-Bessemer GMVH Integral Compressor Engine 


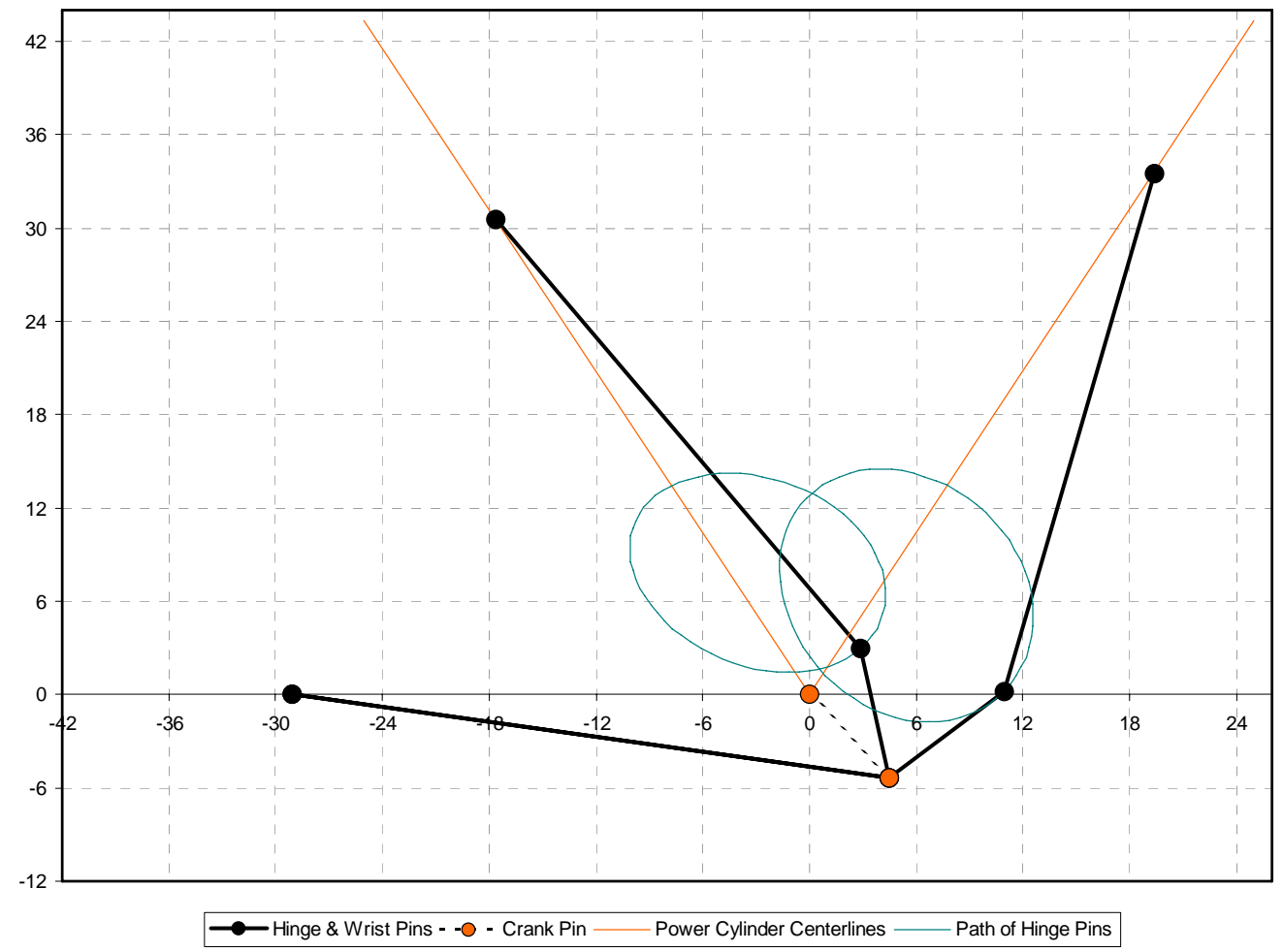

Figure 5-2. Kinematic Model Illustration of GMVH-6 Articulation

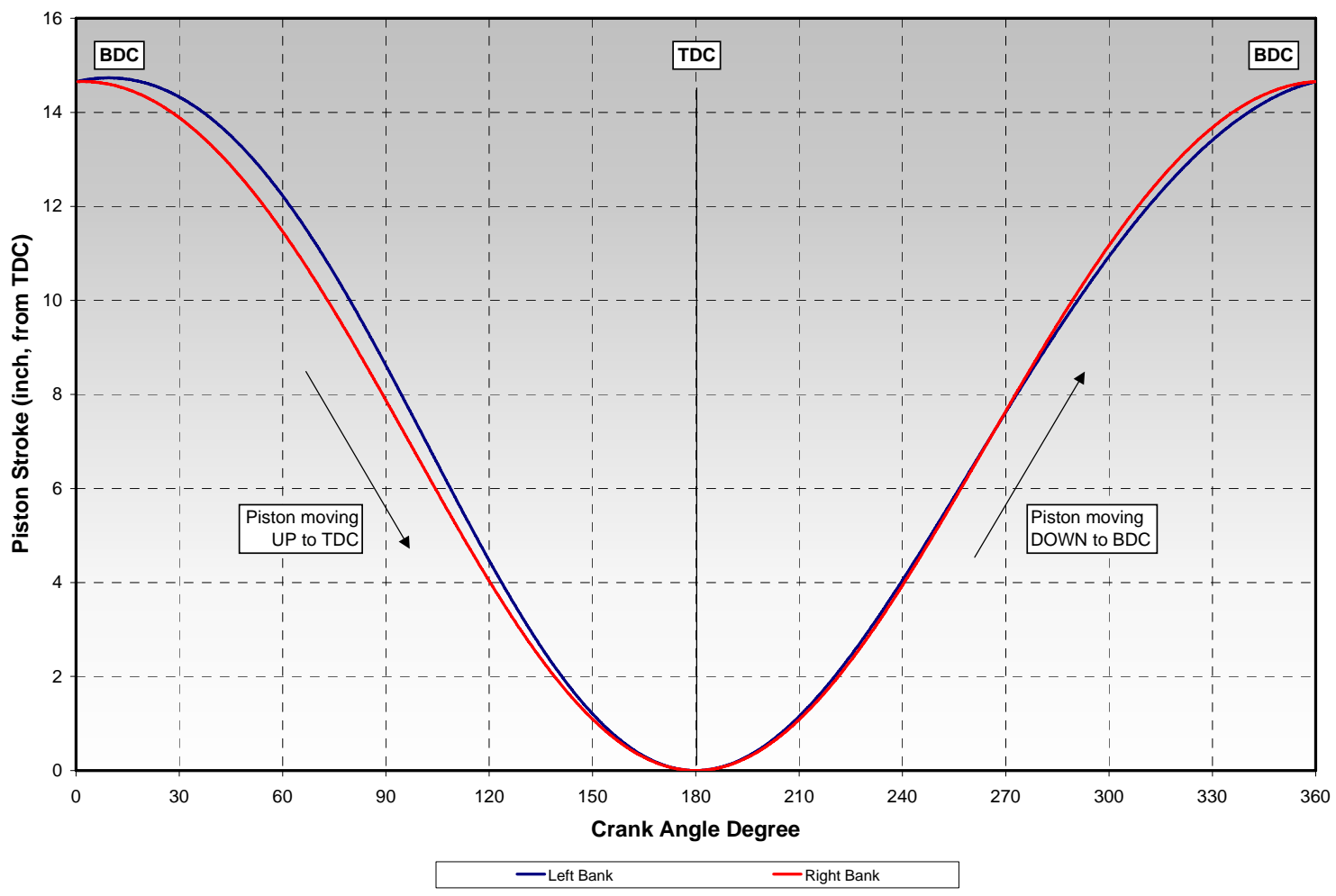

Figure 5-3. Kinematic Model Results of Left and Right Bank Piston Travel versus Crank Angle Degree 


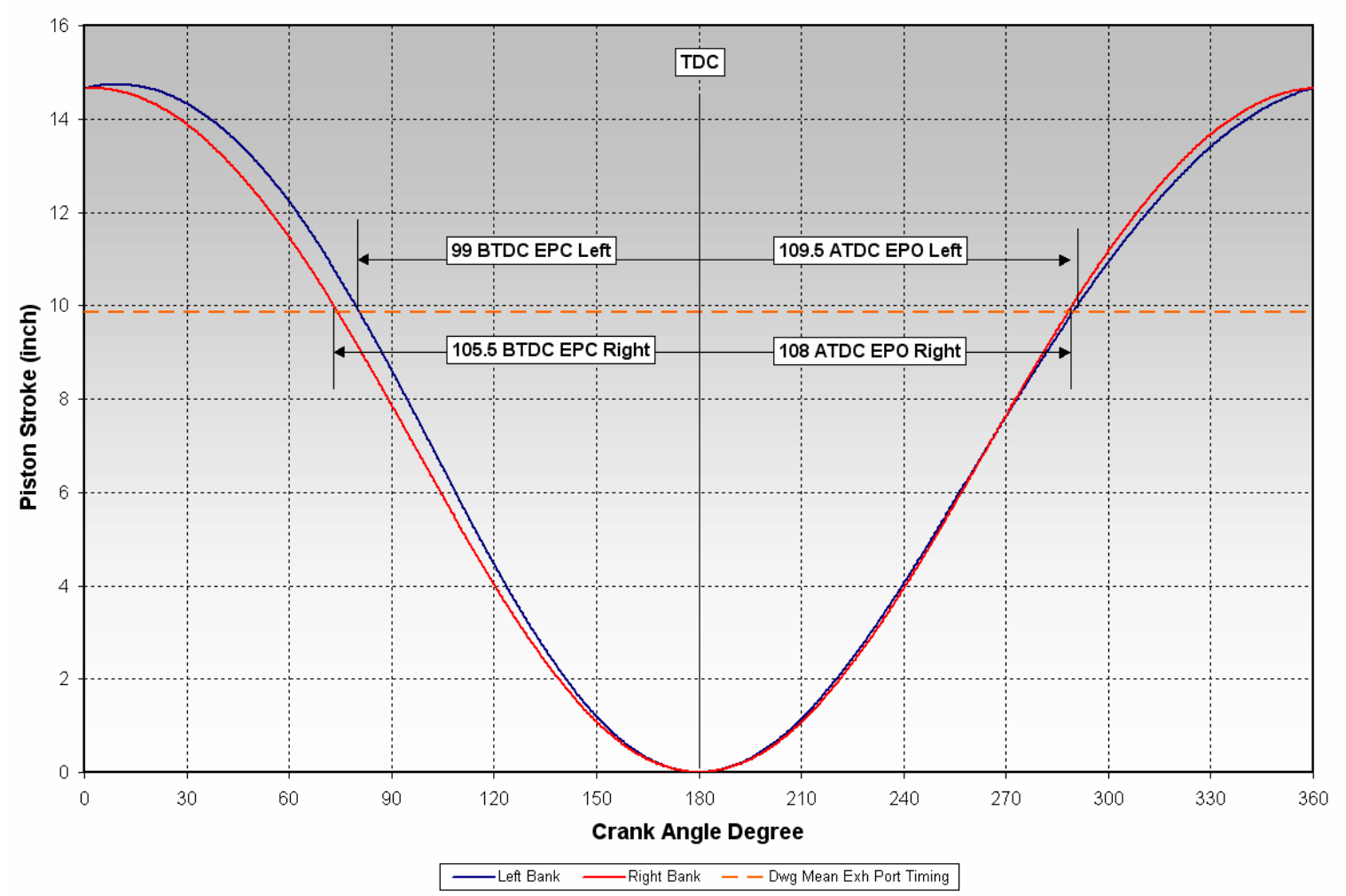

Figure 5-4. Nominal Exhaust Port Timings for Left and Right Banks

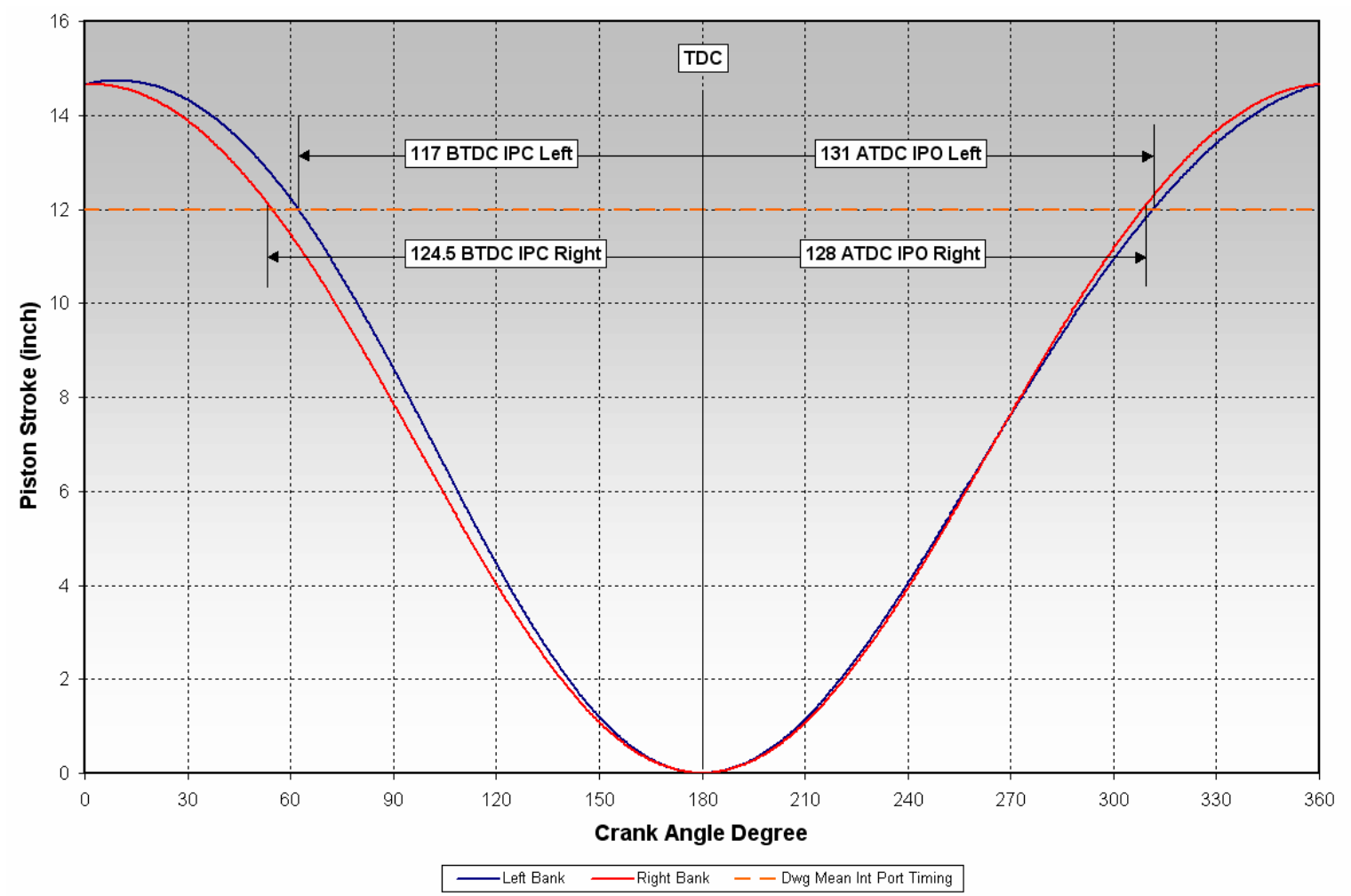

Figure 5-5. Nominal Intake Port Timings for Left and Right Banks 
A two-stroke engine does not have the exhaust stroke to 'push' the residual combustion gasses out of the cylinder into the exhaust system. In the GMVH design, the exhaust port opens early in the expansion, or power, stroke and a portion of the residual gasses 'blows down' into the exhaust due to the high pressure differential. After a few more crank angles in the expansion stroke, the intake ports open and pressurized fresh air enters the cylinder. The intake ports are also opened early, before bottom dead center (BDC), allowing fresh air to begin scavenging the remaining residual gasses out of the cylinder into the exhaust system. The air motion is, by design, directed upward toward the cylinder head to both effectively scavenge residual from the whole cylinder volume and prevent excess short-circuiting of fresh air straight through the cylinder into the exhaust. This air motion makes a 'looping' path from the intake ports to the exhaust ports, thus the loop-scavenged term. The scavenging event continues past BDC of the piston travel and into the compression stroke. Earlier opening of the exhaust port for blowdown also gives later closing of the exhaust port due to being cast into the cylinder. Therefore, some cylinder contents are pushed into the exhaust system by the piston in the time between IPC and EPC. Figures 5-6 shows the scavenging events on a plot of cylinder pressure versus crank angle degree (P-T). Figure 5-7 shows the scavenging events on a logarithmic plot of cylinder pressure versus cylinder volume (logP-logV).

The scavenging process is quite complex. It is dependent on dynamic pressure differentials between the inlet, cylinder, and exhaust. Scavenging residual combustion gasses with fresh air undoubtedly creates some pure displacement and some mixing of the gasses, as well as some short-circuiting of the fresh inlet air to the exhaust. Many mathematical models have been developed to quantify this highly dynamic process that range from simple zerodimensional to complex multi-dimensional ${ }^{[1-5]}$. Pulsations in the manifolds, due to design and/or unsteady combustion, could affect the dynamic pressures during scavenging and likely create deviations in flow between cycles and cylinders. All the factors that affect airflow and cylinder scavenging, in turn affect the trapped air/fuel ratio, combustion rate, and emissions.

An additional aspect of integral compressors engines, especially the two-stroke designs, is that they feature direct in-cylinder fuel admission to prevent scavenging of raw fuel into the exhaust. This direct fuel admission is performed in originally equipped engines with camactuated poppet valves in each cylinder that have a fixed duration tied to crankshaft speed. Individual balance valves are installed in the jumper lines to each cylinder, which are manually adjustable to provide some fuel compensation to individual cylinders to balance combustion pressures across the engine. A governor typically modulates the main fuel header pressure to maintain the engine speed setpoint. In engines equipped with modern electronic fuel injection, the cylinder combustion pressure balancing and speed governing are accomplished by the electronic control module via modulation of the injection duration. The goal of the fuel admission system design is to create a homogeneous mixture of fuel and air in the cylinder by the time ignition occurs near top dead center (TDC). However, similar to the scavenging process, there is undoubtedly some stratification of fuel and air within the cylinder volume and the resulting mixture is not completely uniform. Fuel valve opening (FVO) and closing (FVC) timings for the GMVH are shown in Figures 5-6 and 5-7 along with the scavenging events. 


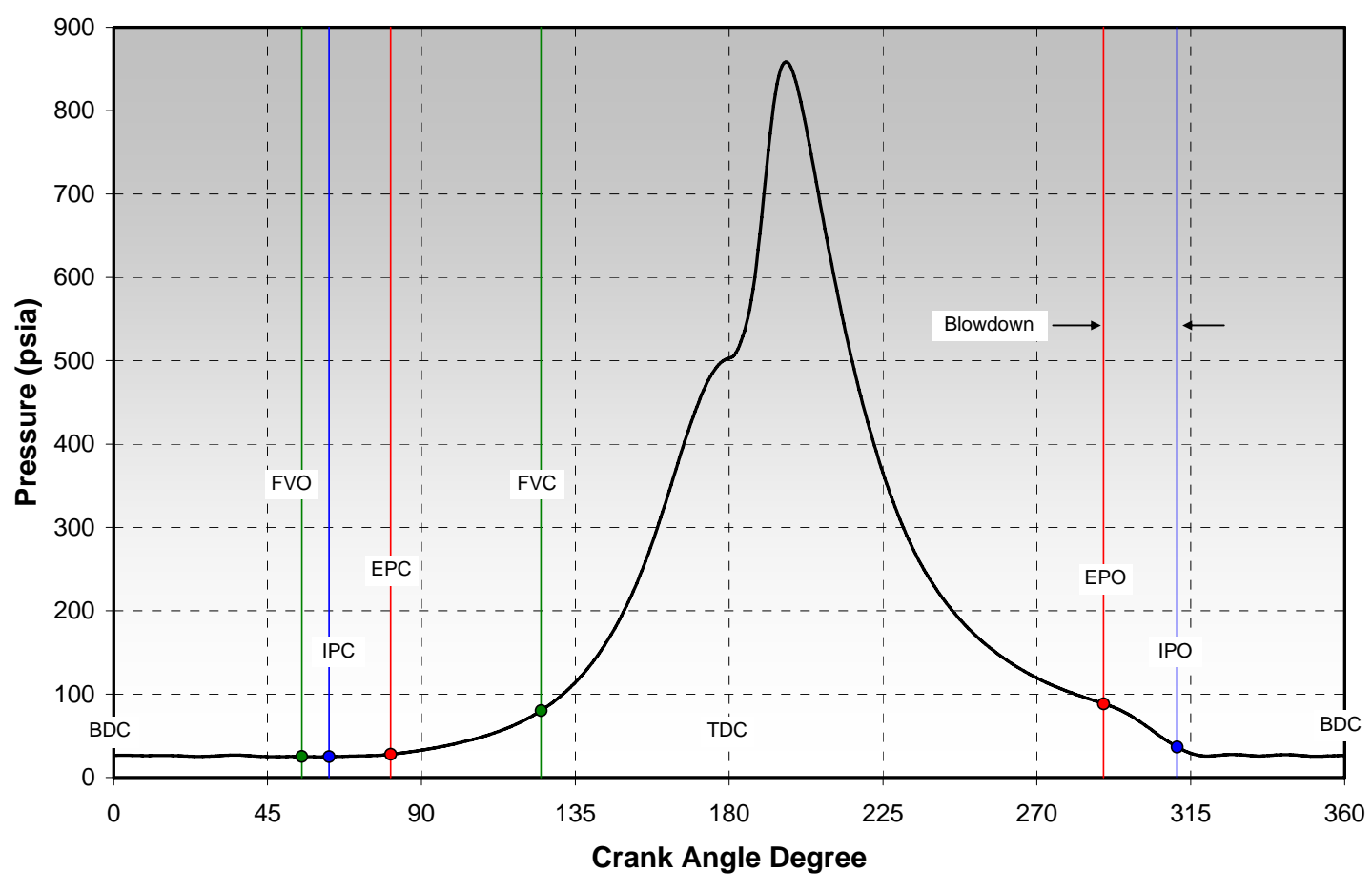

$-\mathrm{Cyl} \# 3 \mathrm{~L}-\mathrm{FVO}-\mathrm{FVC}-\mathrm{EPC}-\mathrm{EPO}-\mathrm{IPC}-\mathrm{IPO}$

Figure 5-6. GMVH Cylinder Pressure versus Crank Angle - Scavenging and Fuel Admission Events Noted

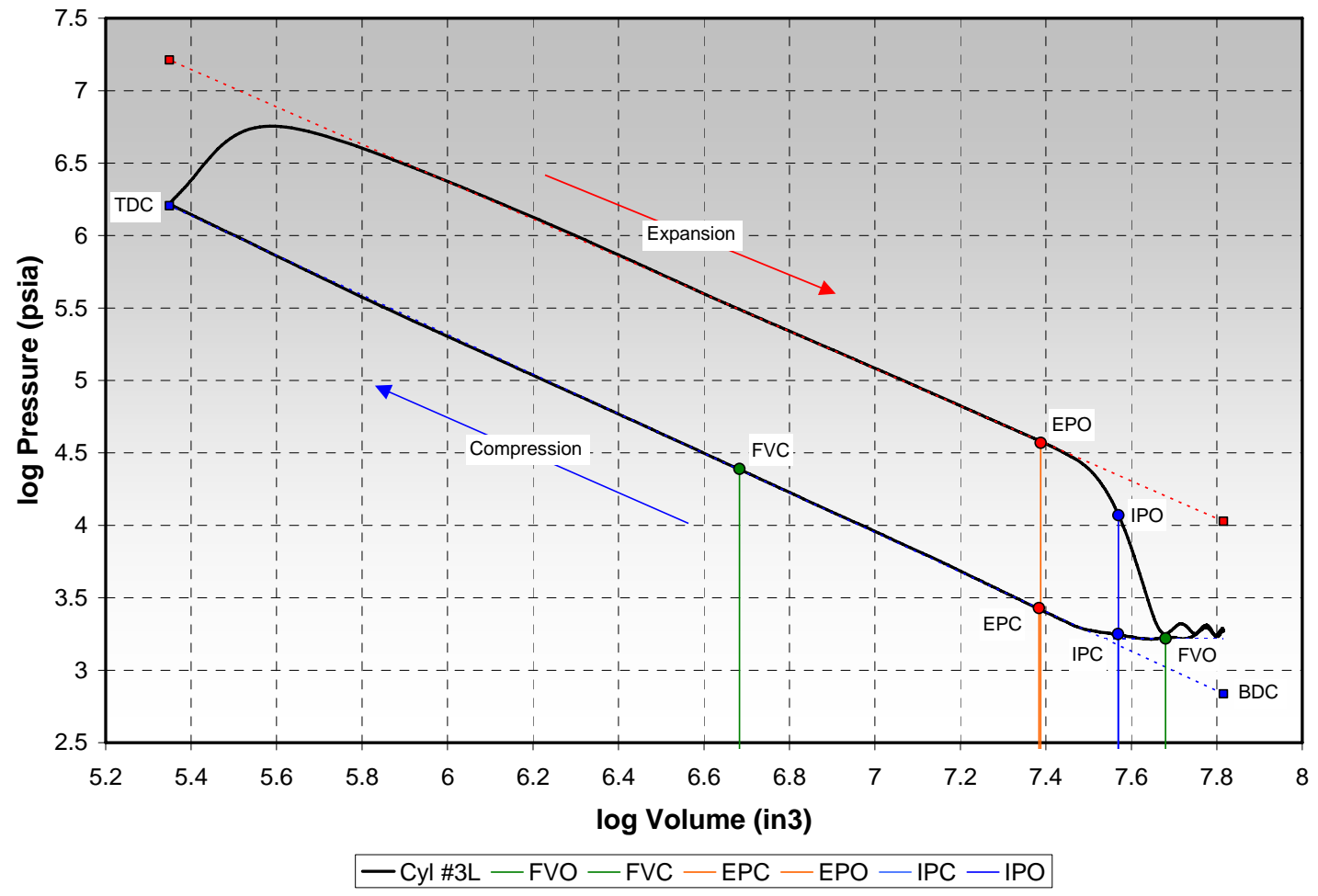

Figure 5-7. GMVH Cylinder Pressure versus Cylinder Volume on Logarithmic Scale - Scavenging and Fuel Admission Events Noted 
The intake and exhaust manifolds on the GMVH-6 engine are comprised of tubular logs with rectangular runners branching to each cylinder. The exhaust manifold features one log which is located within the Vee of the cylinders. The rectangular exhaust runners curve from the cylinder flanged at $30^{\circ}$ from vertical to horizontal flanges at the bottom of the manifold log. Inside the exhaust manifold log there are vertical plates between each pair of cylinders that provide stiffening to the manifold and likely prevent the blowdown pulse from one cylinder directly interfering with the adjacent cylinder. A gap exists between these plates at the expansion joints between cylinder pairs. Additional discussion and photographs of the exhaust system are provided in Section 5.3.4.

The intake system features tubular log manifolds on the outside of each bank of cylinders. The rectangular intake runners are straight from the manifold log to the cylinder flange. Since there are two intake manifolds for each bank, the turbocharger compressor has two outlets feeding through separate intercoolers to each bank manifold. Additional discussion and photographs of the exhaust system are provided in Section 5.3.4. A simple schematic of the intake and exhaust systems, as well as the cylinder arrangement and fuel system, is provided in Figure 5-8.

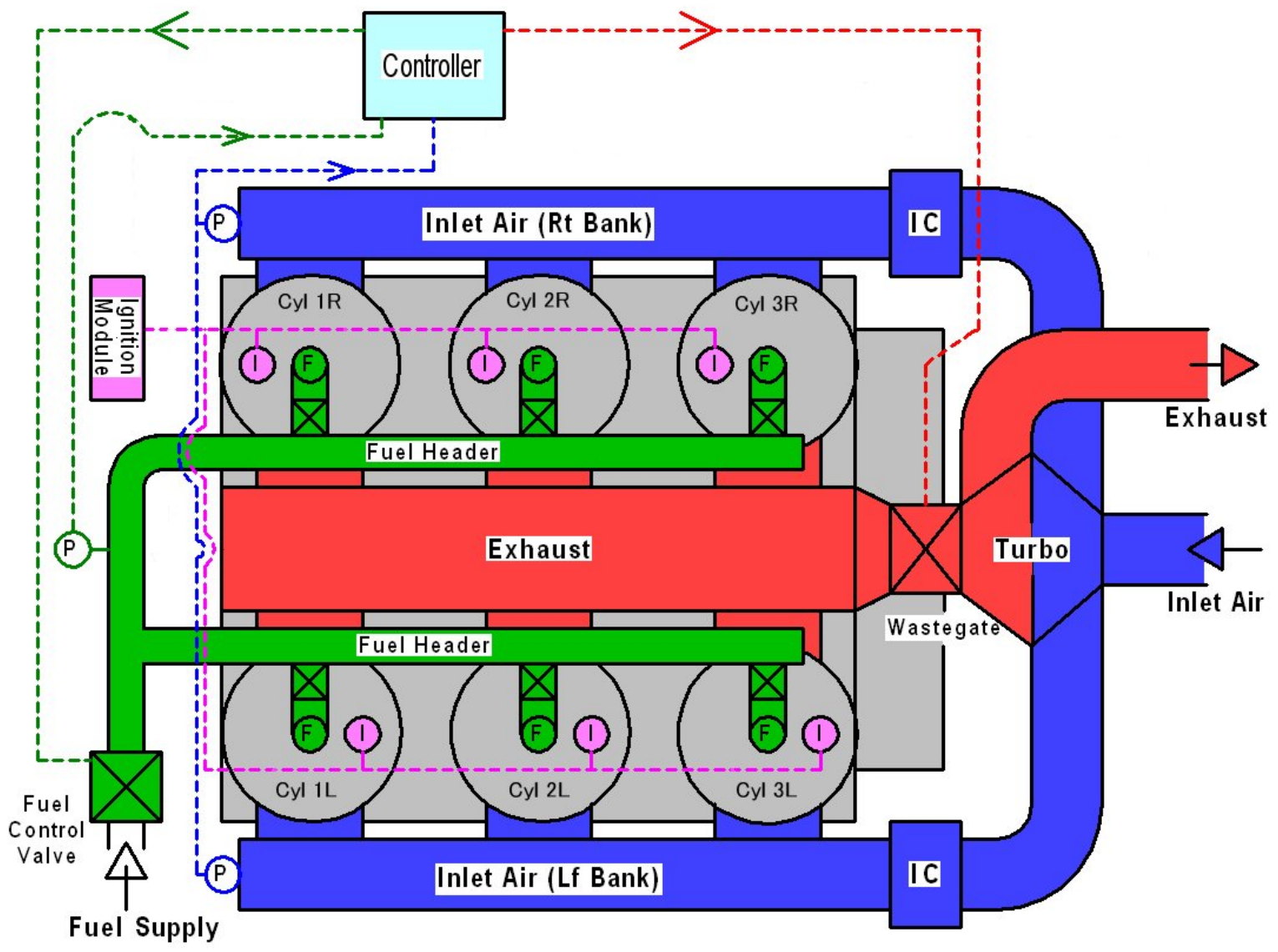

Figure 5-8. Top-View Schematic of GMVH-6 Engine 


\subsection{GMVH-6 BASELINE TESTING}

Baseline testing of the GMVH-6 engine involved operation in both open chamber and pre-chamber configurations. The engine was tested over engine speeds of 231, 264, 297, and $330 \mathrm{rpm}$. Engine load was also varied from 70, 85, 90, and 100 percent of rated. Within this map of engine speed and load, the air/fuel ratio and spark timing was varied. In analyzing the data, the spread of compression pressures was seen to remain very consistent regardless of the operating condition. This consistency is shown in Figure 5-9, where the pressure at $20^{\circ}$ before top dead center (TDC) for all cylinders at all operating conditions tested is plotted versus air manifold pressure. All data obtained on the GMVH-6 prior to disassembly indicate that the low cylinder (pressure @ 20 BTDC) is always cylinder 3L and the high cylinder (pressure @ 20 BTDC) is always $2 \mathrm{R}$.

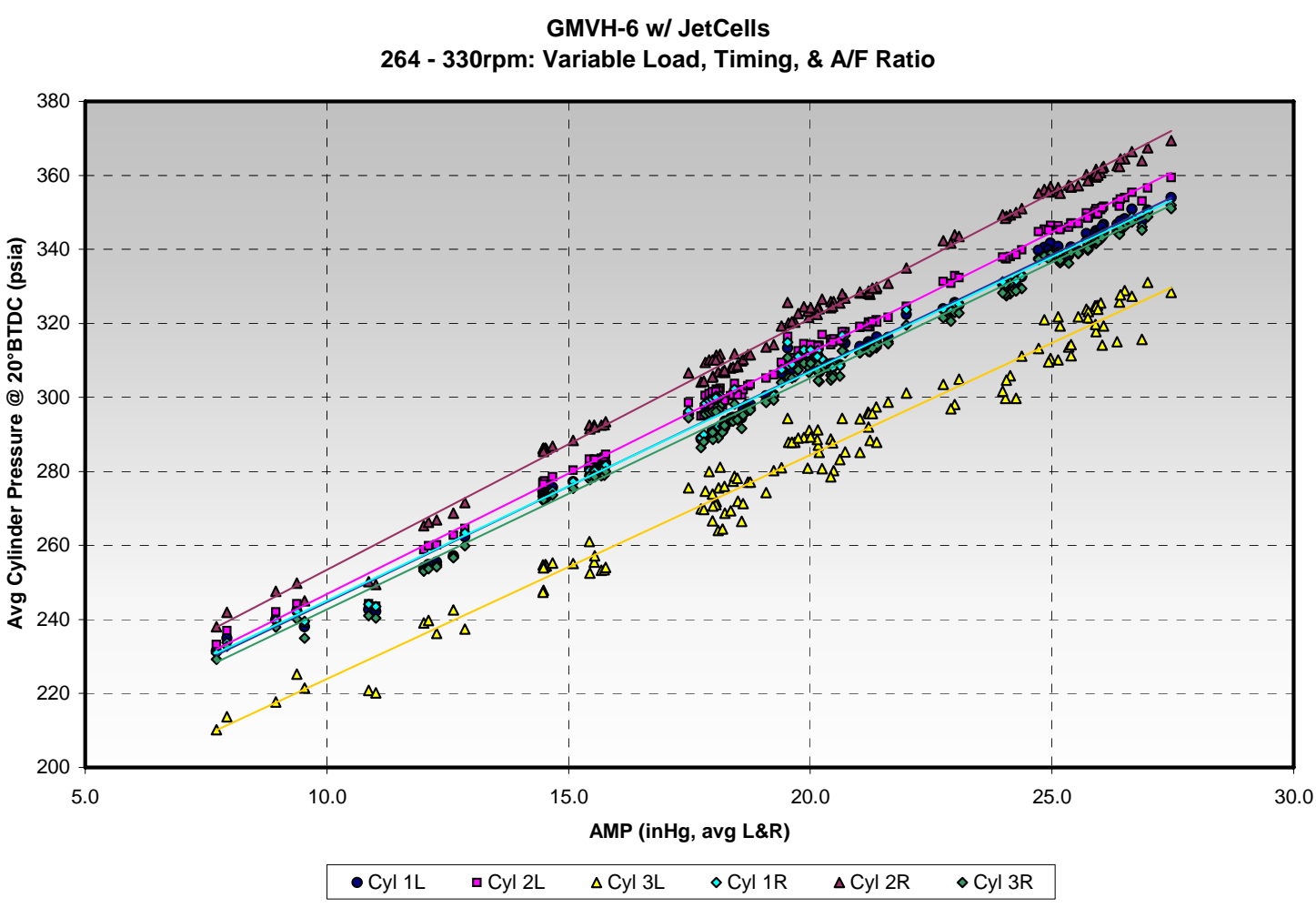

Figure 5-9. Comparison of Cylinder to Cylinder Compression Pressure (20 BTDC) at All Operating Conditions

Engine test data was acquired for comparison of performance and emissions, simulation validation, and analytical purposes. For comparison purposes the fuel efficiency and $\mathrm{NO}_{\mathrm{X}}$ emissions versus various operating conditions were documented. The fuel efficiency was quantified in terms of Brake Specific Energy Consumption (BSEC) in units of BTU/bhp-hr. $\mathrm{NO}_{\mathrm{X}}$ emissions were quantified in both parts per million (ppm) concentration and brake specific (g/bhp-hr). The efficiency trends for the open chamber tests are shown in Figures 5-10 and 5-11 where BSEC is plotted versus engine speed and load, respectively, at a constant $4 \mathrm{~g} / \mathrm{bhp}-\mathrm{hr} \mathrm{NO}_{\mathrm{X}}$. This data shows peak efficiency occurs at the rated speed and load. 
GMVH-6 Open Chamber - $90 \%$ Load

Constant NOx $=4 \mathrm{~g} / \mathrm{hp}$-hr, Timing for Constant Location of Peak Pressure

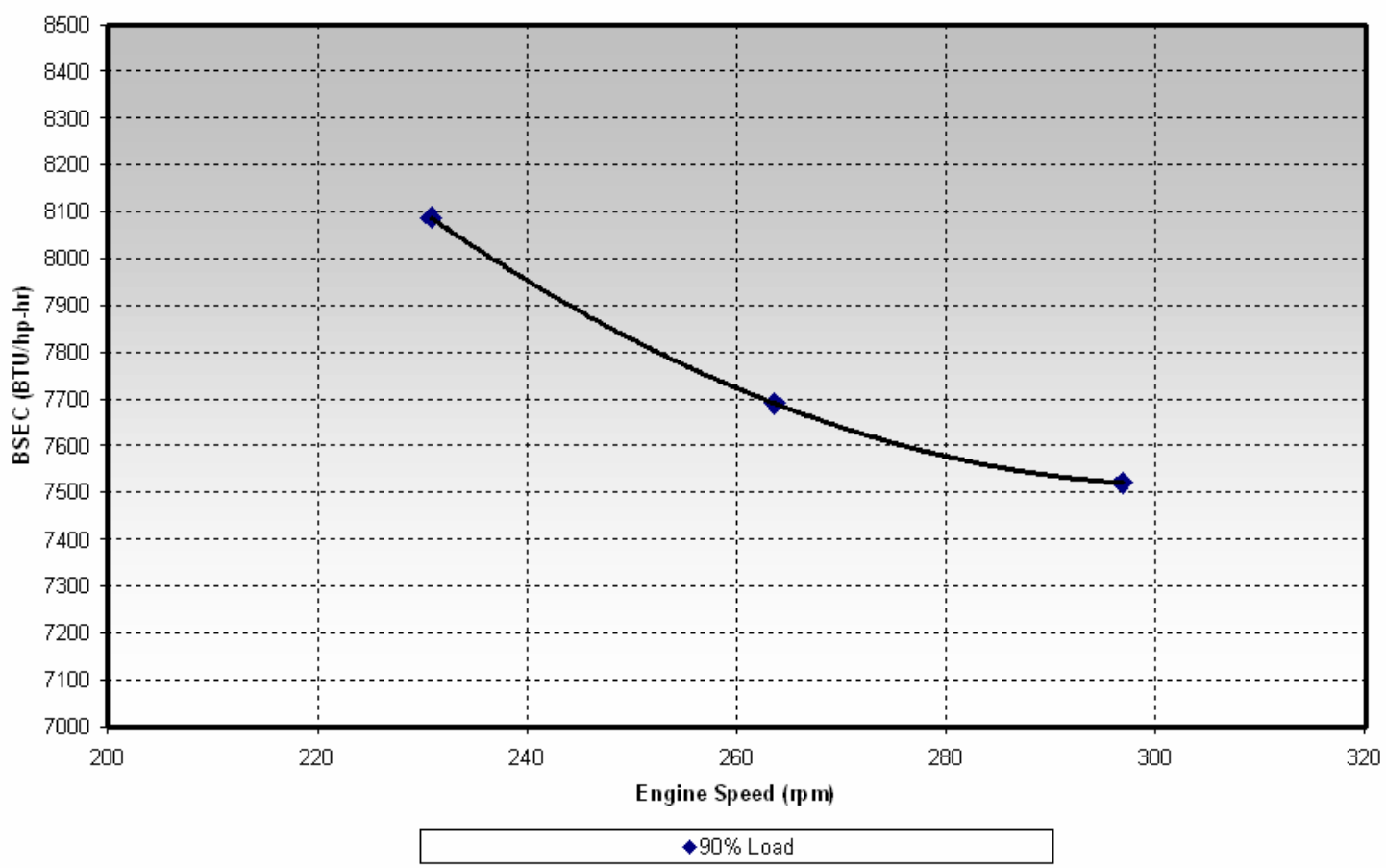

Figure 5-10. Open Chamber Fuel Efficiency versus Engine Speed at Constant $\mathrm{NO}_{\mathrm{x}}$

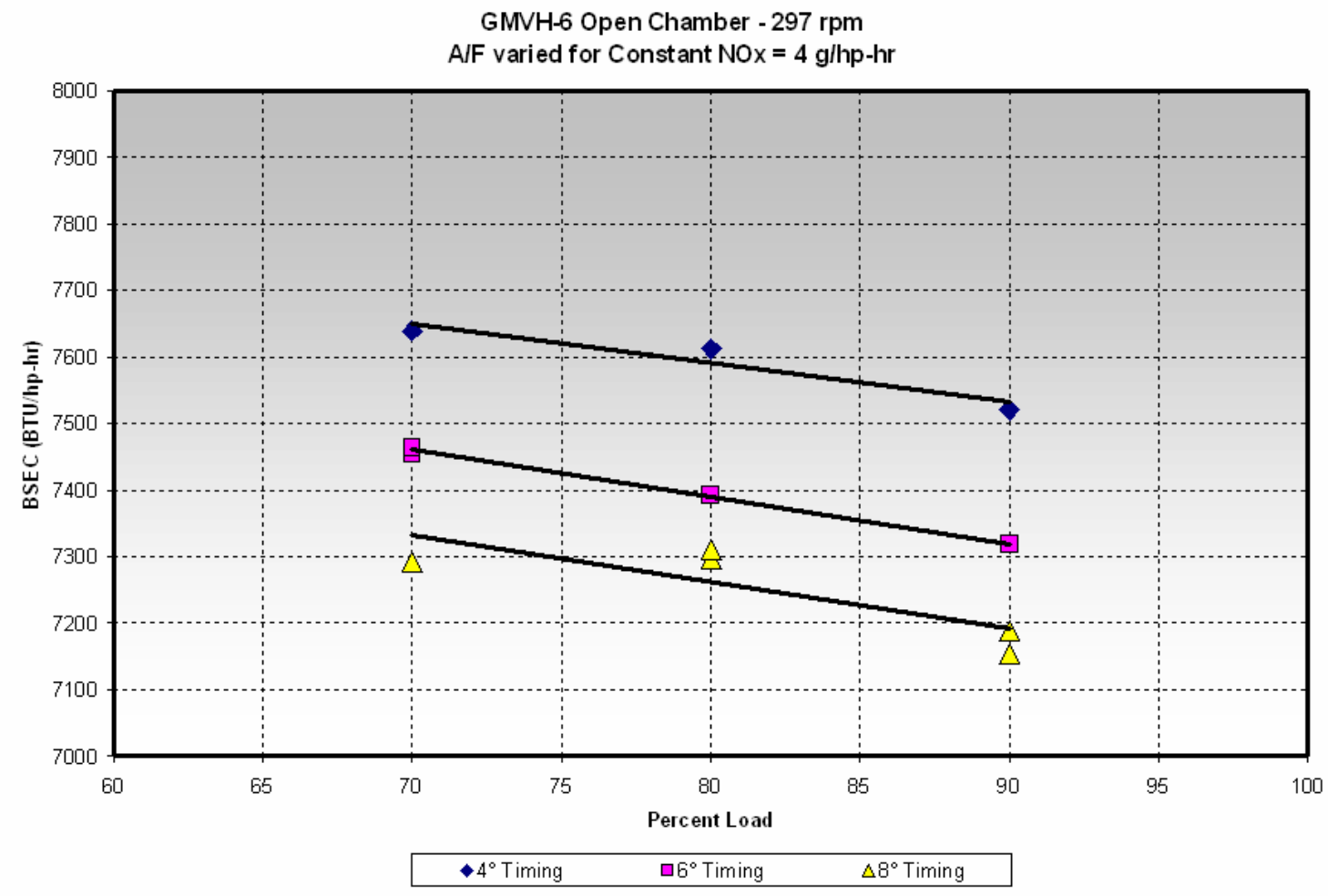

Figure 5-11. Open Chamber Fuel Efficiency versus Engine Load and Ignition Timing at Constant $\mathrm{NO}_{x}$ 
Efficiency data for the prechamber configuration is provided in Figure 5-12, and again shows peak efficiency at maximum load and rated engine speed. A comparison of the $\mathrm{NO}_{\mathrm{X}}{ }^{-}$ Efficiency trade-off for both prechamber and open chamber is provided in Figure 5-13, and includes additional data acquired on the GMVH-6 engine. This plot shows the typical 'knee' in the curves where $\mathrm{NO}_{\mathrm{X}}$ emissions increase rapidly beyond the optimum trade-off point with improving efficiency, and also shows the improved relationship with the prechamber configuration over the open chamber configuration. The prechamber configuration, with its improved ignition capability, provides better efficiency and lower $\mathrm{NO}_{\mathrm{X}}$ emissions. This $\mathrm{NO}_{\mathrm{X}^{-}}$ efficiency improvement with prechambers is due to more stable combustion at leaner air/fuel ratios and faster burn rates. The improved combustion with prechambers is illustrate further in Figures 5-14 through 5-16 for the same operating condition of 330rpm, 100 percent load, and 2 $\mathrm{g} / \mathrm{bhp}-\mathrm{hr} \mathrm{NO}_{\mathrm{x}}$. Average cylinder pressure for cylinder $1 \mathrm{~L}$ from both open chamber and prechamber tests is plotted in Figure 5-14. A higher compression pressure for the open chamber run can be seen, and is due to the need for higher boost to operate at the same speed, load, and $\mathrm{NO}_{\mathrm{X}}$ emissions level. The heat release rate and cumulative heat release for the prechamber and open chamber tests are shown in Figures 5-15 and 5-16, where the faster burn rate can be seen for the prechamber combustion.

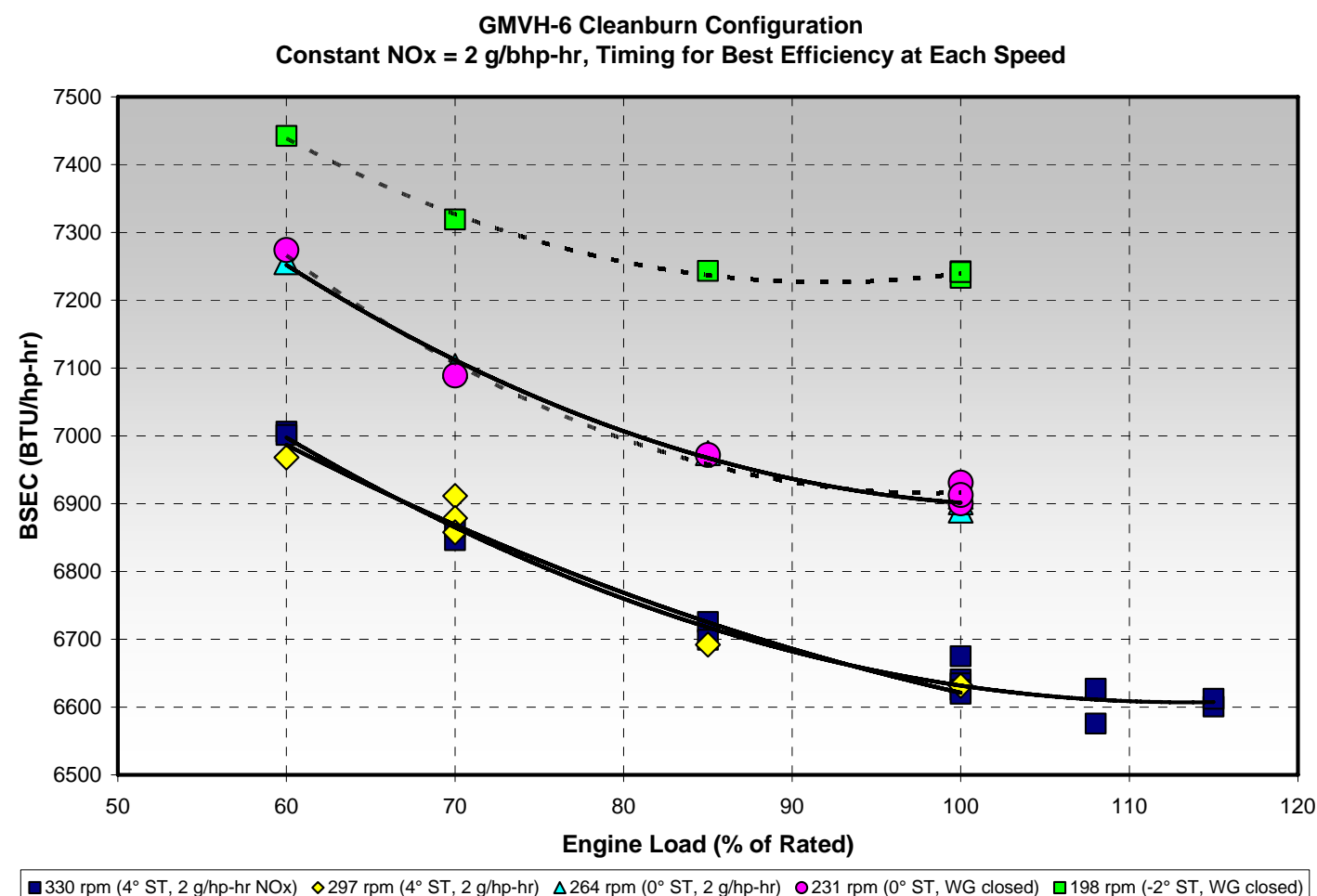

Figure 5-12. Prechamber Fuel Efficiency versus Engine Load, Speed, and Ignition Timing at Constant $\mathrm{NO}_{\mathrm{x}}$ 


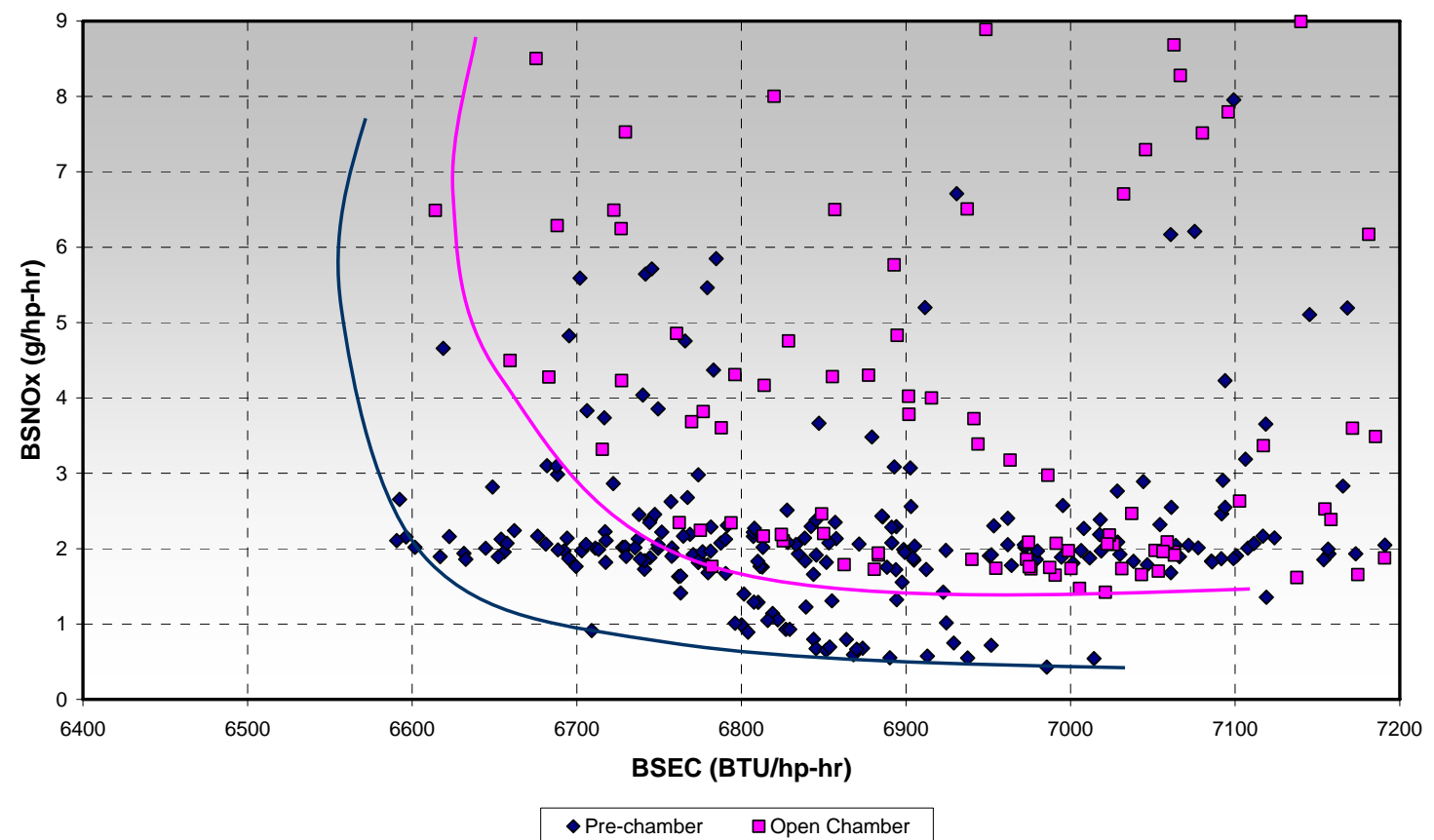

Figure 5-13. Prechamber and Open Chamber $\mathrm{NO}_{\mathrm{x}}$ - Efficiency Trade-Off

GMVH-6 - Cylinder $1 \mathrm{~L}$

330rpm - 100\% Load - 2 g/bhp-hr NOx

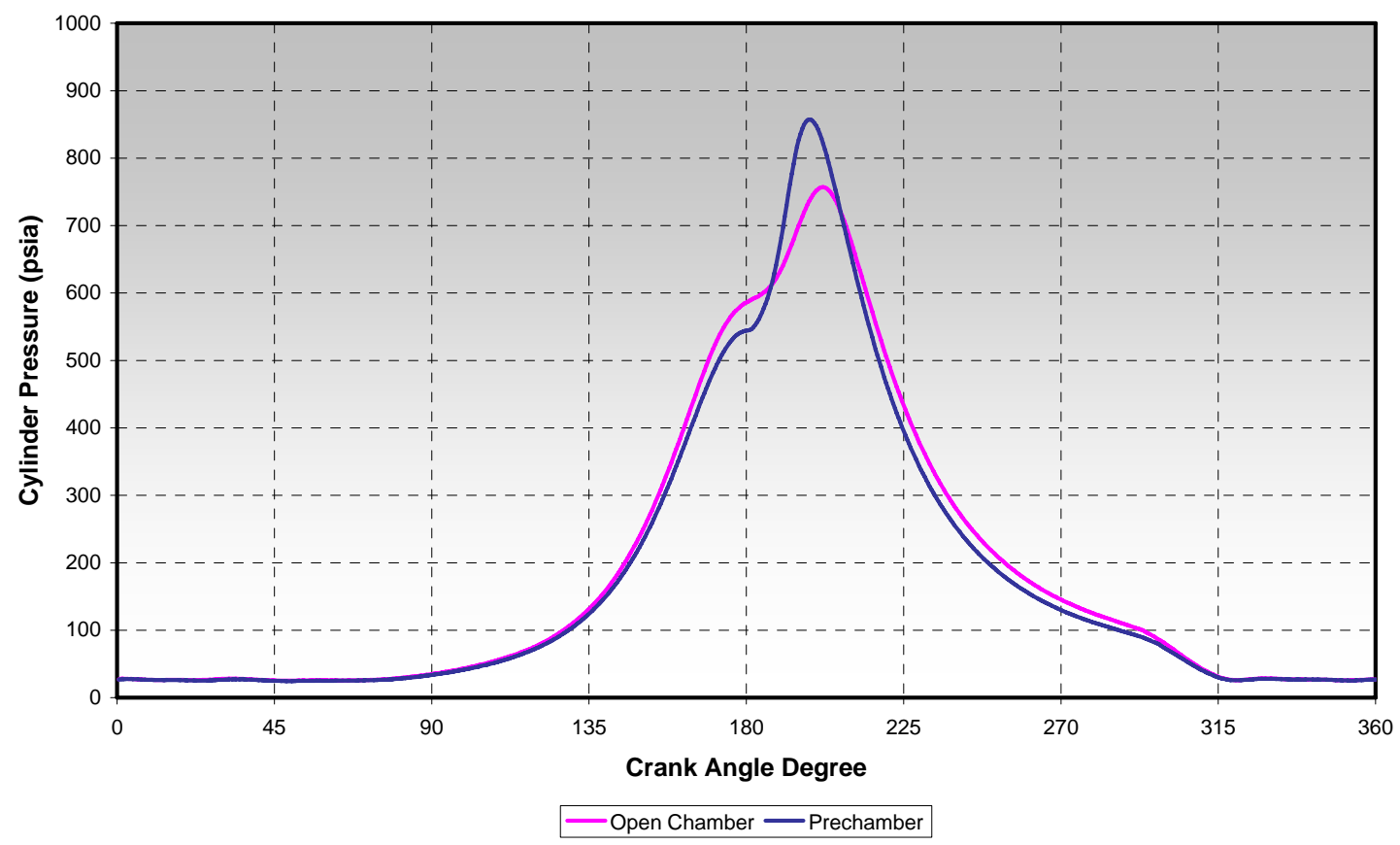

Figure 5-14. Cylinder 1L Pressure Comparison for Prechamber and Open Chamber 
GMVH-6 - Cylinder $1 \mathrm{~L}$

330rpm - 100\% Load - 2 g/bhp-hr NOx

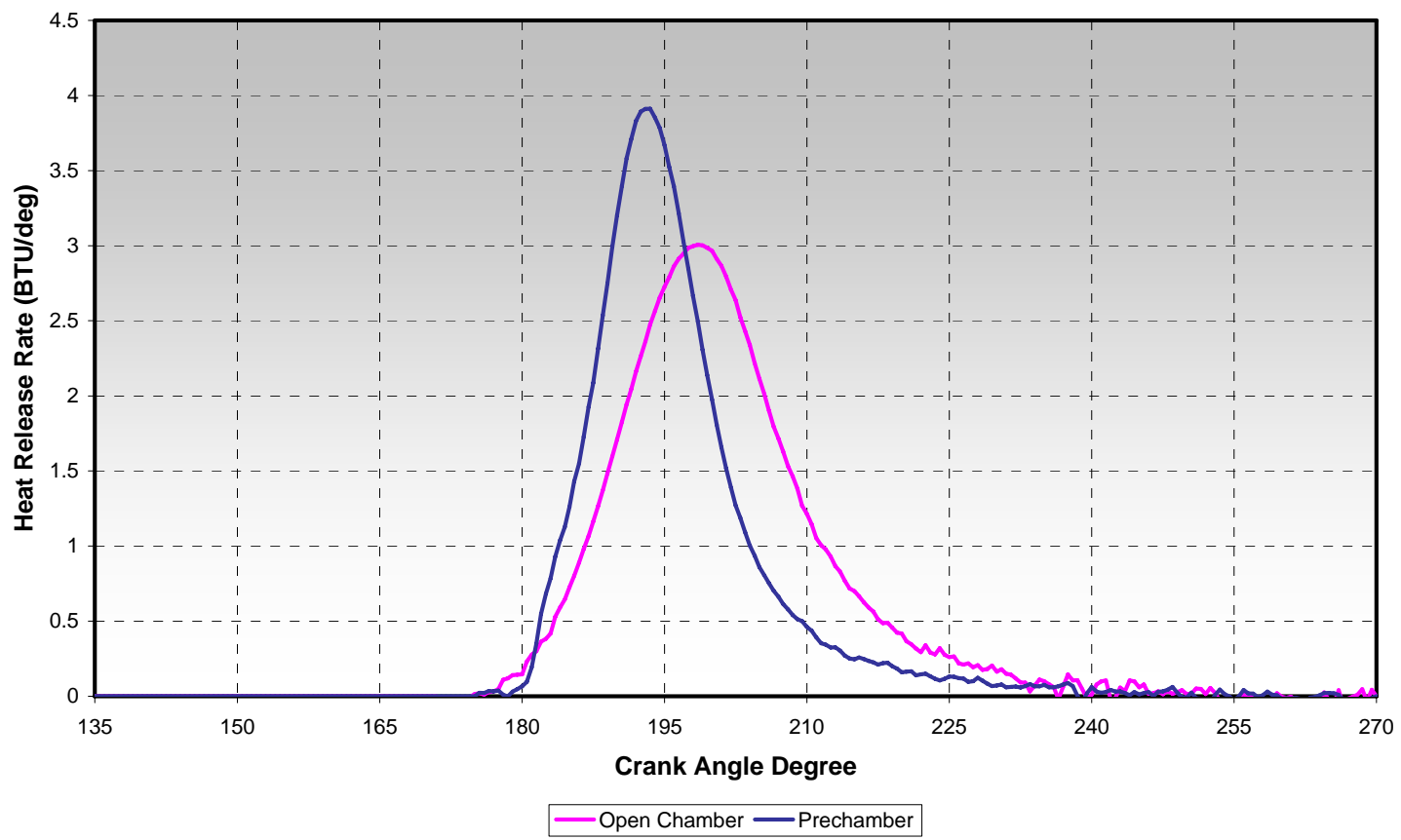

Figure 5-15. Cylinder 1L Apparent Heat Release Rate Comparison for Prechamber and Open Chamber

GMVH-6 - Cylinder $1 \mathrm{~L}$

330rpm - 100\% Load - 2 g/bhp-hr NOx

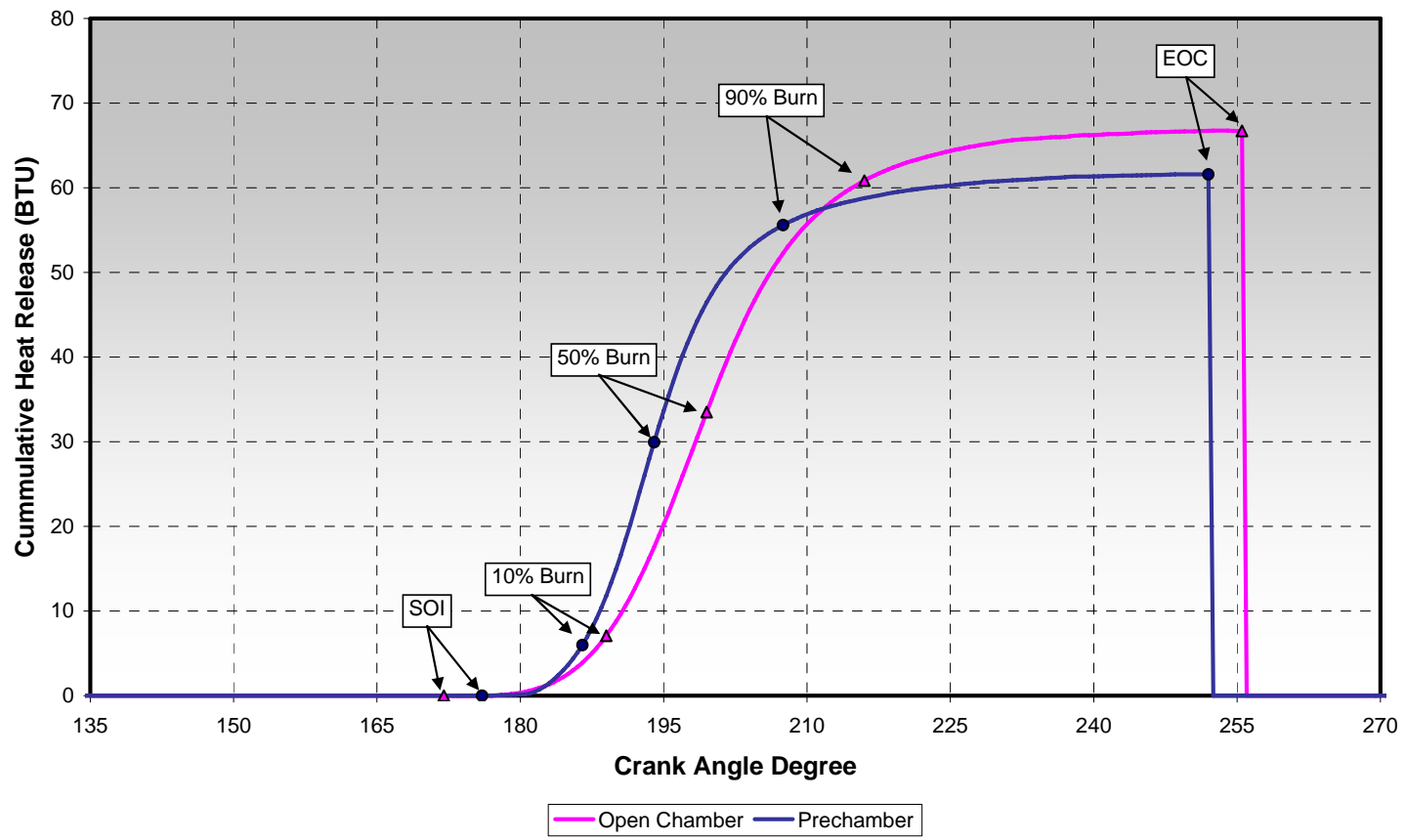

Figure 5-16. Cylinder 1L Cumulative Heat Release Comparison for Prechamber and Open Chamber 
Test data for simulation validation included time-averaged performance parameters and dynamic trace data for each cylinder. Performance parameters included both global and individual cylinder variables. This data, from select runs, was used to tune the model and compare simulation results. Test data for analytical purposes was trended, as in the previous graphs above, and analyzed to investigate factors such as intake and exhaust pulsations. Further discussions on these efforts are provided in appropriate sections below.

\subsection{GEOMETRIC ANALYSIS}

At the beginning of the project, mean dimensions of cylinder components (from drawings provided by Cooper) were used in data analysis and in the construction of the simulation model. Several assumptions for dimensions and complex volumes were used in the model where drawings were either difficult to interpret or were not obtained. Initial simulations with these values and geometry yielded less than satisfactory results. These initial simulations predicted mass airflow closely, but did not accurately predict the amplitude and phasing of pulsations in the inlet and exhaust manifolds. It was believed that the inaccurate manifold dynamic predictions were due to the use of inaccurate discharge coefficients and inaccurate representations of the complicated cylinder plenum geometry that could not be measured externally. It was also believed that the selection of mean values may have also contributed to the erroneous simulation results. Based on these issues, the engine was disassembled so that actual measurements could be obtained. In doing so, it could also determine if any geometric variances were contributing significantly and directly to the compression pressure spread. As mentioned previously, it is well known that geometric factors (such as compression ratio and port geometry) can affect compression pressures and must be quantified prior to any manifold redesign.

The GMVH-6 engine was disassembled and all pistons and connecting rods were removed. Three of the six cylinders were left installed on the base, while the other three cylinders were removed for flow testing. Several measurements were taken on each cylinder's components as listed in Table 4-2. From these measurements, the following parameters were obtained:

- $\quad$ Base and cylinder air chest geometry - individual cylinder airbox volume

- Intake and exhaust manifolds - internal dimensions and geometry, specifically at junctions and transitions in each manifold

- Mechanical and effective compression ratio - individual cylinder clearance volume (head, piston, crevices), TDC piston height, stroke, and exhaust port timings

- $\quad$ Port flow - port dimensions and area, shape, timings, angles, lip radius, and volumes for each port in each cylinder

- Fuel valve lift profile - individual fuel valve travel versus crank angle

Two important observations were made during disassembly. The first critical observation was that the 'air chest' cast into the base was open and communicating with the inlet air system. 
The second critical observation was that one of the six cylinders had a different casting number and different geometry of the inlet and exhaust ports.

\subsubsection{BASE AIR ChEST}

The base air chest was initially believed to be blocked off by gaskets, since it serves no purpose in breathing with separate intake manifolds as is the case with the turbocharged version of the GMV. The base air chest was the original inlet air path with earlier versions of the GMV engine that were piston scavenged. The base air chest was, however, found to be open and connecting the airboxes from each cylinder to a common volume, thus acting like a large accumulator. This explained immediately why the initial simulations showed significantly higher inlet manifold pressure pulsations than were measured. The discovery of the base plenum being active and connected to the inlet system was a very important finding, as accurate simulation would have never been achieved without this feature being incorporated into the model.

The size and shape of the air chest volume was unknown during initial modeling of the engine. After discovering that the base plenum had been connected, base drawings were requested from Cooper. To accurately reflect the base air chest in the simulation model, several physical measurements were made and the base drawing consulted for hidden geometry. A CAD model, depicted in Figure 5-17, was then generated from the measurements to calculate the air volume and to allow for visual investigation on the proper method to simulate the flow paths. A total volume of 65,106 in ${ }^{3}$ was derived from this CAD model. A photograph of the GMVH base with cylinders removed is shown in Figure 5-18 where arrows highlight the air chest ports.
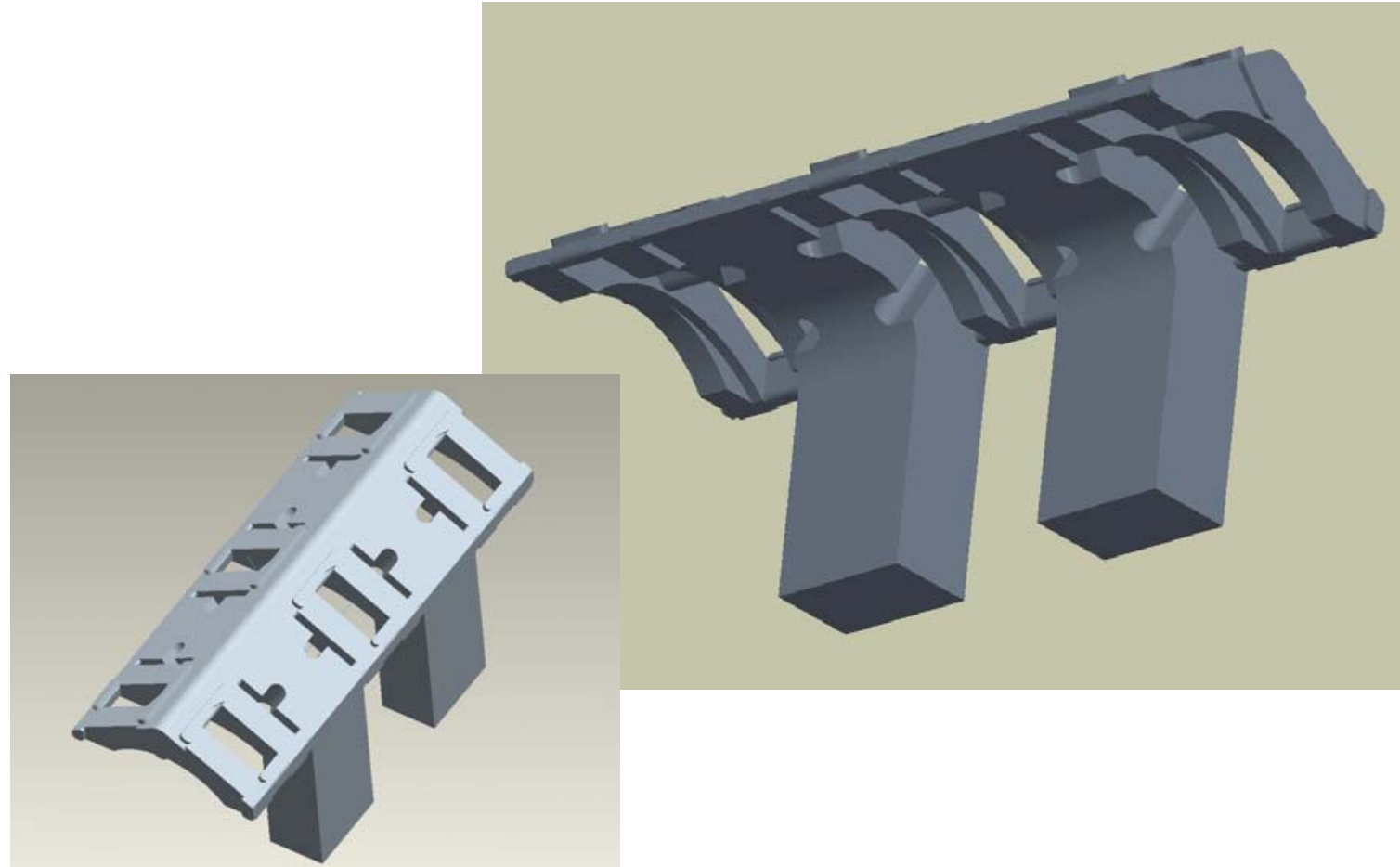

Figure 5-17. CAD Model of Base Air Chest (air volume shown as solid) 


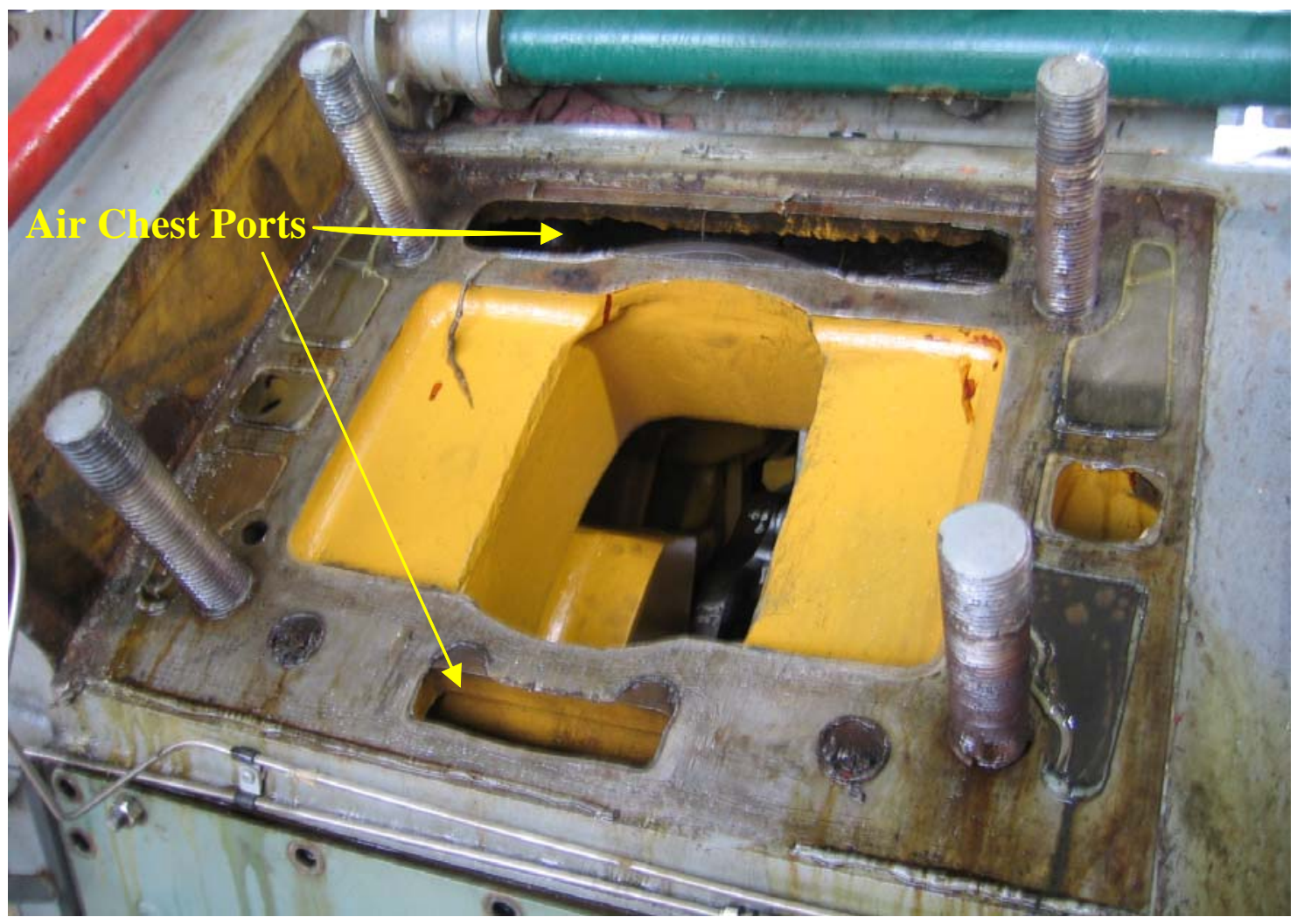

Figure 5-18. Photograph of GMVH Base with Cylinder Removed - Air Chest Ports Highlighted

\subsubsection{Cylinder Castings and Port Shape}

Further investigation on the disassembled engine showed that cylinder $1 \mathrm{R}$ had a different casting number than the other six cylinders. The exhaust port shape for cylinder 1R was different from the other cylinders and matched Shape No. 3 shown in Figure 5-19. All other cylinders matched Shape No. 1 in Figure 5-19. The drawings in Figure 5-19 are an excerpt from the original OEM drawing showing allowable port shapes. Although cylinder $1 \mathrm{R}$ did not appear to be a problem in terms of compression pressure, this different port shape yielded different flow characteristics and therefore was replaced during re-assembly with a cylinder that had a matching casting number and exhaust port shape. Cylinder port airflow testing (described below) was initially to be performed on only cylinders $1 \mathrm{~L}$ and $3 \mathrm{~L}$, however, the mis-matched cylinder $1 \mathrm{R}$ was added to the test matrix to provide insight to the affect of port shape on flow characteristics. 


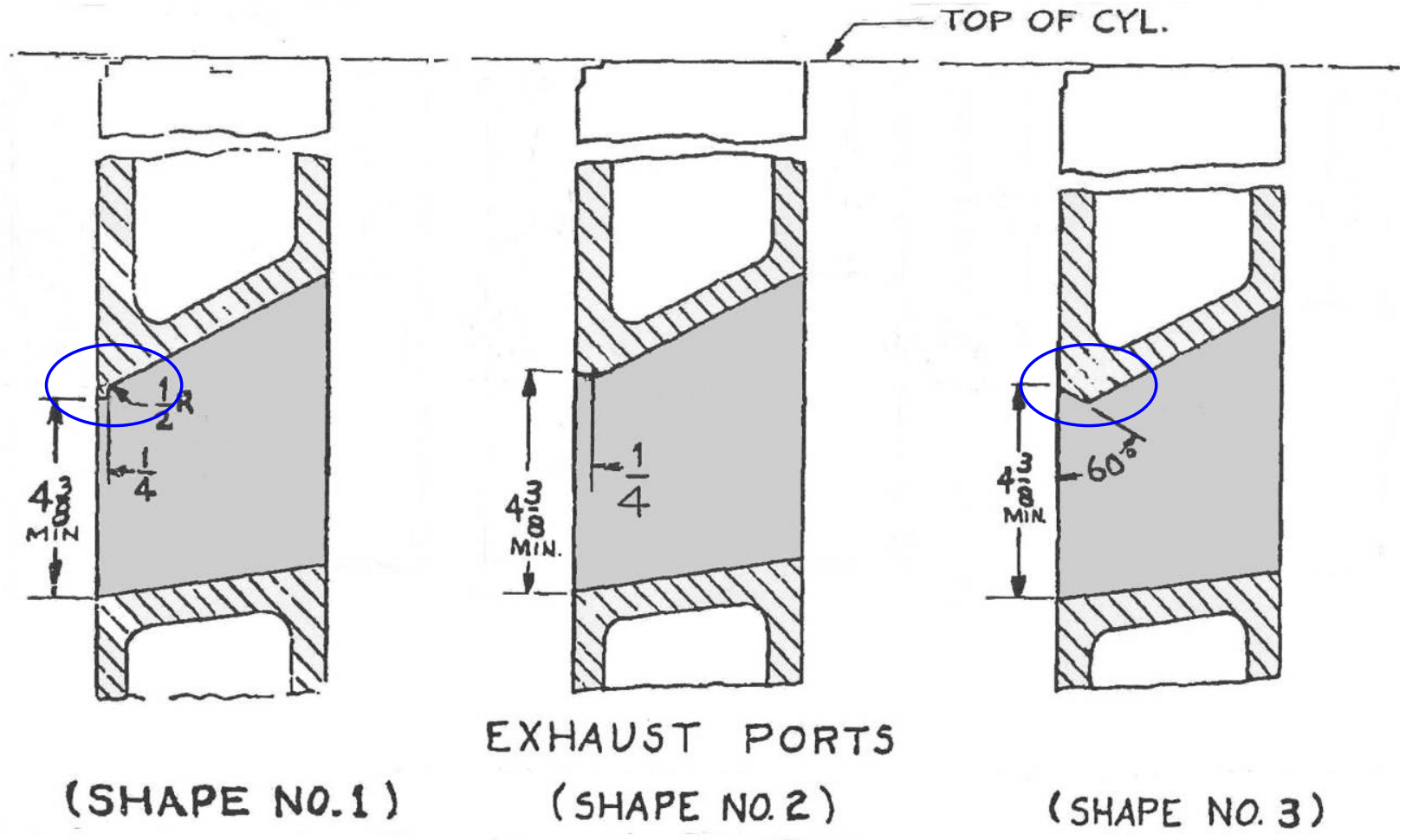

Figure 5-19. Exhaust Port Shapes

\subsubsection{CyLinder INLET AirboX}

The cylinder inlet volume ('airbox' within each cylinder casting) is another critical parameter for accurate simulation of the fluid dynamics in the engine. The cylinder inlet airbox is the volume between the intake manifold flange, base air chest ports, and inlet ports to the combustion chamber. Drawings provided by Cooper were of a 1950's vintage and hand drawn. The true geometry of the cylinder inlet air plenum was difficult to distinguish by the dotted lines and a few cross-sectional views. Therefore, initial estimates of the inlet volume were incorrect due to misinterpretation of the drawing. Once apart, the cylinder inlet volume was physically measured by filling the airbox with metered water. This required sealing the ports (at the cylinder wall) and base openings. The inlet port runners were therefore included in these volume measurements. A difference was measured between the two different casting number cylinders installed on this engine, with cylinder $1 \mathrm{R}$ having approximately 4.3 percent smaller volume. The results of measurements on the three removed cylinders are shown in Figure 5-20. 


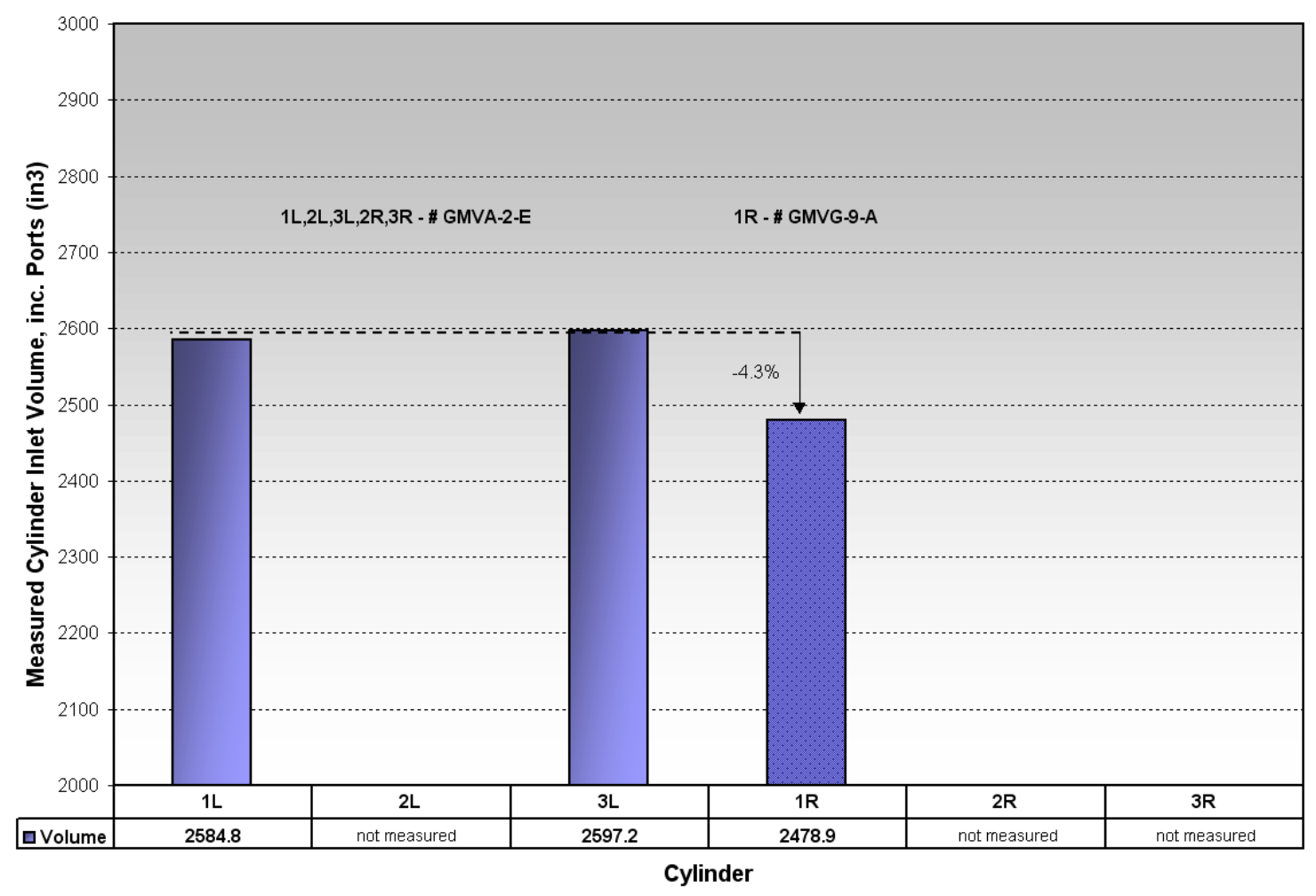

Figure 5-20. Cylinder Inlet Volume Measurements

\subsubsection{INLET AND EXHAUST SYSTEM}

In addition to deriving the base air chest and cylinder airbox volumes, measurements were made on both the intake and the exhaust manifolds with the engine disassembled to capture the internal geometry in detail for an improved model. It was felt critical that every junction and transition be represented in the model for accurate simulation. Several images to help illustrate the complex geometries of the inlet and exhaust systems are provided in Figures 5-21 through 5.24. The first image, Figure 5-21, is the cross section schematic of the GMVH with the inlet air paths colored in blue and the exhaust paths colored in red. Photographs of the external geometry of the inlet air system are shown in Figure 5-22. Photographs of the external geometry of the exhaust system are shown in Figure 5-23. Internal geometry of the exhaust system (one section) is shown in photographs in Figure 5-24. 


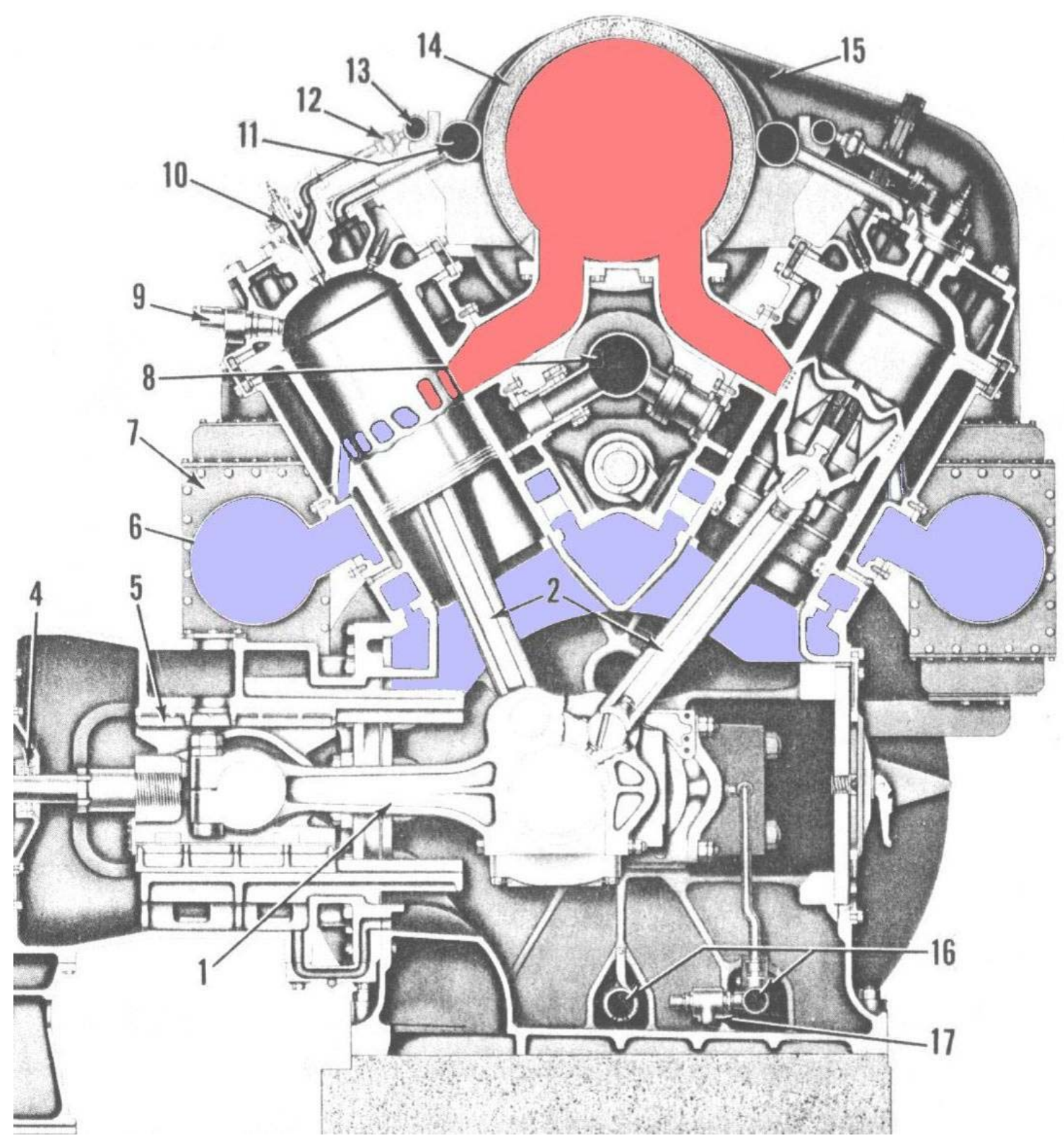

Figure 5-21. GMVH Cross Section with Inlet (blue) and Exhaust (red) Highlights 

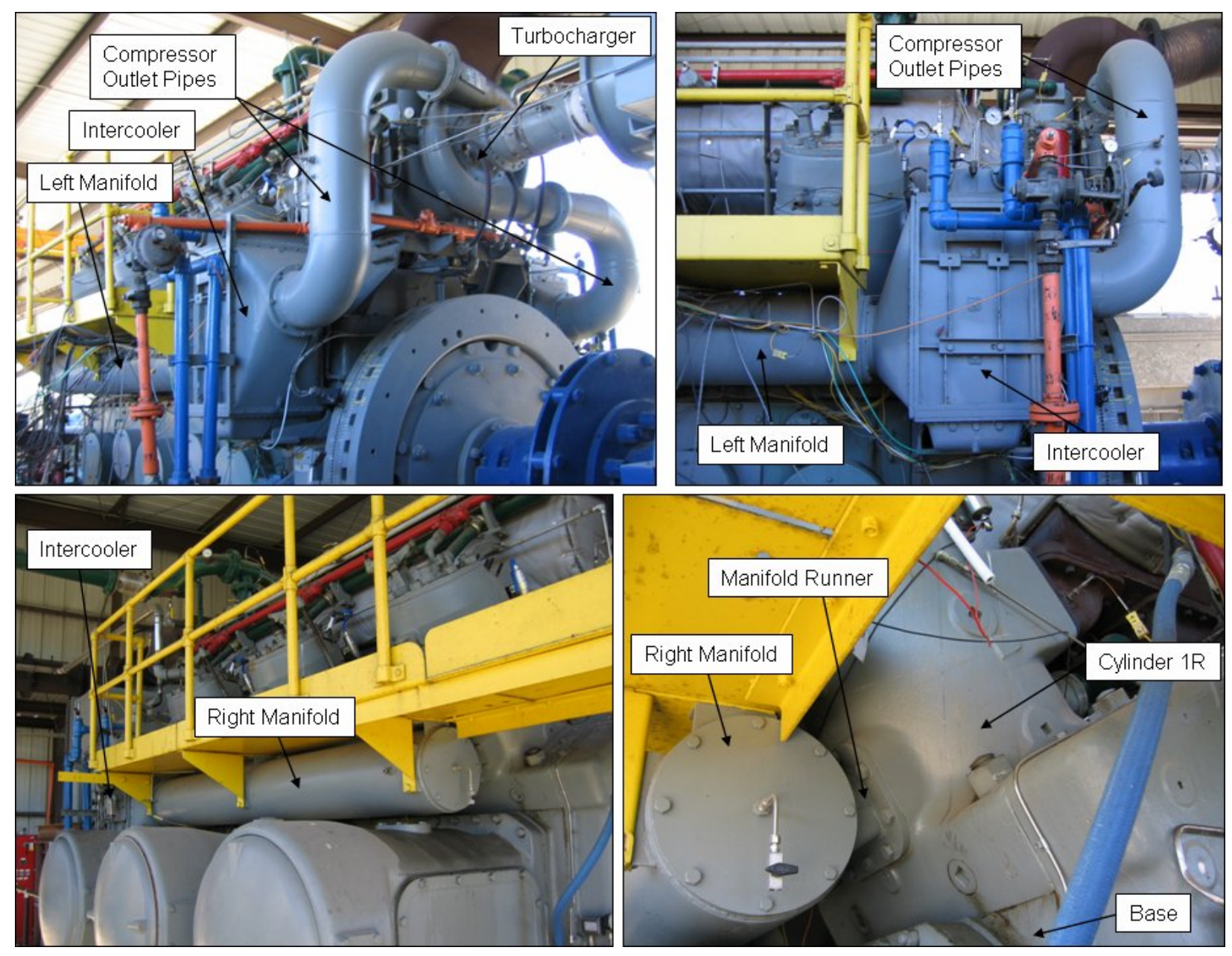

Figure 5-22. Photographs of External Inlet Air System
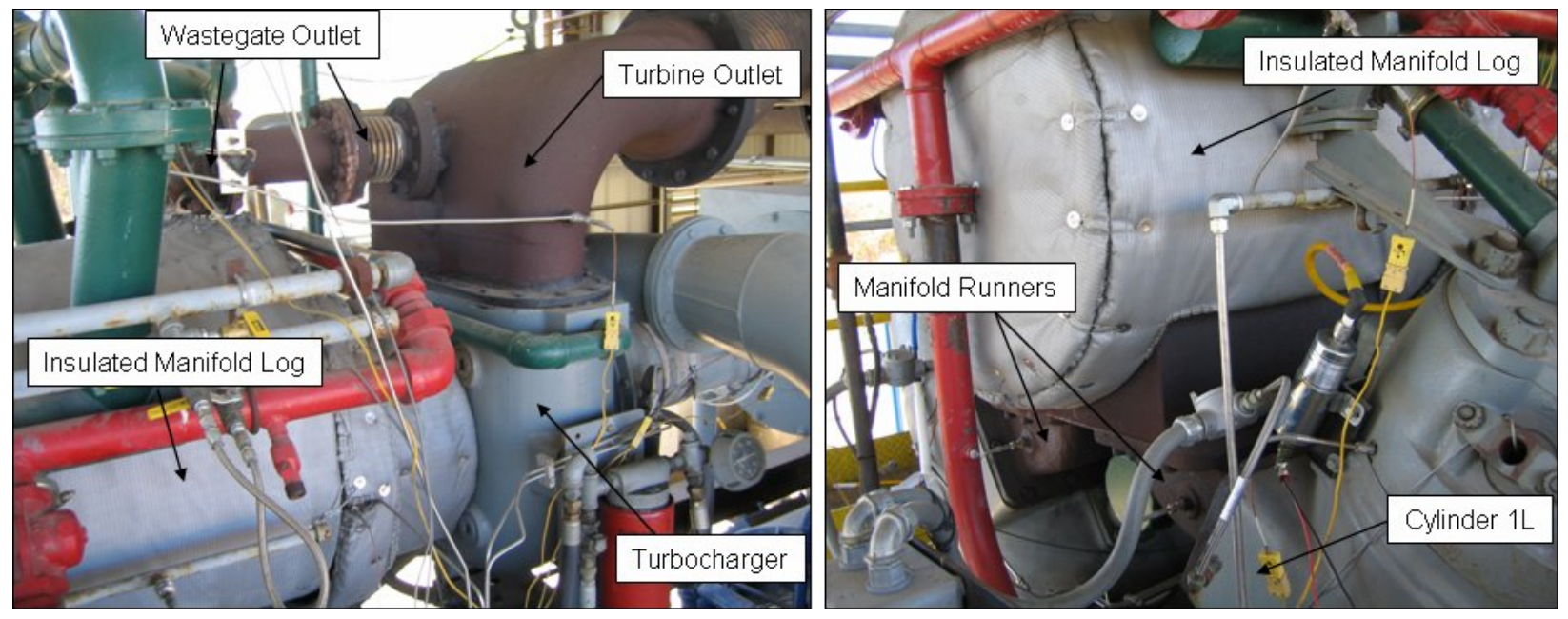

Figure 5-23. Photographs of External Exhaust System 

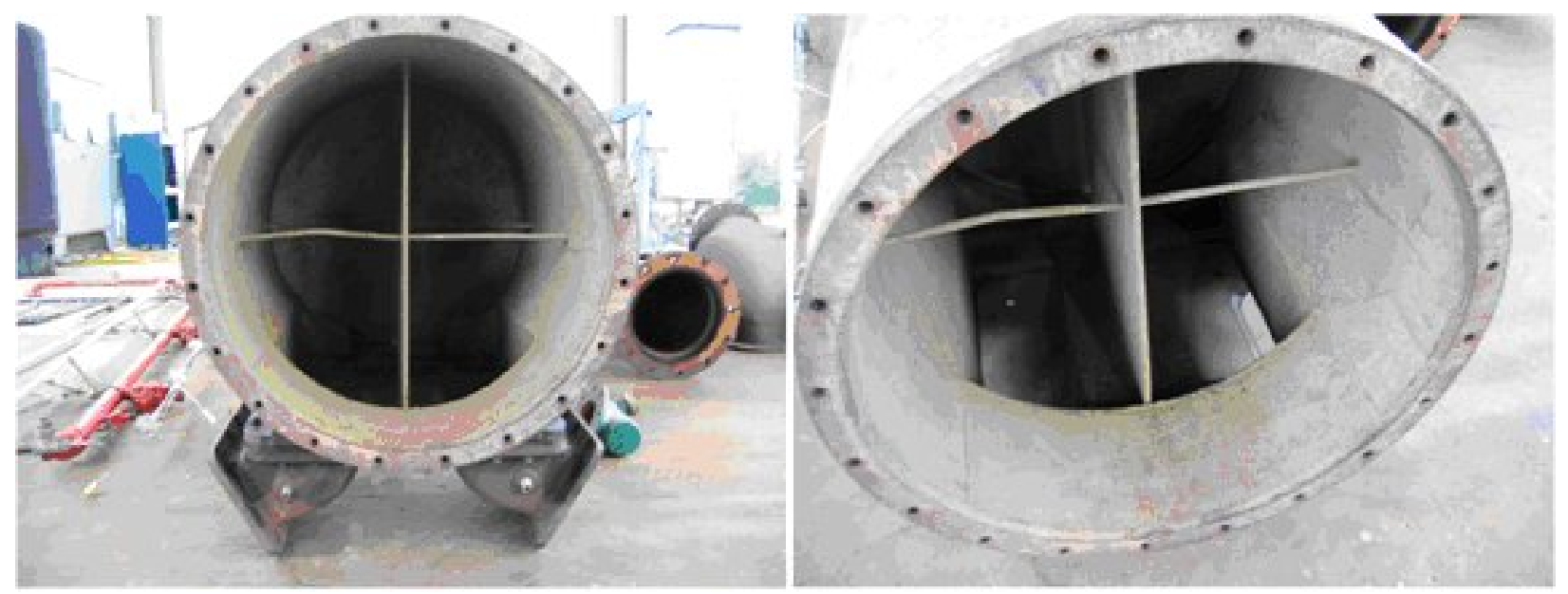

Figure 5-24. Photographs of Internal Geometry of Exhaust Manifold

\subsubsection{Piston StRoke}

One of the first measurements to be taken on all cylinders was the piston stroke as a function of crank angle degree to determine if there were any variations in crankshaft throws. The piston travel profile resulting from the articulation is slightly different between the left and right banks, as discussed previously. Measurements of each piston stroke are shown with the calculated motion in Figures 5-25 and 5-26 for left and right banks, respectively. The measurements were made by barring the engine, so only the up-stroke and crossover of TDC and BDC was measured. Measurements of the down-stroke were not taken as they would be skewed by any slack in the bearings due to pulling the piston down against ring friction. As can be seen in Figures 5-25 and 5-26, negligible variations were observed between cylinders, and the results tracked the calculated motion very well. The left bank variation in TDC to BDC stroke was only 0.019" out of a mean stroke of 14.737" and right bank variation was only 0.011" out of a mean stroke of 14.660". Furthermore, the mean stroke values for left and right banks were within 0.004" from the kinematic model calculations. Individual measured and drawing mean piston stroke values are provided on Figure 5-27 for comparison. 


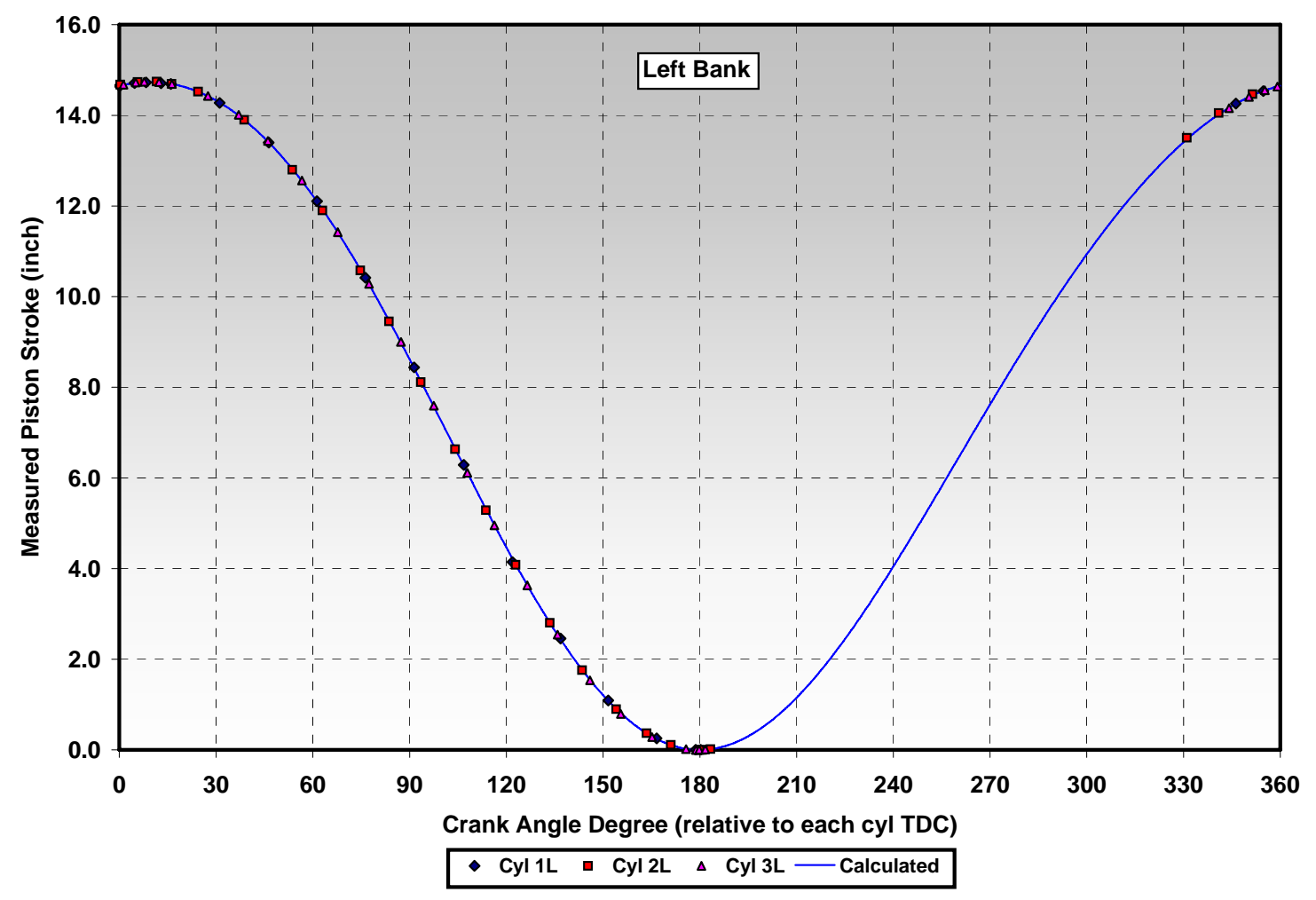

Figure 5-25. Measured Left Bank Piston Motions versus Calculated Motion

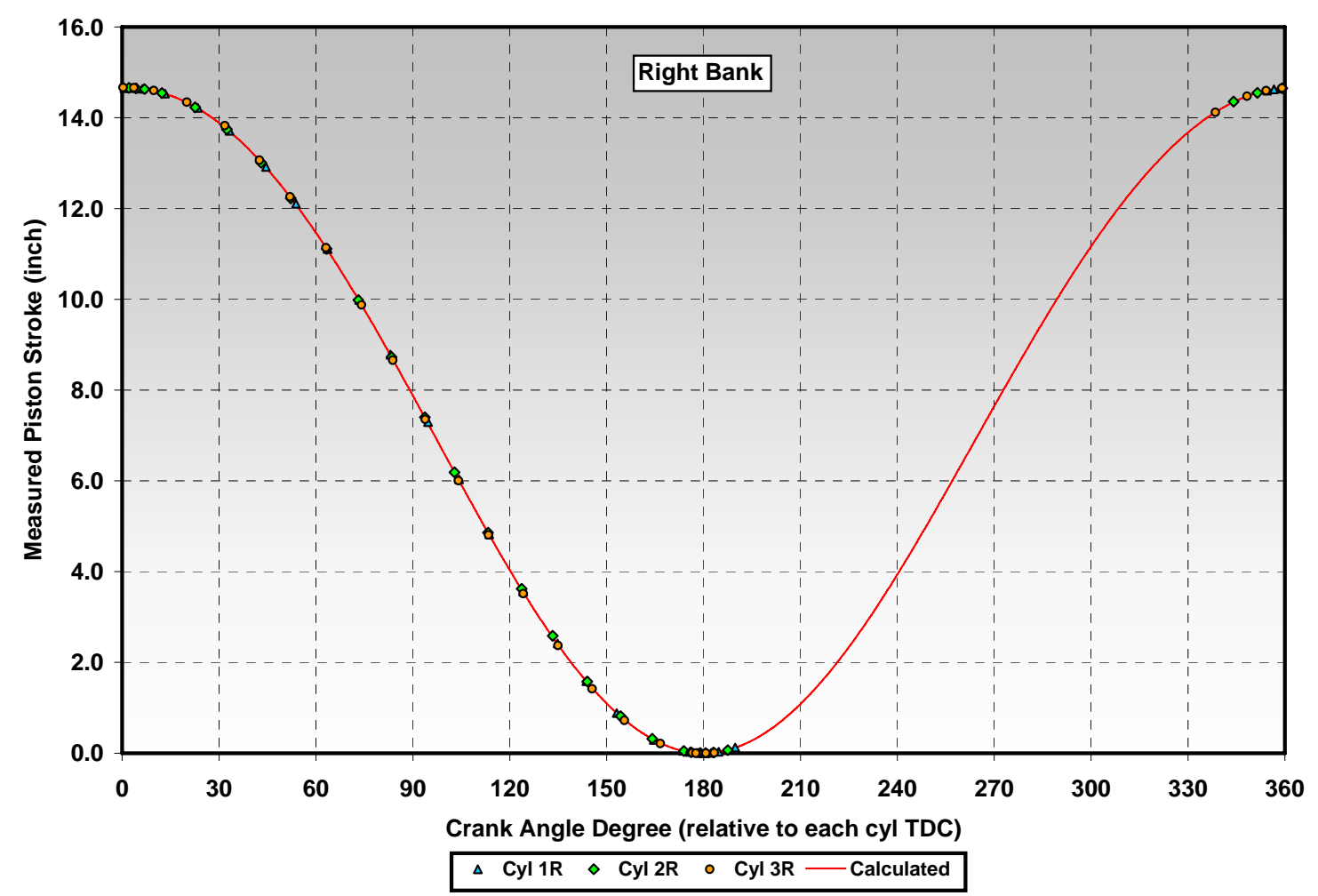

Figure 5-26. Measured Right Bank Piston Motions versus Calculated Motion 


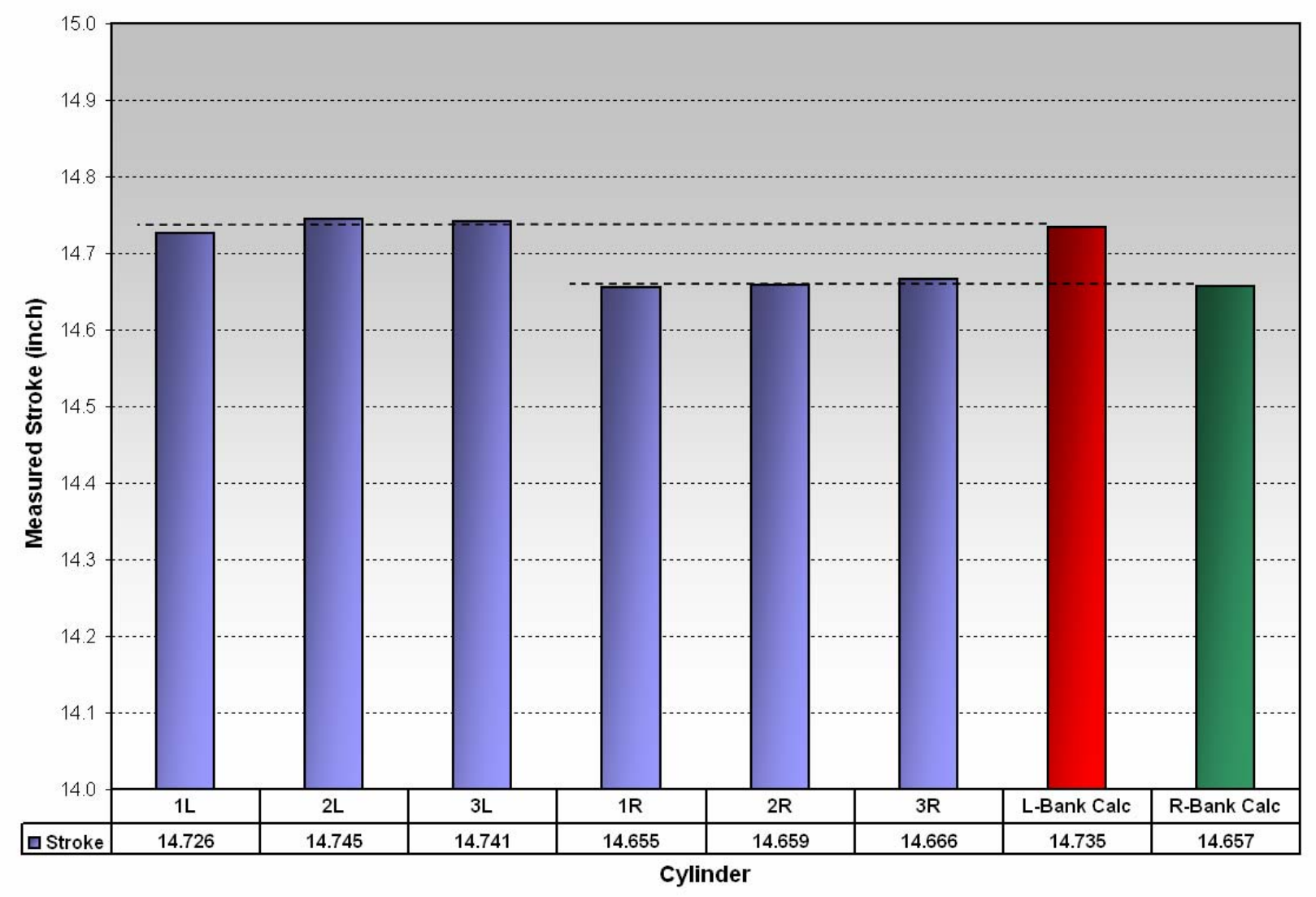

Figure 5-27. Measured Piston Stroke per Cylinder Compared to Drawing Mean Values

\subsubsection{COMPRESSION RATIO}

Once the stroke was measured, several measurements on each cylinder were combined to calculate the compression ratio. Each cylinder bore was measured, and found to be consistent between cylinders within \pm 0.003 inch. Each cylinder head was measured for the combustion chamber volume, in which the values ranged $\pm 3.7 \mathrm{in}^{3}$ or within 1 percent. Each piston crown was also measured to calculate the volume displaced in the combustion chamber at TDC. Resulting calculations of TDC clearance volumes showed a maximum variation between cylinders of 3.4 percent. The exhaust port heights were then measured to determine the effective strokes and resulting effective compression ratios. The effective stroke was determined by the measuring the piston travel from TDC to the point where the piston edge crossed the top of the highest exhaust port. There was some discussion that the effective stroke should be calculated using the point where the top ring passes the highest exhaust port. However, later flow testing of the cylinders showed minimal flow during the travel from top ring to piston edge crossing. Figure 5-28 shows the measured exhaust port heights (top of port to top of cylinder) and Figure 5-29 shows the effective compression ratio for each cylinder. As can be seen in Figure 5-28, cylinder 3L had two of the five ports significantly lower than the mean and cylinder $2 \mathrm{R}$ had one. It should be noted that a smaller value represents a shorter distance from the top of the cylinder resulting in earlier openings and later closings. Figure 5-29 shows the effective compression ratio for each cylinder, as well as the calculated TDC clearances. These calculated effective compression ratio values indicate a spread of 0.3 points out of a mean of 7.7:1. Note that cylinder $2 \mathrm{R}$ has the lowest effective compression ratio, cylinder $3 \mathrm{~L}$ the next lowest, and cylinder 
$1 \mathrm{~L}$ the highest. The spread of 0.3 points in effective compression ratio was initially thought to be reasonably low, since a spread of $>0.8$ points was calculated to be required to match the measured spread in compression pressures (assuming compression ratio alone caused the spread.) The disconcerting result of this analysis was that cylinder $2 \mathrm{R}$ has consistently yielded the highest compression pressure but has the lowest effective compression ratio. However, the low effective compression ratio for 3L does trend with it having a low compression pressure.

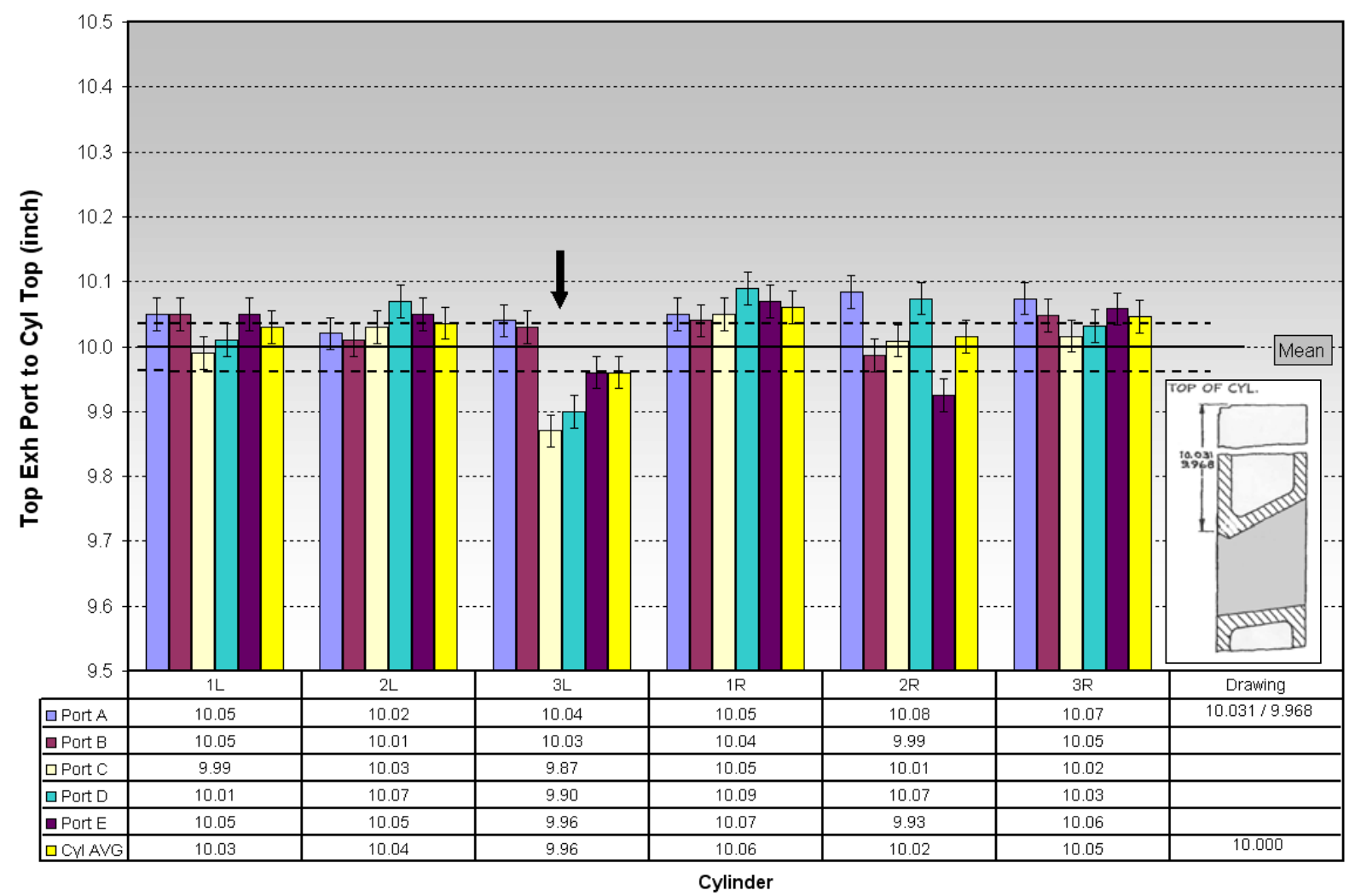

Figure 5-28. Measured Distances from Cylinder Top to Exhaust Port Top 


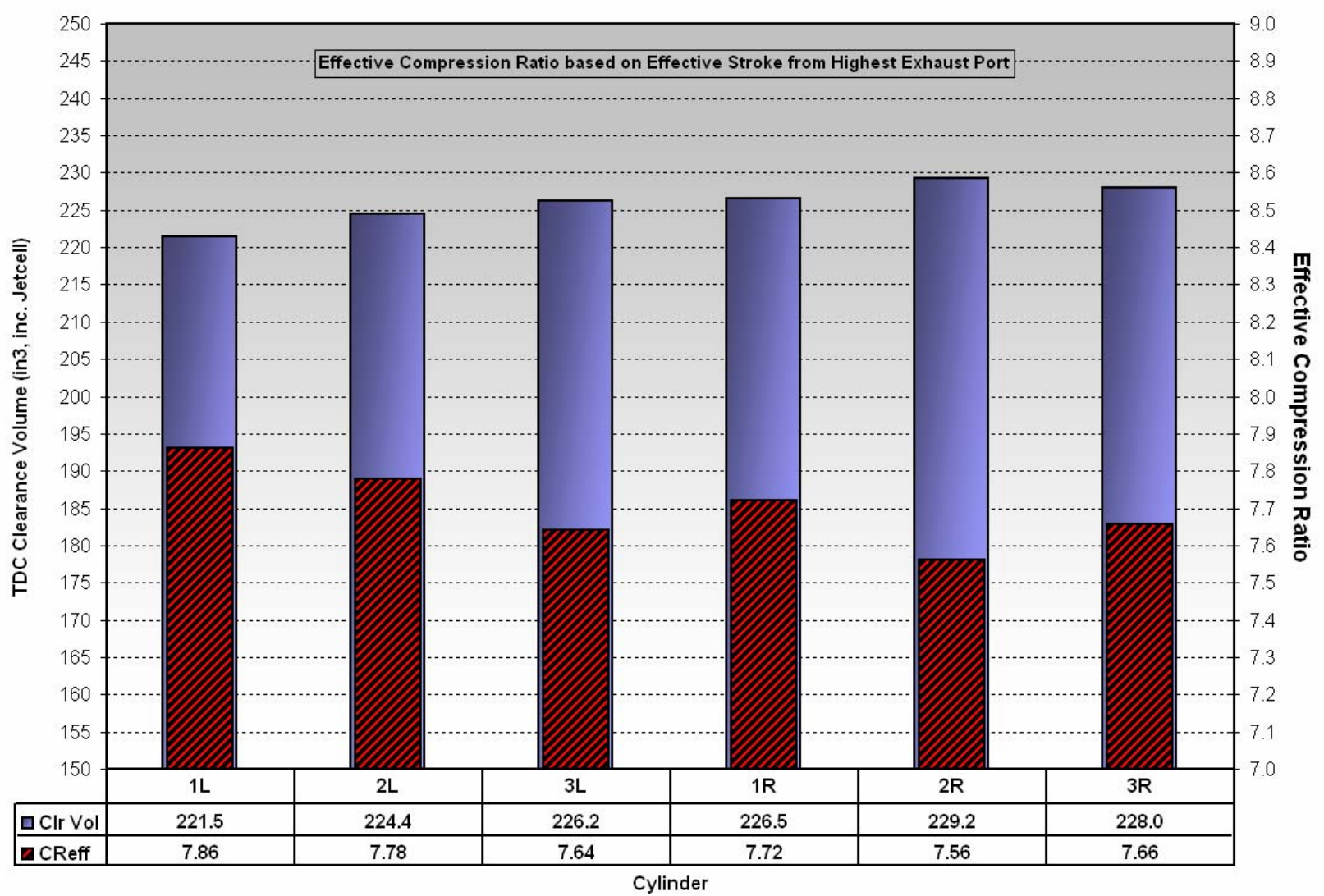

Figure 5-29. Calculated TDC Clearance Volumes and Effective Compression Ratios for Each Cylinder

\subsubsection{PORT GeOMETRY}

The next factor to be investigated was port flow geometry. The geometric parameters involved with port flow include the port timings, port area, and port shape. The exhaust port opening and closing timings (based on top edge distance to cylinder top and piston edge crossing) are shown in Figures 5-30 and 5-31, respectively. The effect on exhaust timings due to the two out-of-specification ports on cylinders $3 \mathrm{~L}$ and $2 \mathrm{R}$ can be seen in these figures. The bank-to-bank differences are due to the non-symmetrical piston motions from articulation (see Figure 5-4). Earlier exhaust opening and later closing not only lowers the effective compression ratio but also affects air flow by allowing earlier blowdown and later trapping of cylinder mass.

The exhaust port areas were calculated from the height, width, and corner radius measurements. The measured areas include the 'open' areas at the cylinder wall surface facing the combustion chamber. The five cylinders that had the same casting number were very consistent in exhaust port open area. Cylinder $1 \mathrm{R}$, which had the different casting number, had significantly smaller exhaust port open areas which were approximately 8 percent less than the other cylinder's exhaust ports. Calculated values of exhaust port open area for each cylinder and each port are shown in Figure 5-32. 


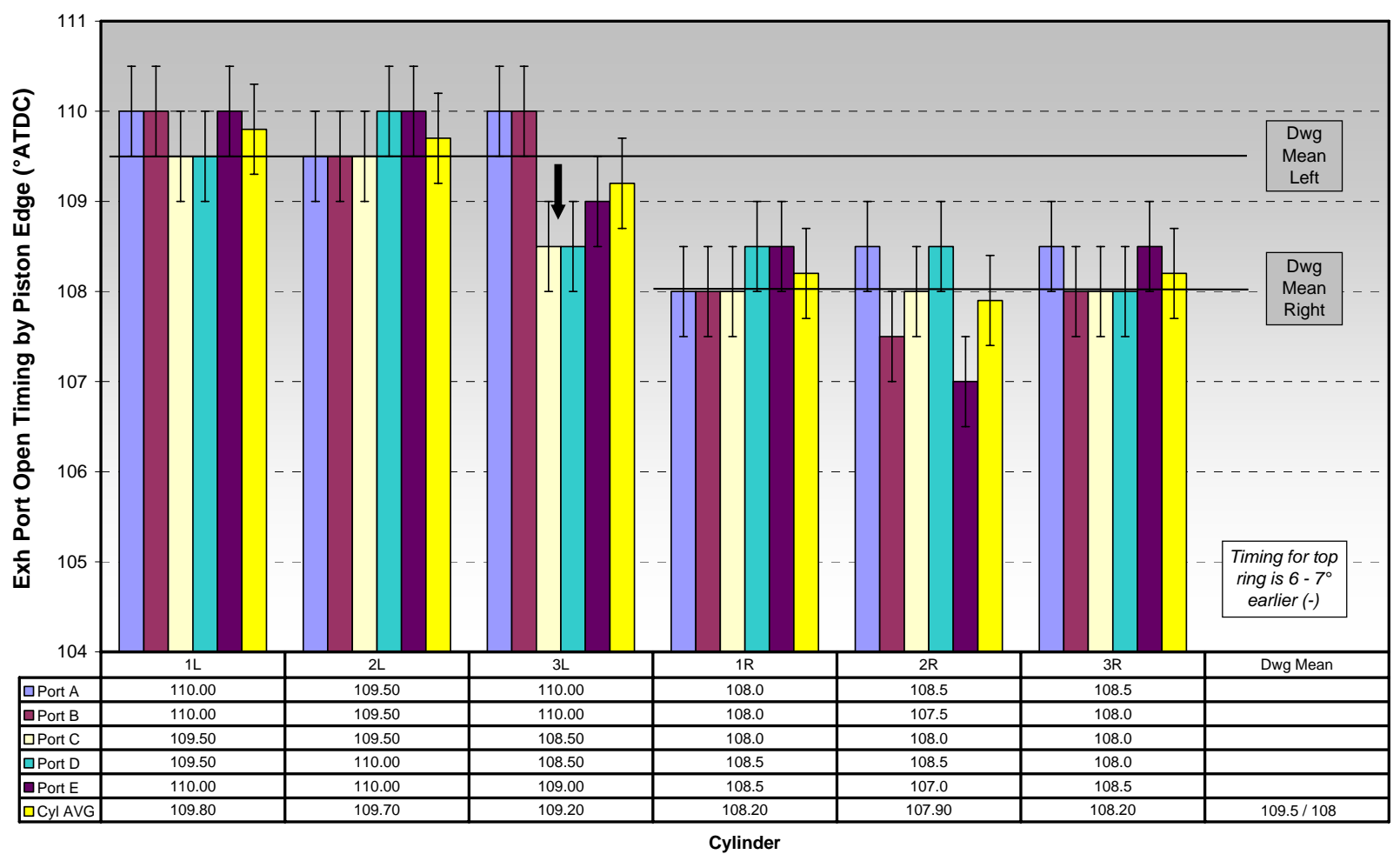

Figure 5-30. Calculated Exhaust Port Opening Timings for Each Cylinder

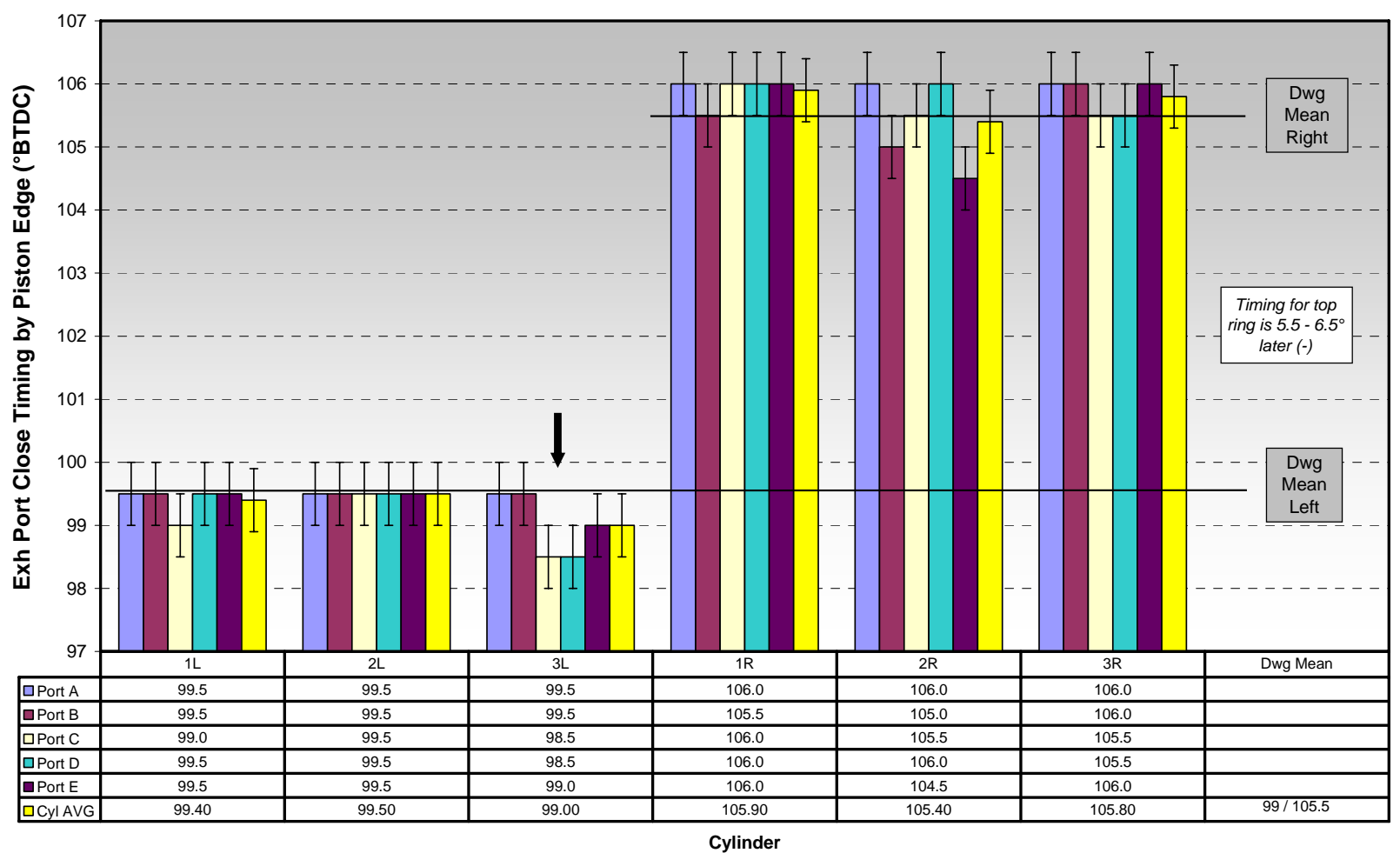

Figure 5-31. Calculated Exhaust Port Closing Timings for Each Cylinder 


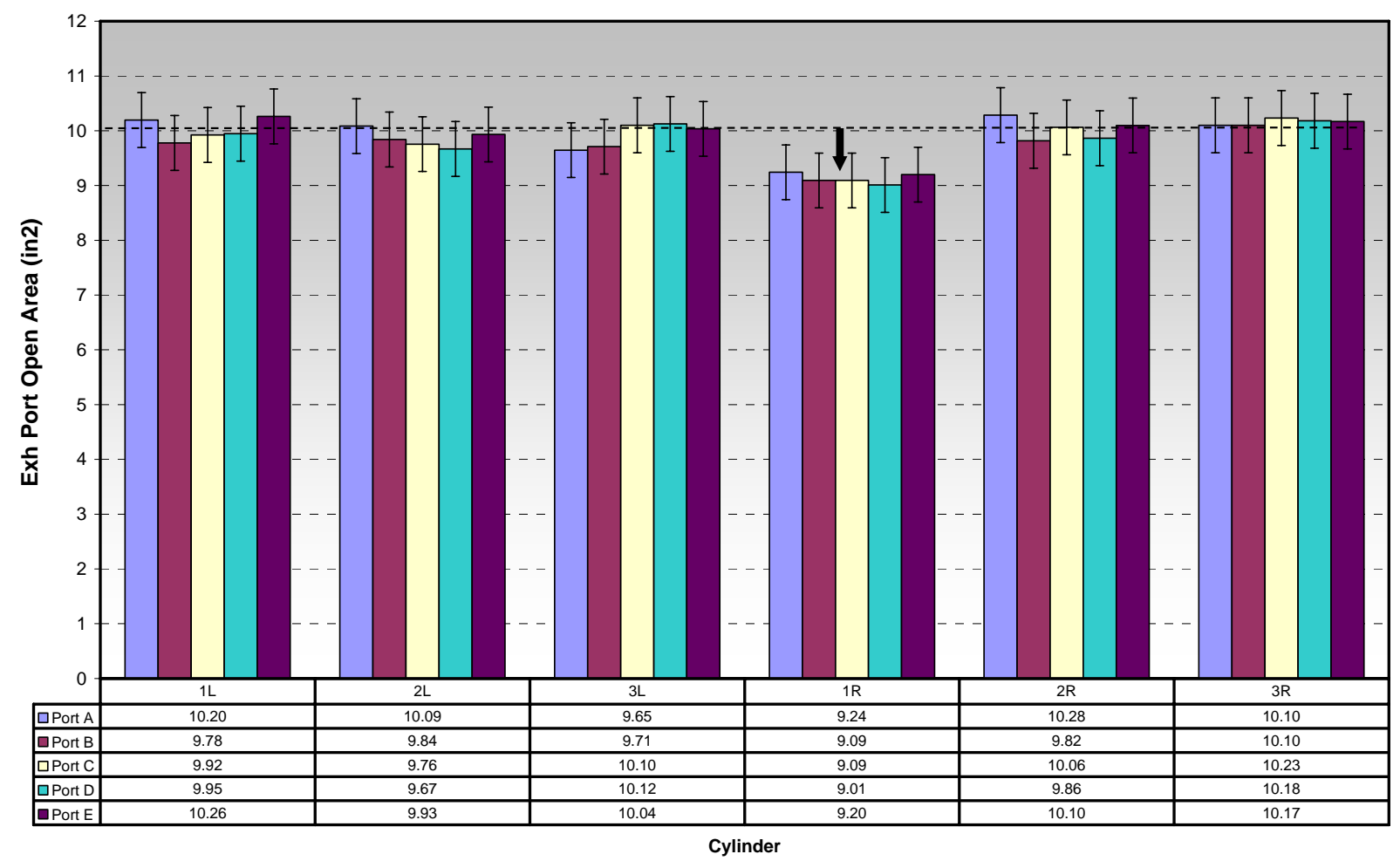

Figure 5-32. Calculated Exhaust Port Areas for Each Cylinder

Intake port opening and closing timings are shown in Figures 5-33 and 5-34, respectively. In these figures, the timings for cylinder $1 \mathrm{R}$ are shown to deviate from the other cylinders, which is due to the top port edges being on the low side (later opening and later closing). The bank-tobank differences are due to the non-symmetrical piston motions from articulation (see Figure 5-5). The calculated intake port open areas are shown in Figure 5-35. The difference in area between ports on a given cylinder is due to pairs of the 8 ports having different skew angles as shown in Figure 5-36. Comparing the data in Figure 5-35, cylinder 1R is again shown to differ from the other cylinder's values. Thus, the different casting cylinder originally installed on $1 \mathrm{R}$ has differences in both the exhaust and intake ports. The five cylinders with the same casting number were consistent in terms of the intake port dimensions acquired. The intake ports enter the cylinder from the airbox at an angle of nominally 30 degrees from vertical, as shown in Figure 5-36. The actual angles for each intake port were also measured, and cylinder $3 \mathrm{~L}$ had an average angle variance of 3.8 percent lower than the nominal value. 


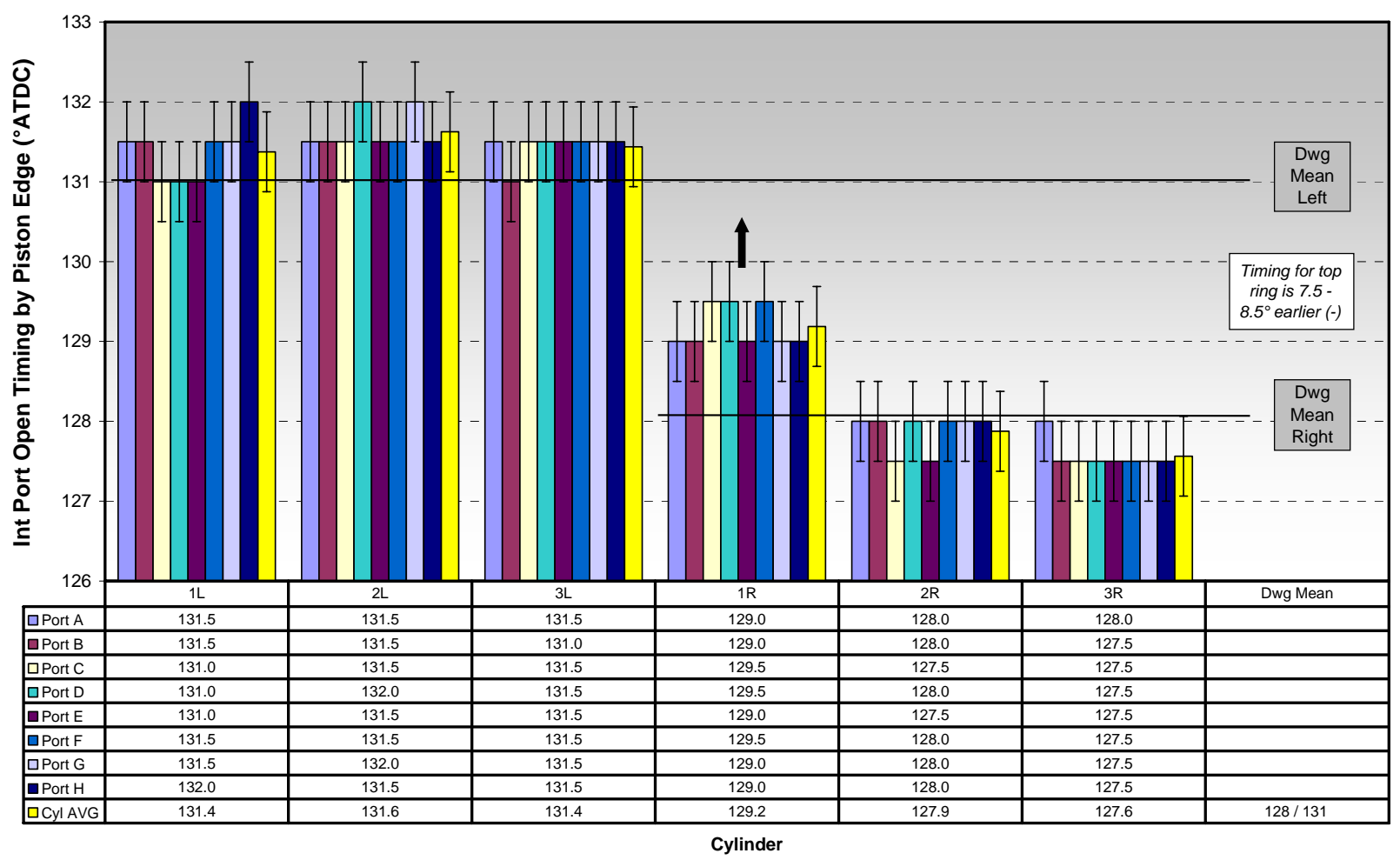

Figure 5-33. Calculated Intake Port Open Timings for Each Cylinder

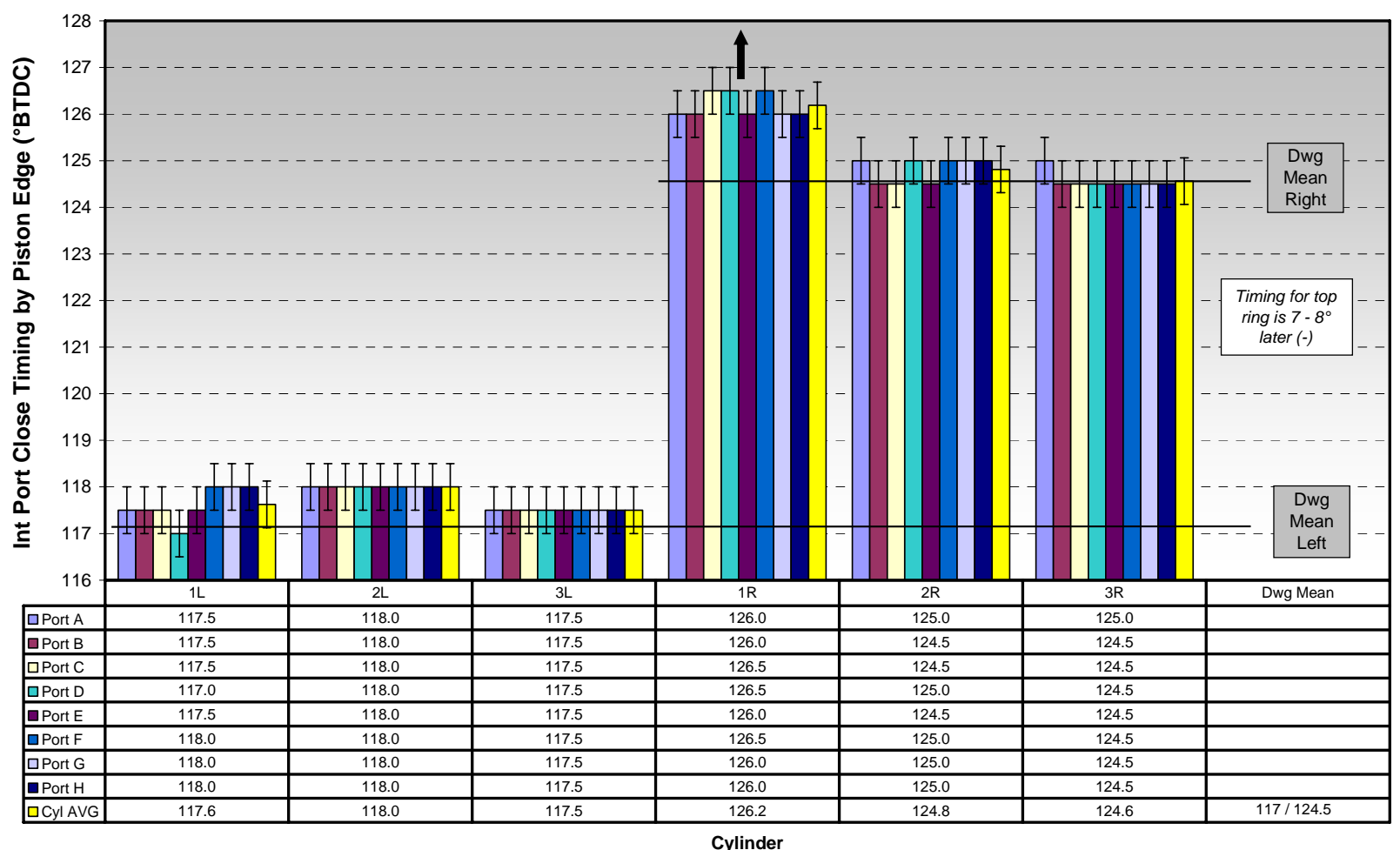

Figure 5-34. Calculated Intake Port Closing Timings for Each Cylinder 


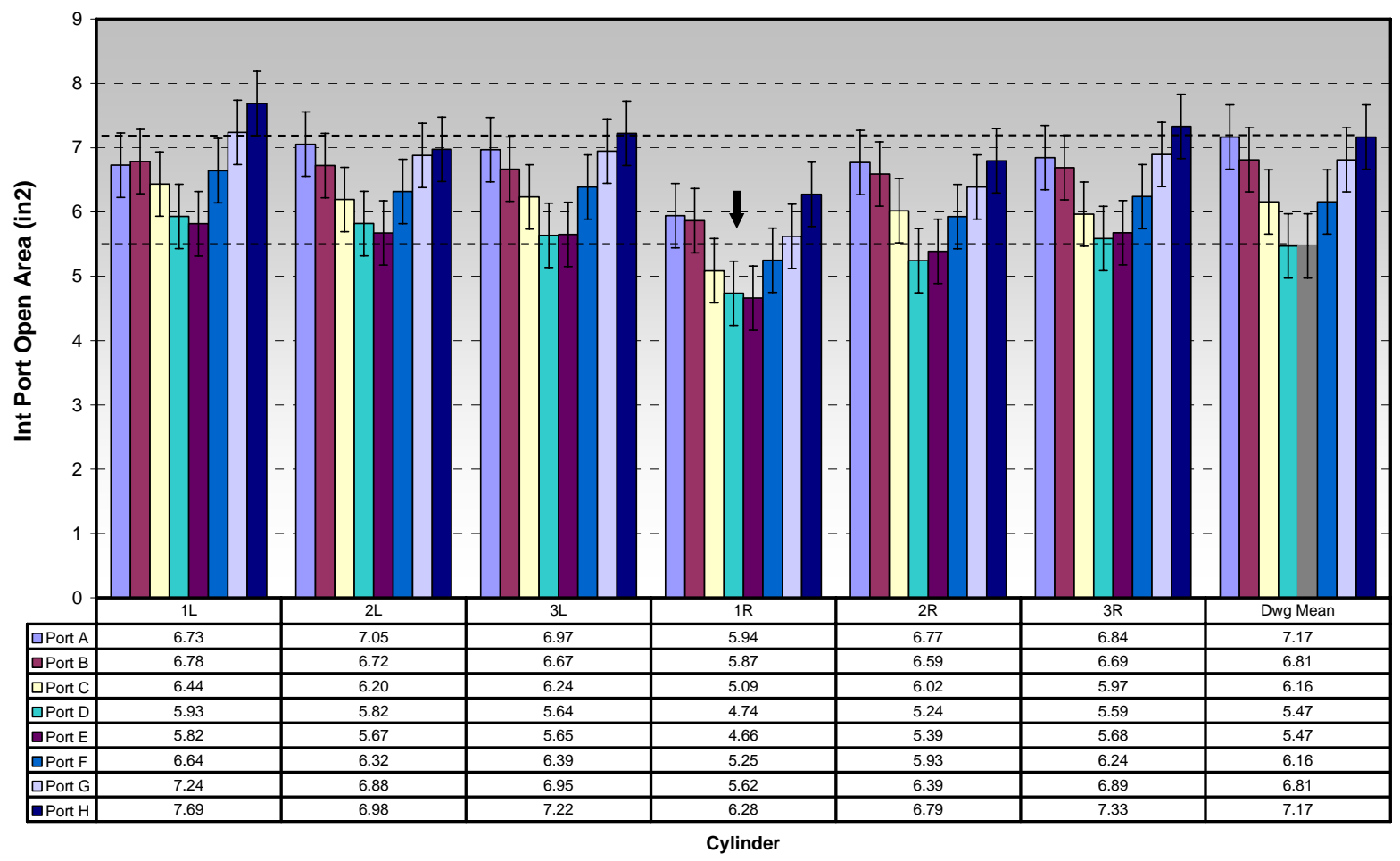

Figure 5-35. Calculated Intake Port Areas for Each Cylinder

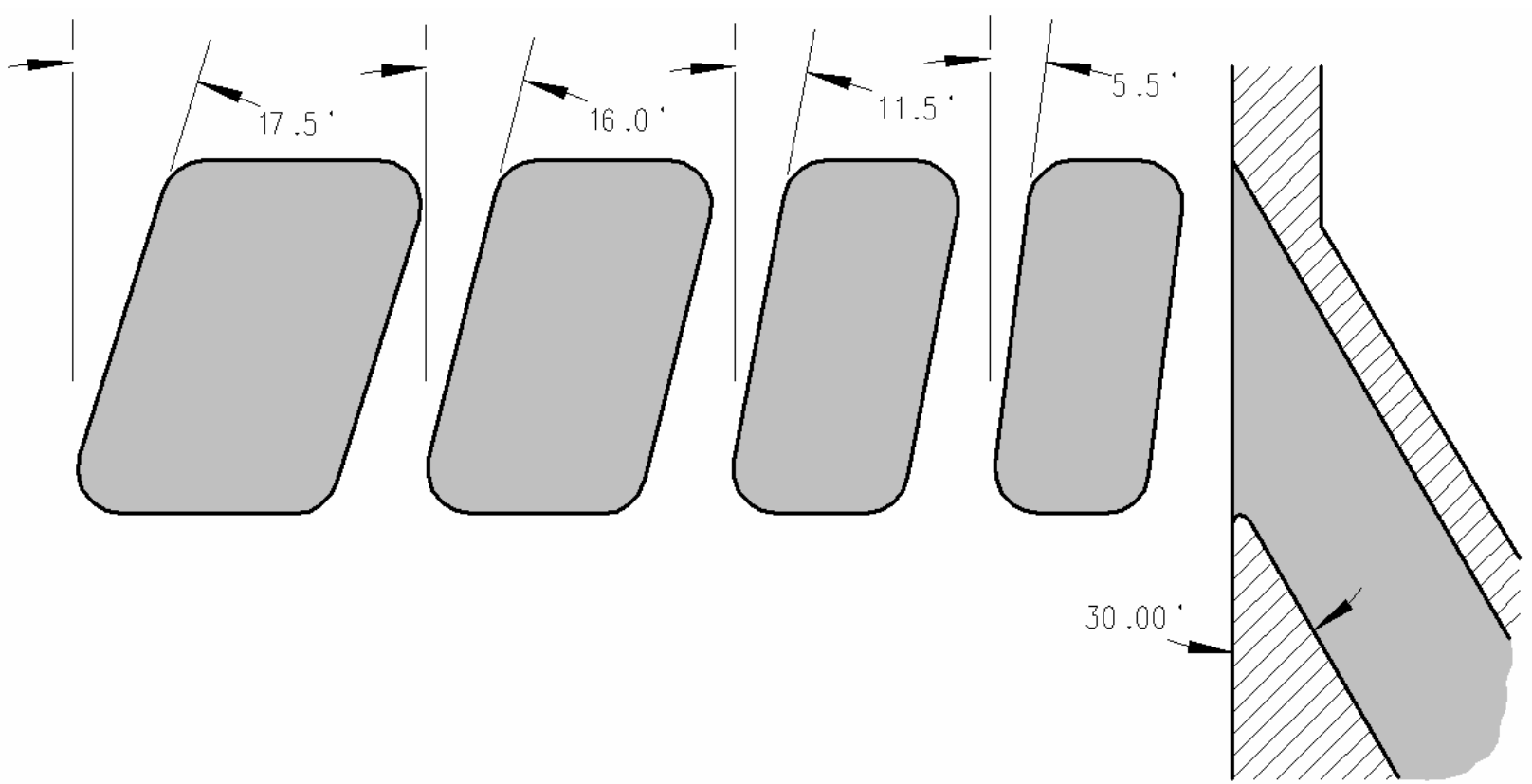

Figure 5-36. Schematic of Intake Port Geometry

\subsubsection{Fuel Valve Travel}

The last significant geometric measurement made was the fuel valve travel. This was done because several questions arose during early engine testing regarding the actual fuel valve 
timing and duration, as well as possible variations in the fuel admission. Fuel valve travel was measured as a function of crankshaft angle degree. Results of the measurements on each cylinder's fuel valve are shown in Figure 5-37. The data show very consistent fuel valve lift profiles, with only a slight reduction in duration for cylinders 3L and 3R (same cam lobe) of one degree. These measurements were made after re-assembly of the engine.

GMVH-6 Fuel Valve Travel

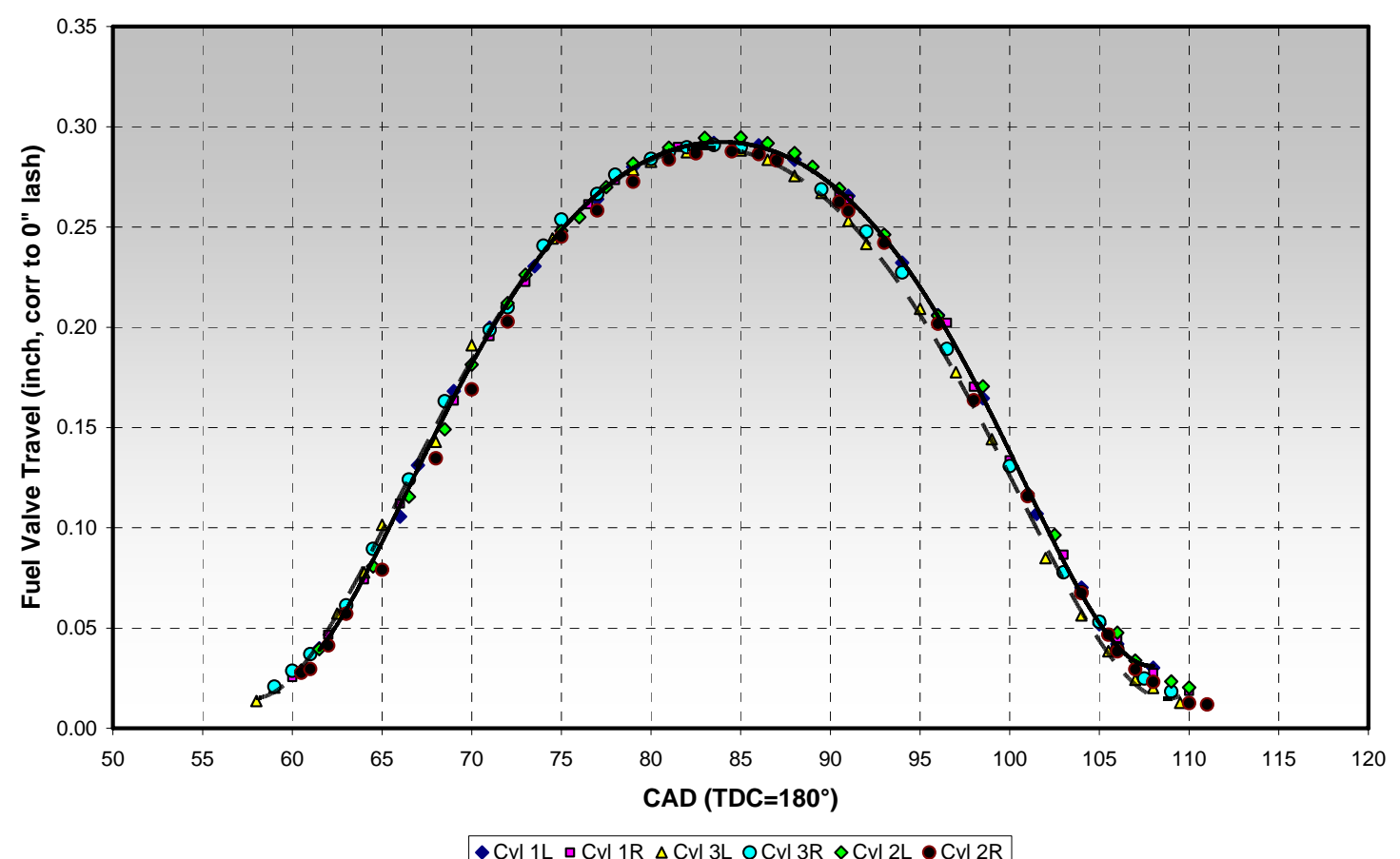

Figure 5-37. Measured Fuel Valve Travel

\subsection{PORT FLOW TESTING}

Flow testing was desired to obtain accurate discharge coefficient data for modeling and secondly to determine the variation between cylinders due to geometry of the ports. Cylinders $1 \mathrm{~L}$ and 3L, representing a high and low compression pressure on a given bank, were removed from the base and flow tested. Cylinder $1 \mathrm{R}$ had a different exhaust port shape, as discussed above, and was removed to be flow tested as well. The testing involved flows of both the inlet and exhaust ports at various piston heights and pressures. The compressed air supply was limited in capacity, so only half of the area ratio range was achieved in most tests. Data was acquired from the various sensors at a rate of $5 \mathrm{~Hz}$ to allow a significant number of samples to be acquired in a short period of time. The dynamic measurements were reviewed at each test point to ensure stable operation. The data were averaged and the total airflow and discharge coefficient was calculated for each condition.

Several measurements on each set of ports (intake or exhaust) for each cylinder were taken at different pressure ratios and port openings. The test stand allowed for setting piston height to set a prescribed opening area and adjustments to the compressed air outlet regulator and control valve allowed for prescribed pressure ratios. The two different size flow nozzles were used for high and low flows, and installed in the meter run to measure the airflow. Two nozzle 
sizes were needed to either keep from choking across the nozzle or keep the delta-pressure in a good measurable range over the flow range tested. Since the air supply was from a compressed air storage facility, the time for conducting this testing was longer than planned due to time required to recharge the tanks between runs. The air flow capacity of the system was also insufficient for normal testing at the larger port openings, although a few quick measurements at the lowest pressure ratio were acquired at full opening to ensure the extrapolation at other pressure ratios was accurate. In addition, the extensive test range at mid to low port openings gave further confidence in the extrapolations.

Cylinder $1 \mathrm{~L}$ was the first tested and extensively mapped. Cylinder 3L was only tested at select points to give necessary indication of flow and discharge coefficient variances, and to reduce total test time. Cylinder $1 \mathrm{R}$ was tested more extensively than $3 \mathrm{~L}$, due to the more significant geometric differences, although a few conditions were eliminated for time reduction. The raw (as-measured) data for cylinder 1L intake are given in Figures 5-38 and 5-39. Figure 5-38 shows the mass flow versus piston location from BDC for several pressure ratios. In this figure the flow at higher piston positions is very low because the piston edge is above the port but the top ring is below, and flow is through the crevice area. As the piston edge uncovers the ports, the flow then increases linearly with reducing piston location or increasing port opening by the piston edge. The increasing flow with pressure ratio is clearly present. Figure 5-39 shows the mass flow versus plenum pressure, which is the pressure upstream of the ports, for several piston positions. The flow is shown in this figure to increase rapidly at first with increasing pressure (pressure ratio) and taper off as pressure increase continues.

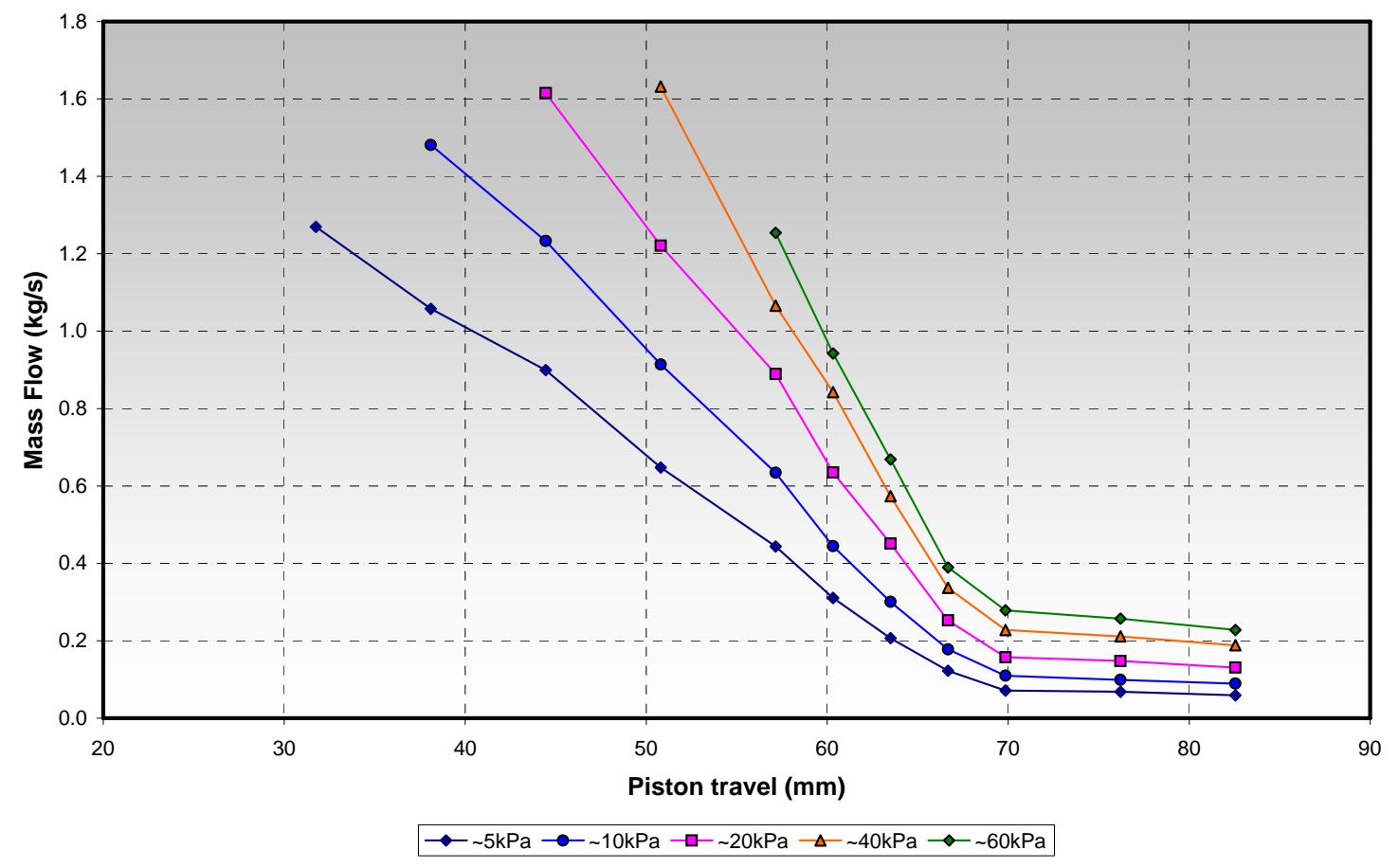

Figure 5-38. Cylinder 1L Intake - Mass Flow versus Piston Travel from BDC 


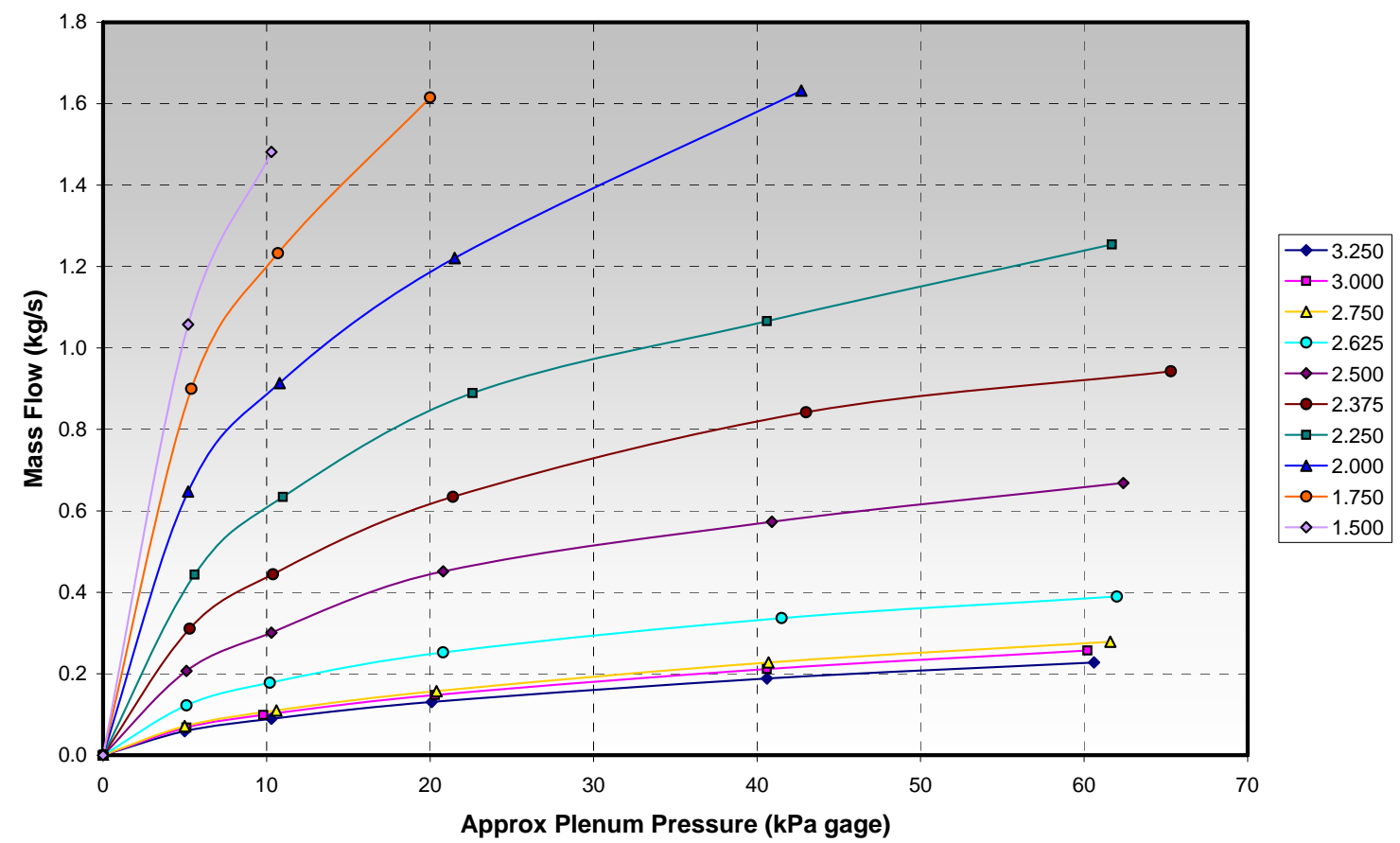

Figure 5-39. Cylinder 1L Intake - Mass Flow versus Plenum Pressure

The raw (as-measured) data for cylinder 1L exhaust are given in Figures 5-40 and 5-41. Figure 5-40 shows the mass flow versus piston location from BDC for several pressure ratios. In this figure the flow at higher piston positions is again very low because the piston edge is above the port but the top ring is below, and flow is through the crevice area. Fewer points were acquired on the exhaust with the piston edge above the port top since the trend was documented with the limited data taken at these positions. As the piston edge uncovers the ports, the flow then increases linearly with reducing piston location as similarly seen with the intake test data. Again, the increasing flow with pressure ratio is clearly present. Figure 5-41 shows the mass flow versus plenum pressure for several piston positions. The flow is shown in this figure to increase similarly as with the intake tests with increasing pressure.

The geometric analysis showed that there is some variation between ports and between cylinders. Therefore, it is important to view the measured data in terms of actual pressure and area ratios. The area ratio is based on the open area (vertical exposed area at port edge in cylinder). The pressure ratio is the ratio of pressure across the ports (upstream/downstream). A comparison of the intake mass flow versus area ratio is shown in Figure 5-42, for the three tested cylinders at a pressure ratio of 1.05. This figure shows that both cylinders 3L and $1 \mathrm{R}$ have lower mass flow versus area ratio relationships than cylinder 1L. The cylinders 1L and 3L shared similar dimensions pertaining to the inlet plenum and ports, so the cause for reduced flow for 3L is unclear at this time. Cylinder $1 \mathrm{R}$ has several differences in plenum volume and port areas (height-width relationship), which likely explains its reduced flow. 


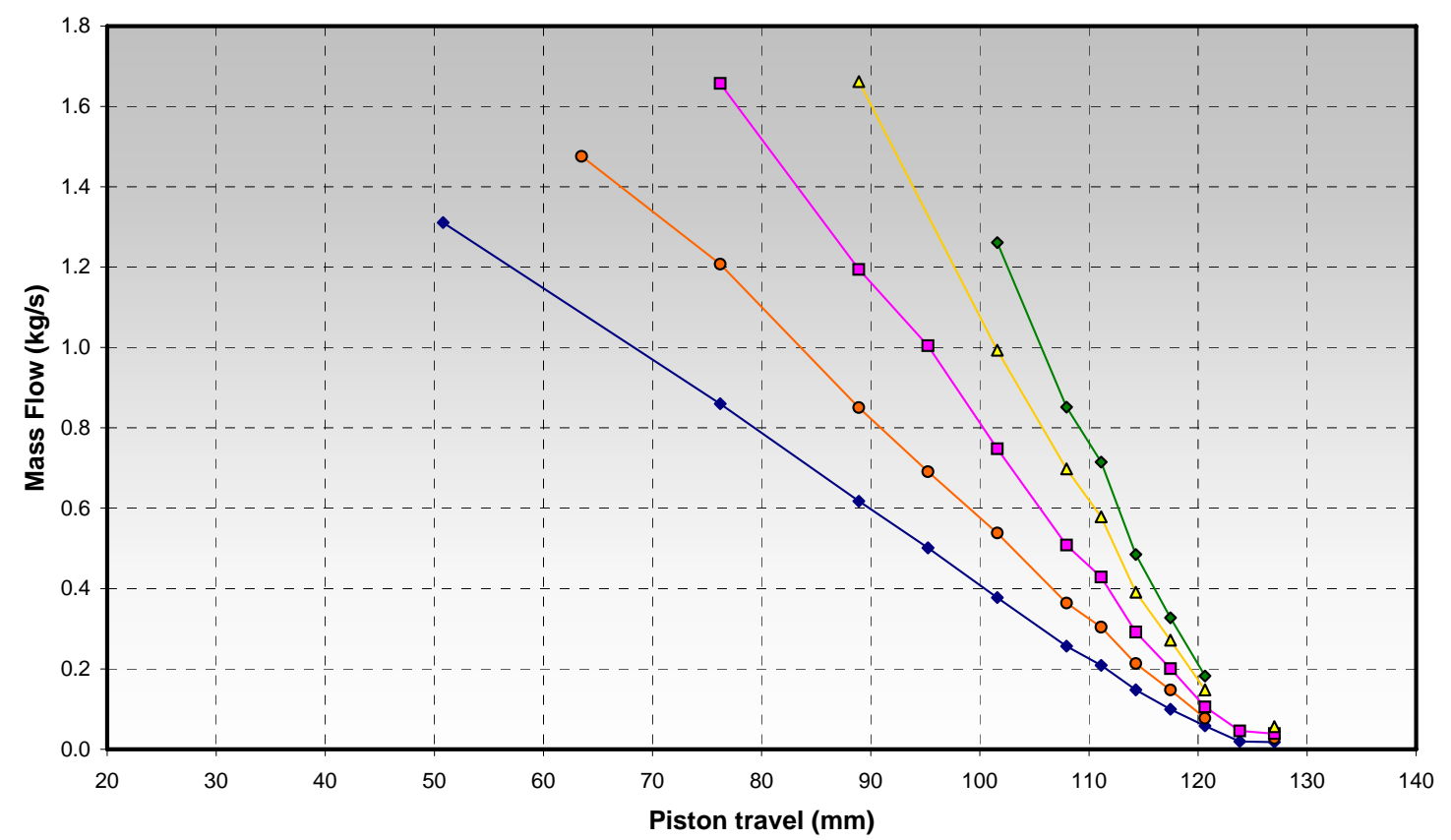

$\sim 5 \mathrm{kPa}-0-\sim 10 \mathrm{kPa} \rightarrow-\sim 20 \mathrm{kPa} \triangle \sim \sim 40 \mathrm{kPa} \multimap \sim 60 \mathrm{kPa}$

Figure 5-40. Cylinder 1L Exhaust - Mass Flow versus Piston Travel from BDC

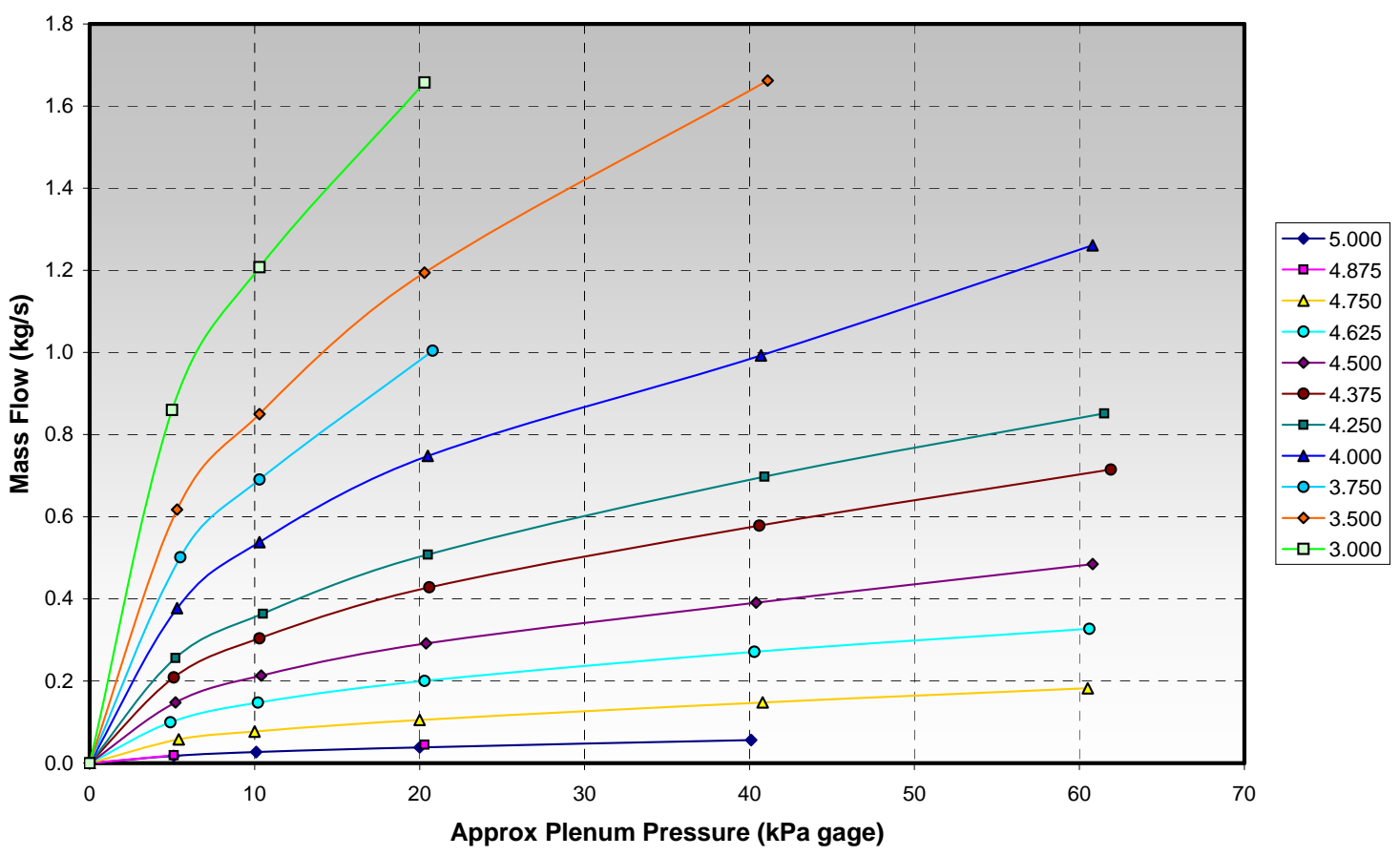

Figure 5-41. Cylinder 1L Exhaust - Mass Flow versus Plenum Pressure 


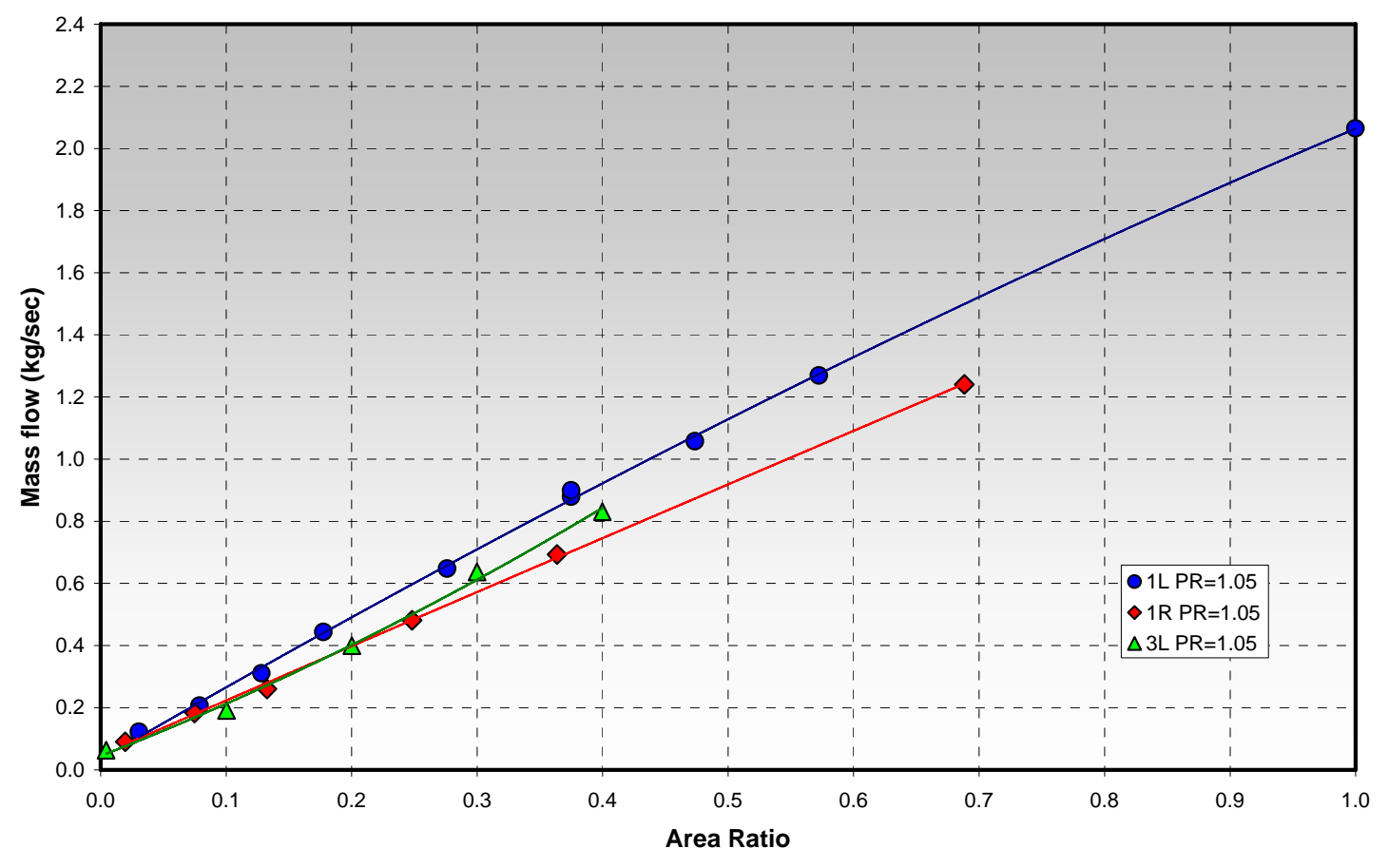

Figure 5-42. Comparison of Intake Mass Flow versus Area Ratio (Pressure Ratio=1.05)

A comparison of the exhaust mass flow versus area ratio is shown in Figure 5-43, for the three tested cylinders at a pressure ratio of 1.05. This figure shows that both cylinders $1 \mathrm{~L}$ and 3L have similar flow characteristics. Cylinder $1 \mathrm{R}$ has a lower mass flow than cylinders $1 \mathrm{~L}$ and 3L. Although cylinder $1 \mathrm{R}$ has a lower total port area, the port timings and widths were similar and should flow similarly at part openings. However, the shapes of the exhaust ports in cylinder 1R are different and is likely the reason for its reduced flow. This is more apparent in the discharge coefficient calculations. 


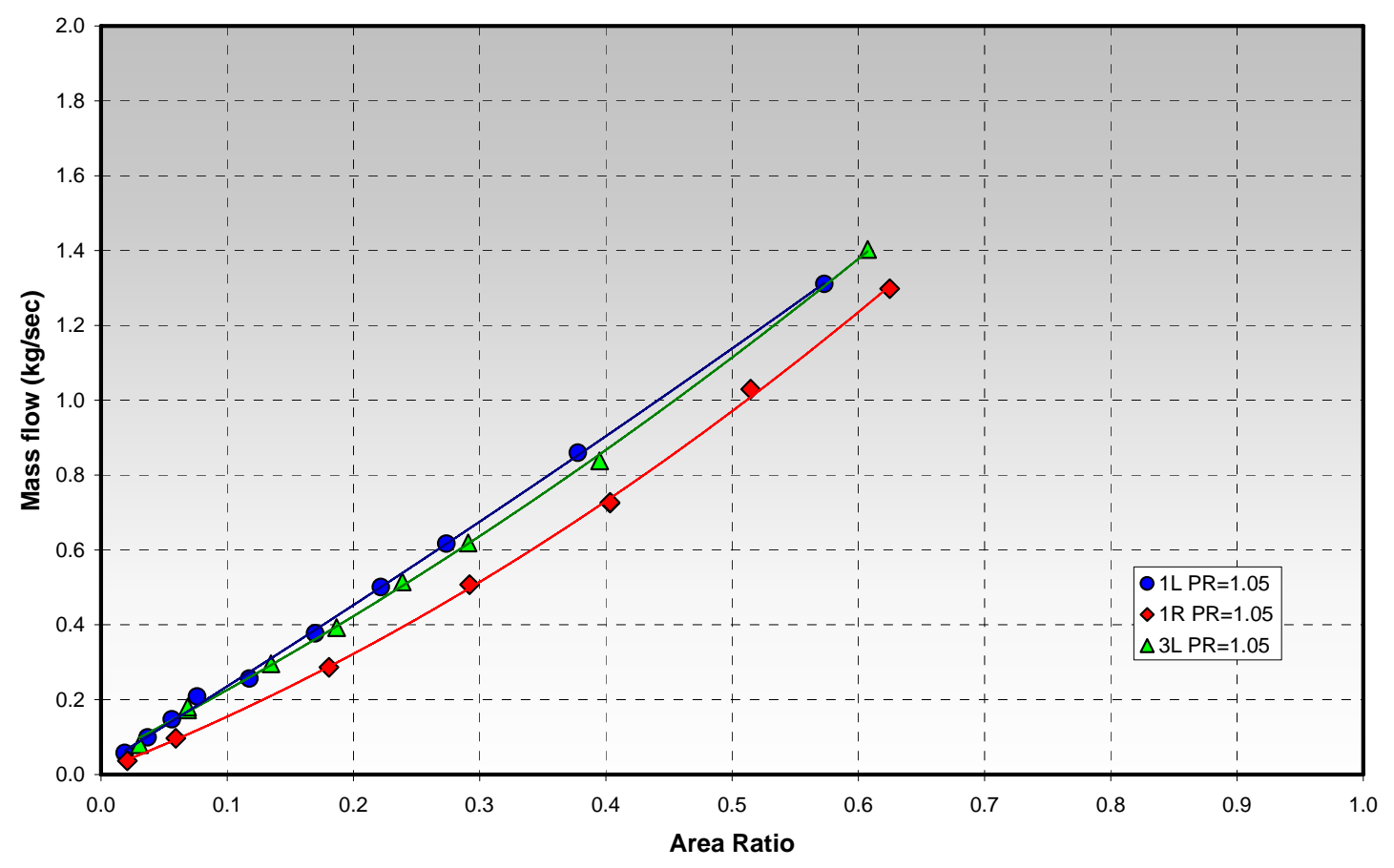

Figure 5-43. Comparison of Exhaust Mass Flow versus Area Ratio (Pressure Ratio=1.05)

The data was further reduced to discharge coefficients versus area ratio and pressure ratio. The discharge coefficient was determined from isentropic flow equations with compensation for the moisture content in the air. The intake port areas were based on the projected open area perpendicular to the top wall, rather than the vertical open area on the cylinder surface. The intake ports and the piston crown have the same angle, so the projected area is more appropriate to use. This projected area is illustrated in Figure 5-44. The exhaust port's top wall angle is somewhat of an opposite angle than the piston crown as shown in Figure 5-45, thus the vertical open area parallel to the cylinder wall was used in exhaust discharge calculations. The resulting discharge coefficients were calculated for the area ratios and pressure ratios that could be tested within the limits of the flow test rig. 


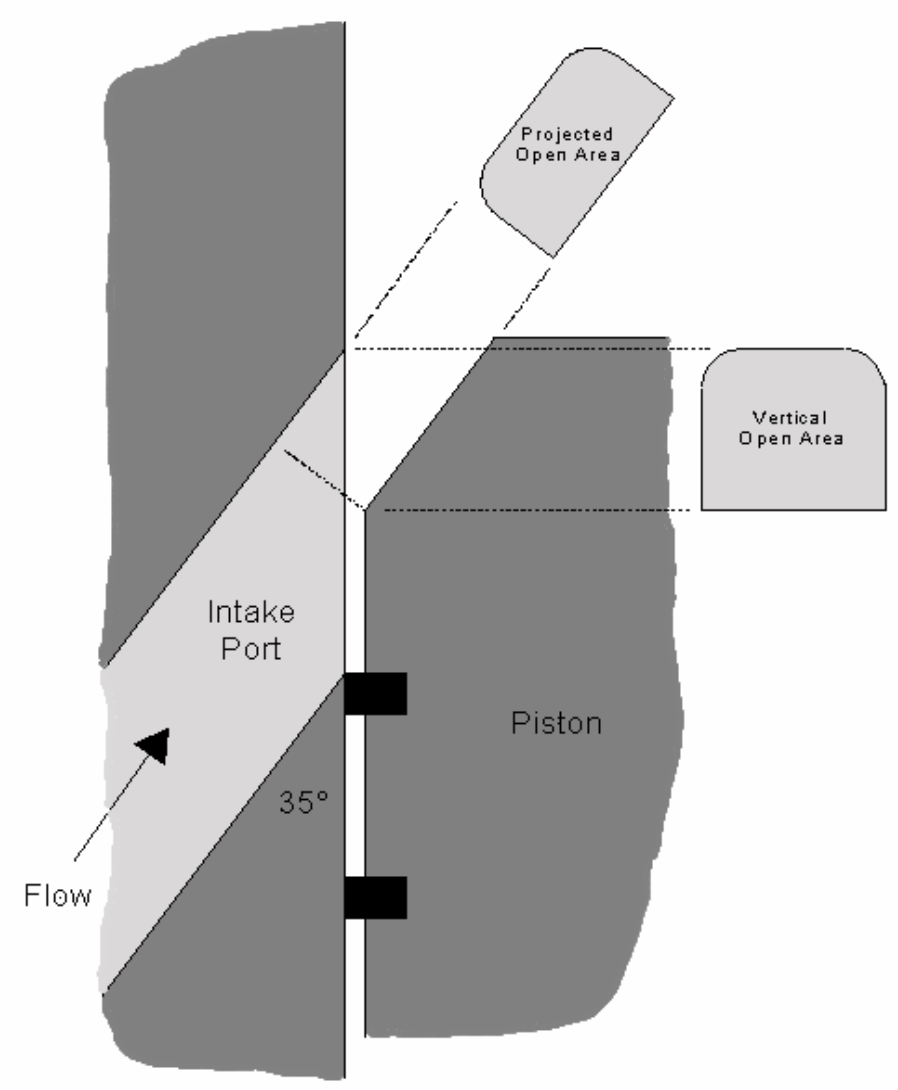

Figure 5-44. Intake Port Flow Area Schematic

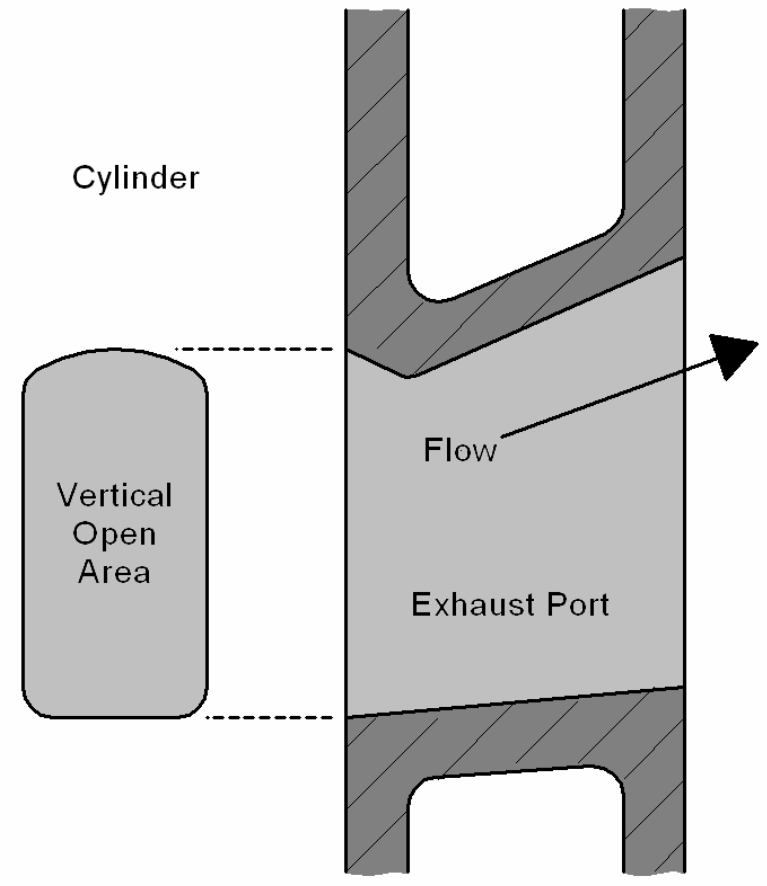

Figure 5-45. Exhaust Port Flow Area Schematic 
The discharge coefficient versus area ratio for cylinder $1 \mathrm{~L}$ intake at various pressure ratios is given in Figure 5-46. A decreasing trend of discharge coefficient versus pressure ratio can be seen in this figure. The discharge coefficient versus area ratio for cylinder $1 \mathrm{~L}$ exhaust at various pressure ratios is given in Figure 5-47. No trend with pressure ratio is exhibited in the exhaust port data. Comparisons of the intake discharge coefficients for the tested cylinders at pressure ratios of 1.05 and 1.2 are given in Figures 5-48 and 5-49, respectively. Similar trends can be seen under both pressure conditions, with an increased discharge coefficient for cylinder $1 \mathrm{R}$ and reduced values for cylinder $3 \mathrm{~L}$ at low area ratios. Comparison of the exhaust discharge coefficients at pressure ratios of 1.05 and 1.2 are given in Figures 5-50 and 5-51, respectively. Similar trends can be seen in both figures, with cylinder $1 \mathrm{~L}$ and $3 \mathrm{~L}$ matching and cylinder $1 \mathrm{R}$ having a more significant reduction in discharge coefficient at low area ratios. This significantly different trend for cylinder $1 \mathrm{R}$ is presumed to be caused by the different shape of the top of the exhaust port runners.

These values and trends closely follow values and trends presented in the literature. ${ }^{[1,2,3]}$ The flow test rig data was added to the computational model to generate a map of discharge coefficients versus area ratio and pressure ratio. Figures 5-52 and 5-53 show the full map of discharge coefficients for the exhaust and intake ports on cylinder $1 \mathrm{~L}$, respectively.

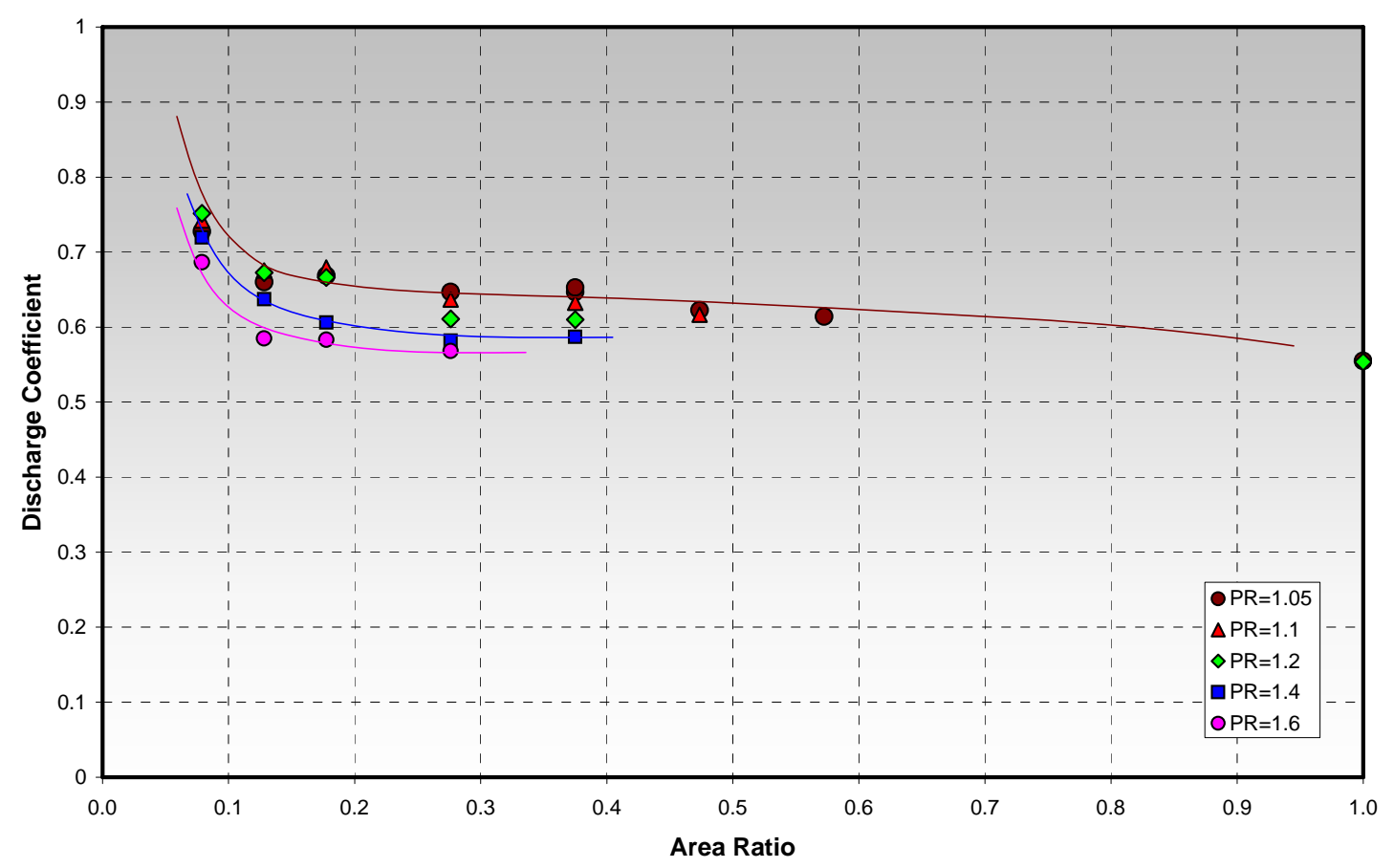

Figure 5-46. Cylinder 1L Intake Discharge Coefficient versus Area Ratio at Tested Pressure Ratios 


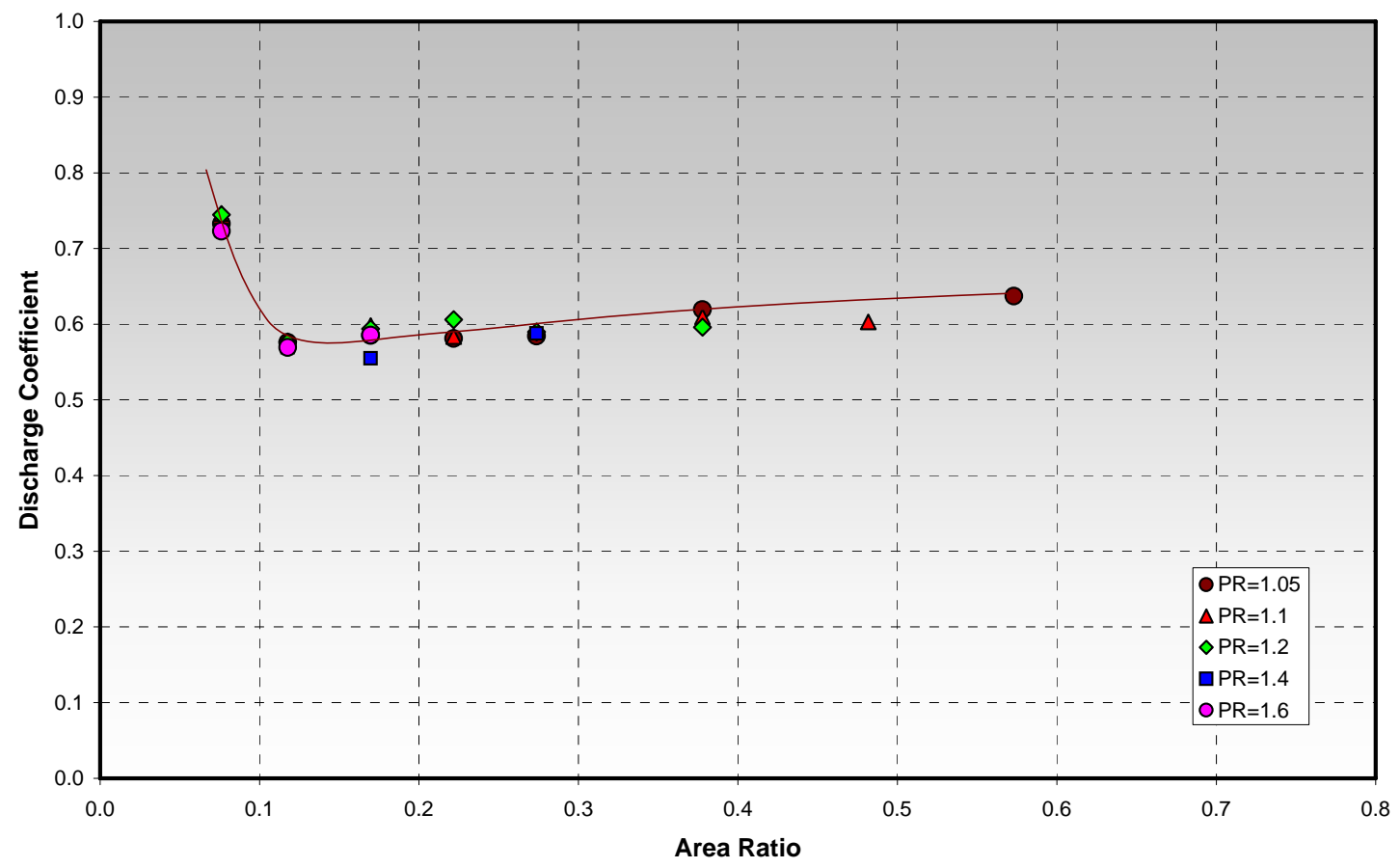

Figure 5-47. Cylinder 1L Exhaust Discharge Coefficient versus Area Ratio at Tested Pressure Ratios

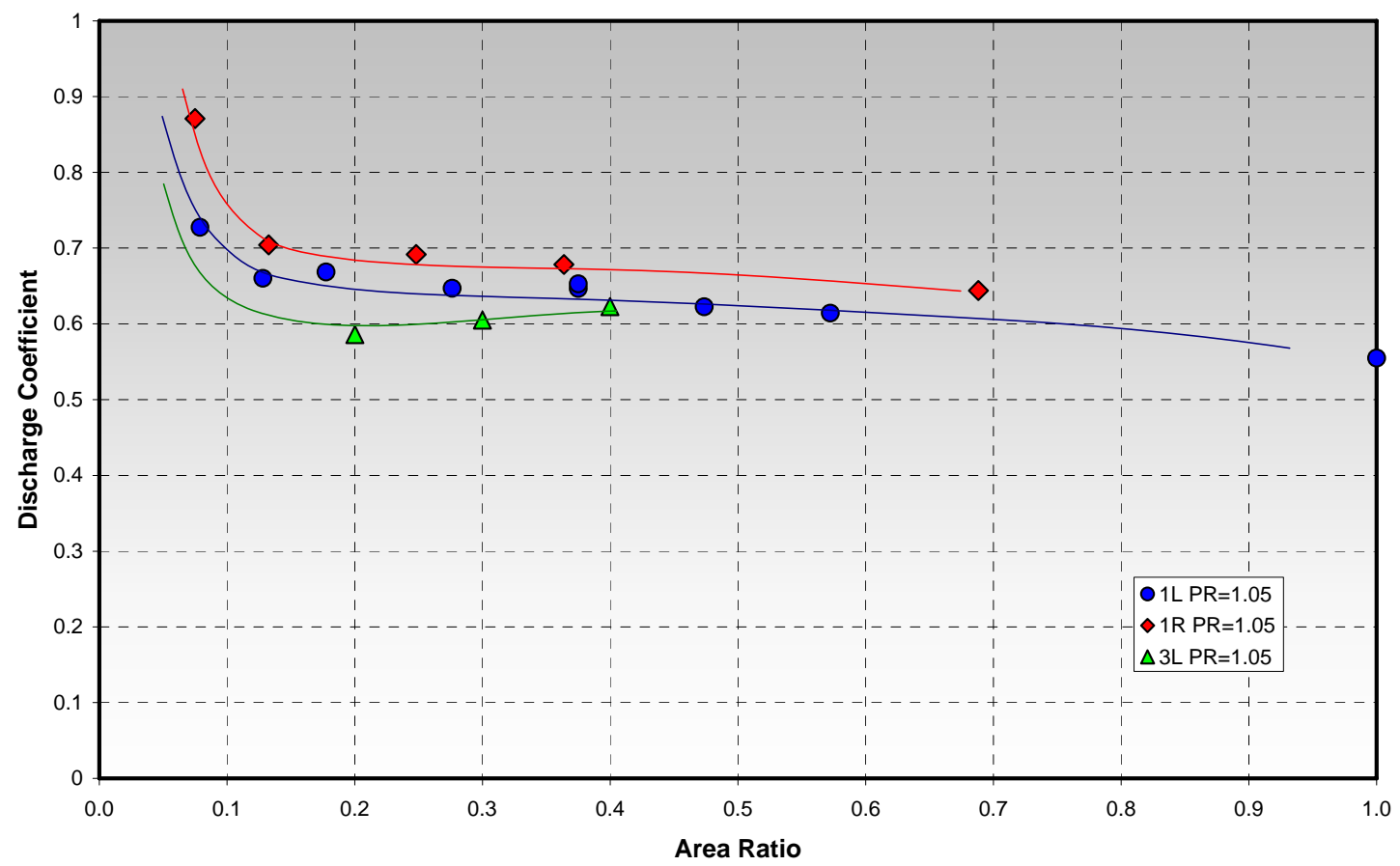

Figure 5-48. Intake Discharge Coefficient versus Area Ratio for Tested Cylinders (Pressure Ratio=1.05) 


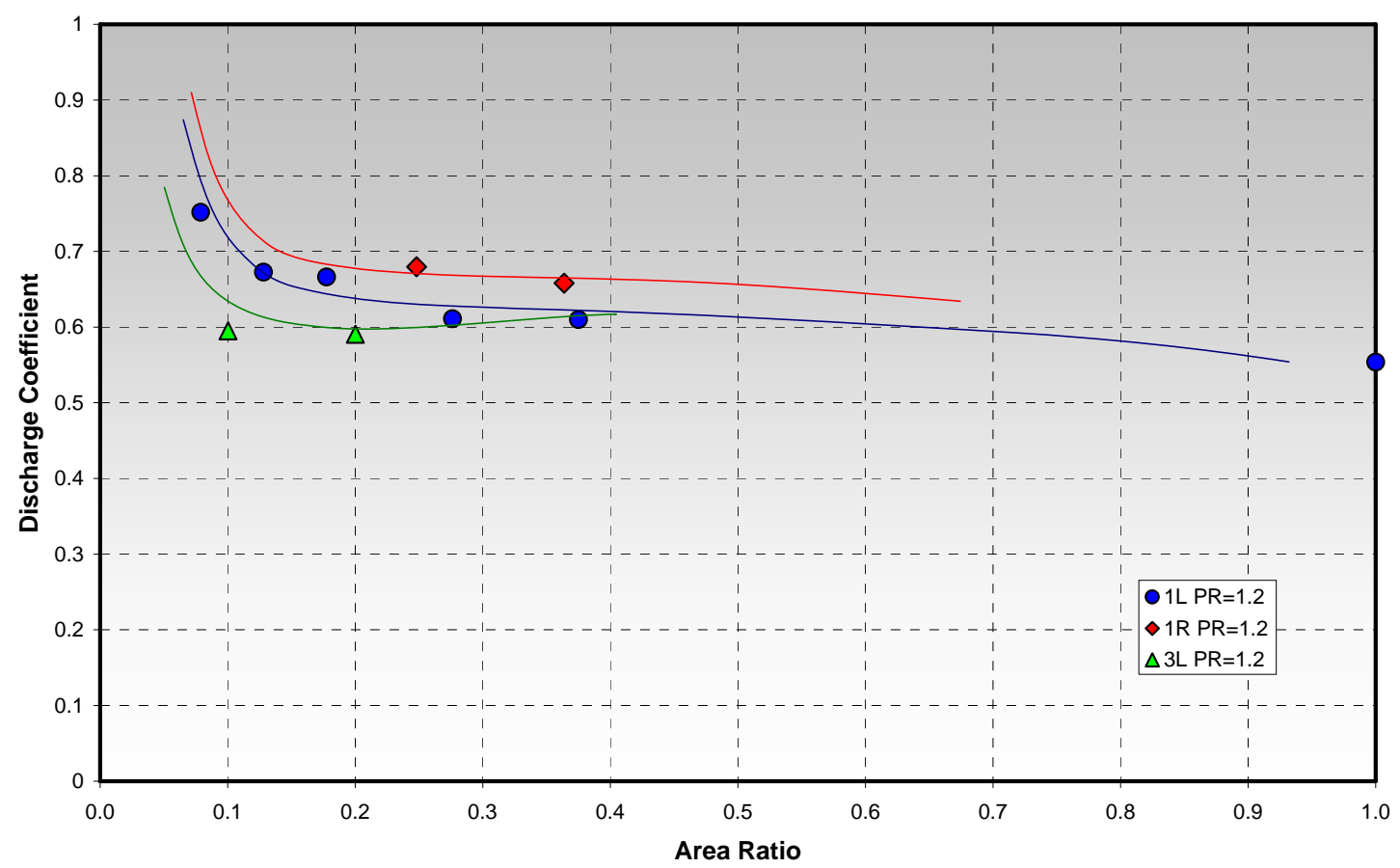

Figure 5-49. Intake Discharge Coefficient versus Area Ratio for Tested Cylinders (Pressure Ratio=1.2)

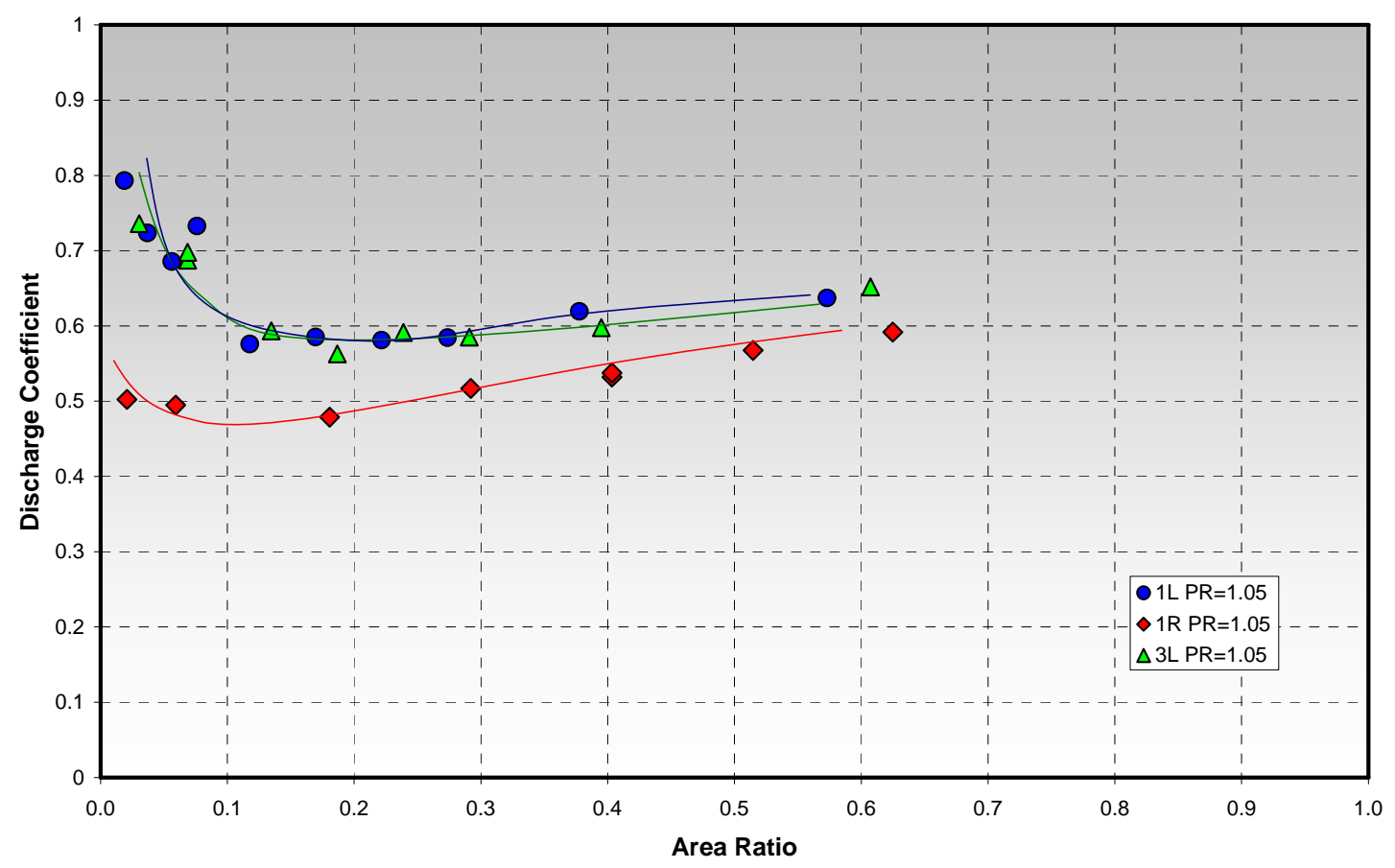

Figure 5-50. Exhaust Discharge Coefficient versus Area Ratio for Tested Cylinders (Pressure Ratio=1.05) 


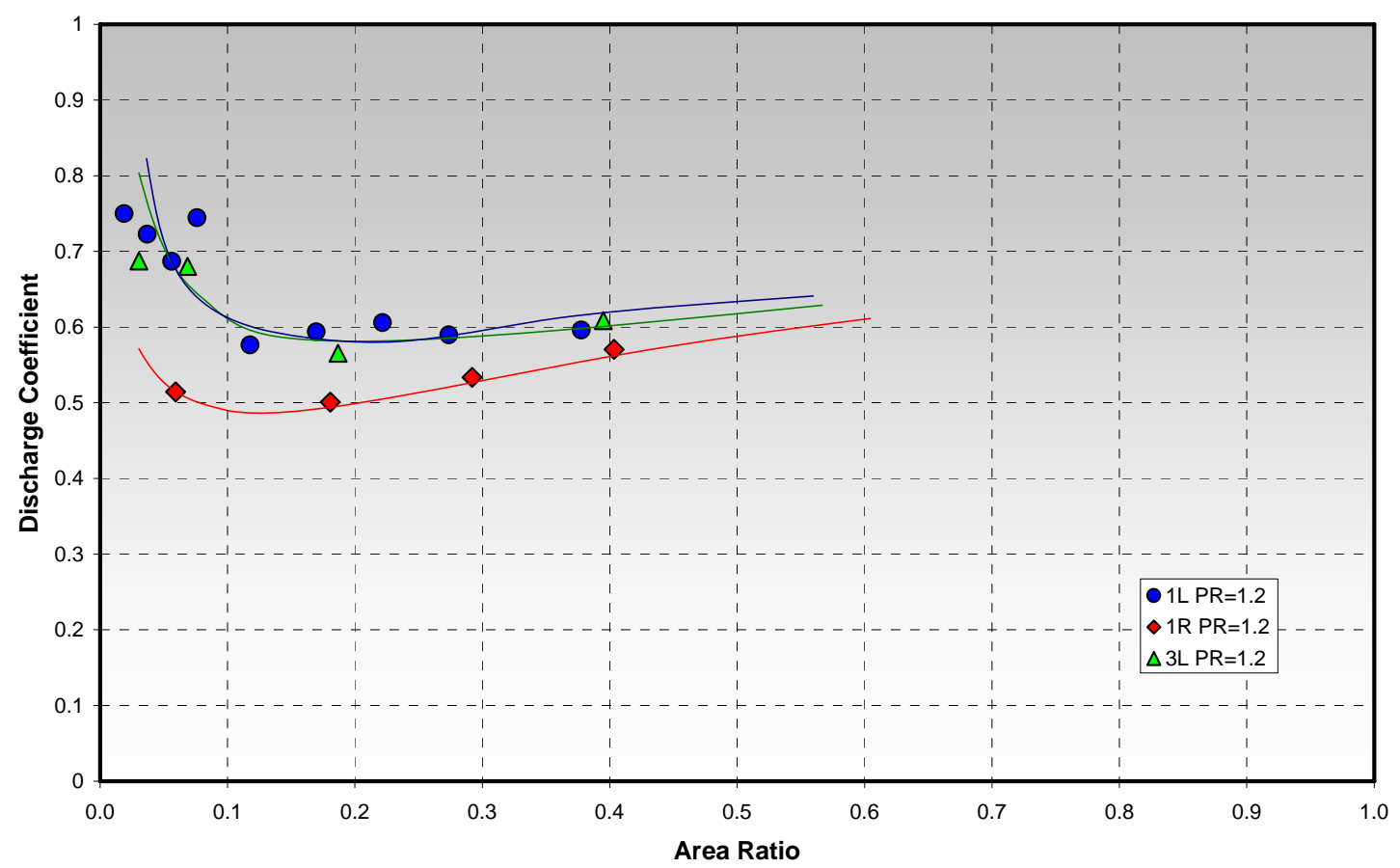

Figure 5-51. Exhaust Discharge Coefficient versus Area Ratio for Tested Cylinders (Pressure Ratio=1.2)

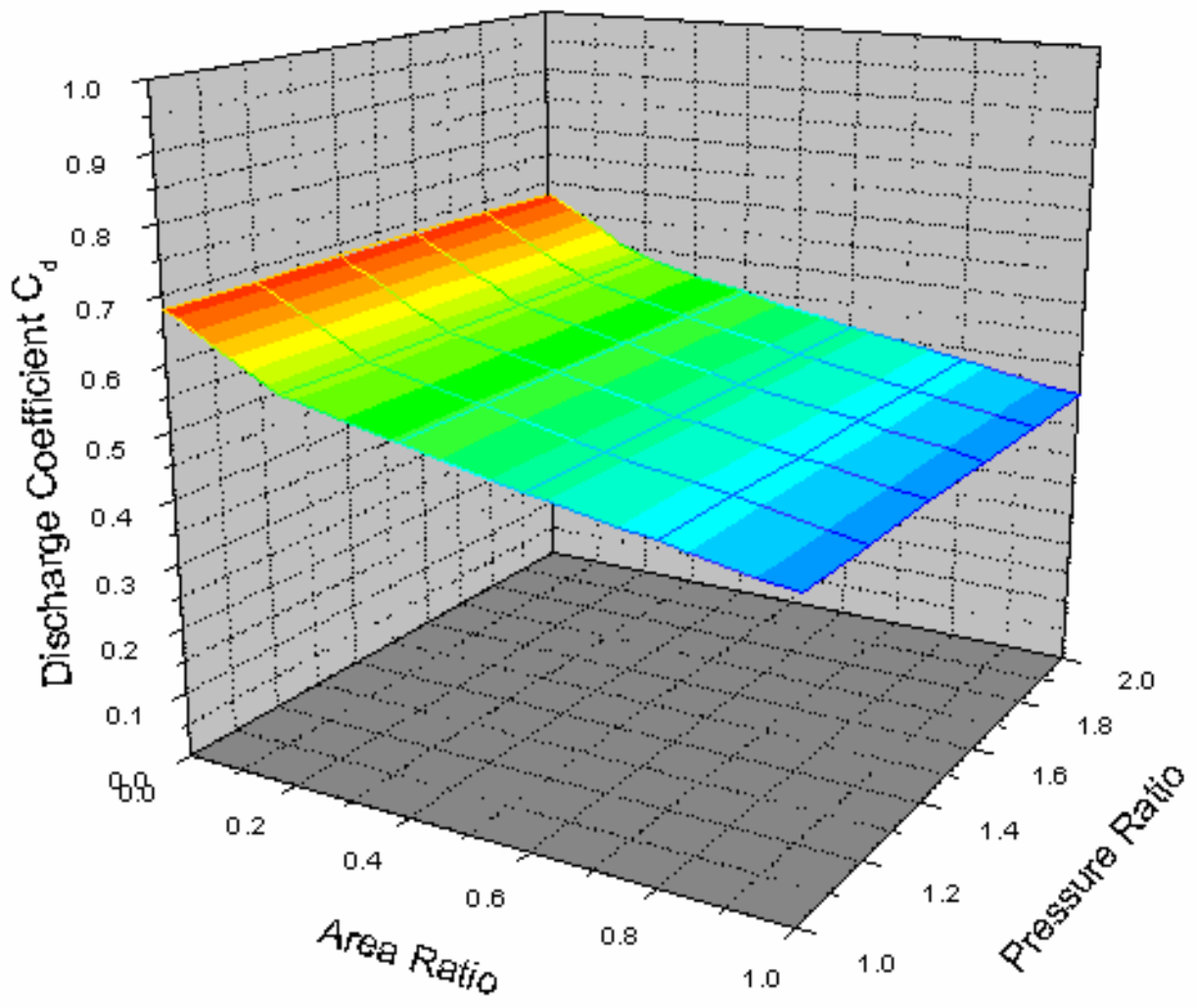

Figure 5-52. Model Generated Exhaust Discharge Coefficients 


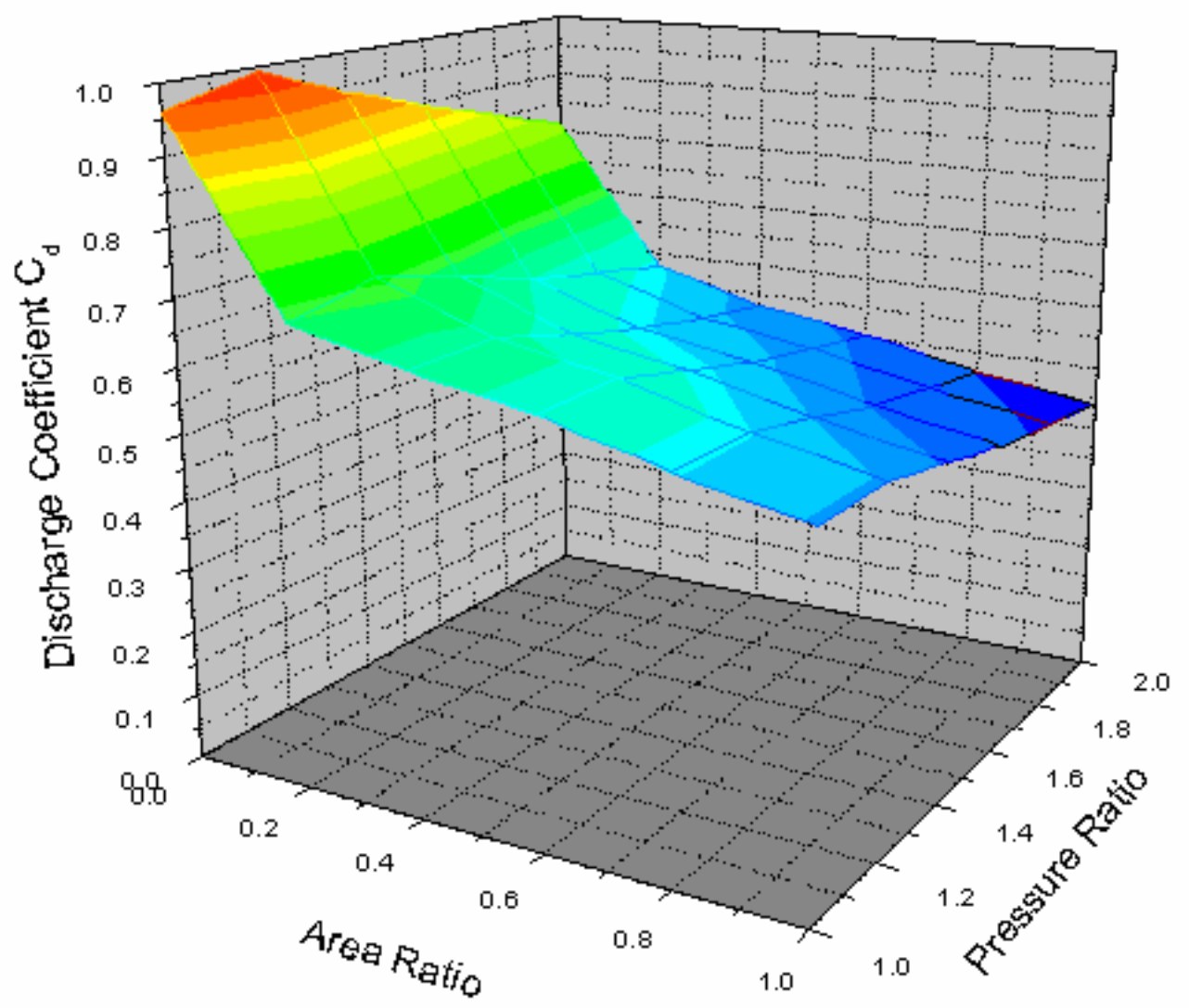

Figure 5-53. Model Generated Intake Discharge Coefficients

\subsection{COMPUTATIONAL MODELING}

Computational modeling was conducted first to help quantify the causes of the compression pressure differences between the cylinders, and second to provide a tool for conceptual manifold design. The computational modeling was performed with software purchased on this project from Optimum Power Technology. The particular software package is titled Automated Design with Virtual 2-Stroke ${ }^{\odot}$. This software is written specifically for modeling of two-stroke engines and is a one-dimensional cycle-simulation model that focuses on the fluid dynamics in an internal combustion engine. Prior to conducting simulations of the GMVH engine, a significant effort was expended with workstation configuration, new software training, and working with Optimum Power Technology to get needed revisions for large-bore integral engine simulation (i.e. addition of direct fuel admission feature).

A model of the GMVH was initially configured with mean dimensions derived from drawings provided by Cooper Compression as well as external physical measurements made on the engine. Data was also provided by Cooper Compression to develop compressor and turbine maps for the turbocharger model installed on this engine. Later in the project, the dimensional data acquired during disassembly was used to refine the model in which several assumptions and nominal values had been initially programmed. It was not until detailed geometry, derived during engine disassembly, was incorporated into the model that satisfactory simulation of the engine was achieved. 


\subsubsection{Model Validation}

The model validation was a difficult yet significant task. The model must accurately simulate the dynamic flows, pressures, and temperatures of the real engine so that a realistic manifold design can be performed. To construct a detailed model of the GMVH-6 engine from scratch, several items were required to be defined for construction. These items were as follows:

- Turbocharger compressor and turbine maps

- All inlet air system components - pipes, intercoolers, junctions, and transitions

- All exhaust system components - pipes, wastegate, junctions, and transitions

- Port geometry, discharge coefficient, and timings

- Scavenging - efficiency versus scavenging ratio

- Cylinder volume and piston motion

- Fuel admission - timing, rate, and total mass per cycle

- Combustion - timing and rate of heat release

- Heat transfer - coefficients for cylinders, block, and manifolds

- Operating conditions - speed, percent wastegate, and ambient conditions

Once the model was constructed, several iterations were performed to compare simulation results to measured parameters. Several parameters in the above list were not known precisely, such as the heat transfer coefficients, and required tuning based on comparison to measurements. An extensive effort was expended at this stage of the project attempting to achieve correlation with engine measurements.

As discussed previously, mean drawing dimensions were used in initial model construction and the base air chest was not known to be an active feature of the inlet air system. Correlation could therefore not be achieved to a satisfactory level and at this time it was decided to conduct the geometric analysis and port flow testing. Plots showing the best initial simulation results to measured data are provided in Figures 5-54 through 5-56. A comparison of cylinder pressure from one cylinder is provided in Figure 5-54 where discrepancies can be seen in the compression pressure and blowdown regions. Figure 5-55 shows a comparison of the dynamic intake manifold pressure where higher pulsation amplitude was predicted in the simulation and the phasing of pulses does not match measured data. The dynamic exhaust runner pressure comparison is shown in Figure 5-56 which shows slightly higher pulsation amplitude and a lower mean value, but better matching of the phasing. 


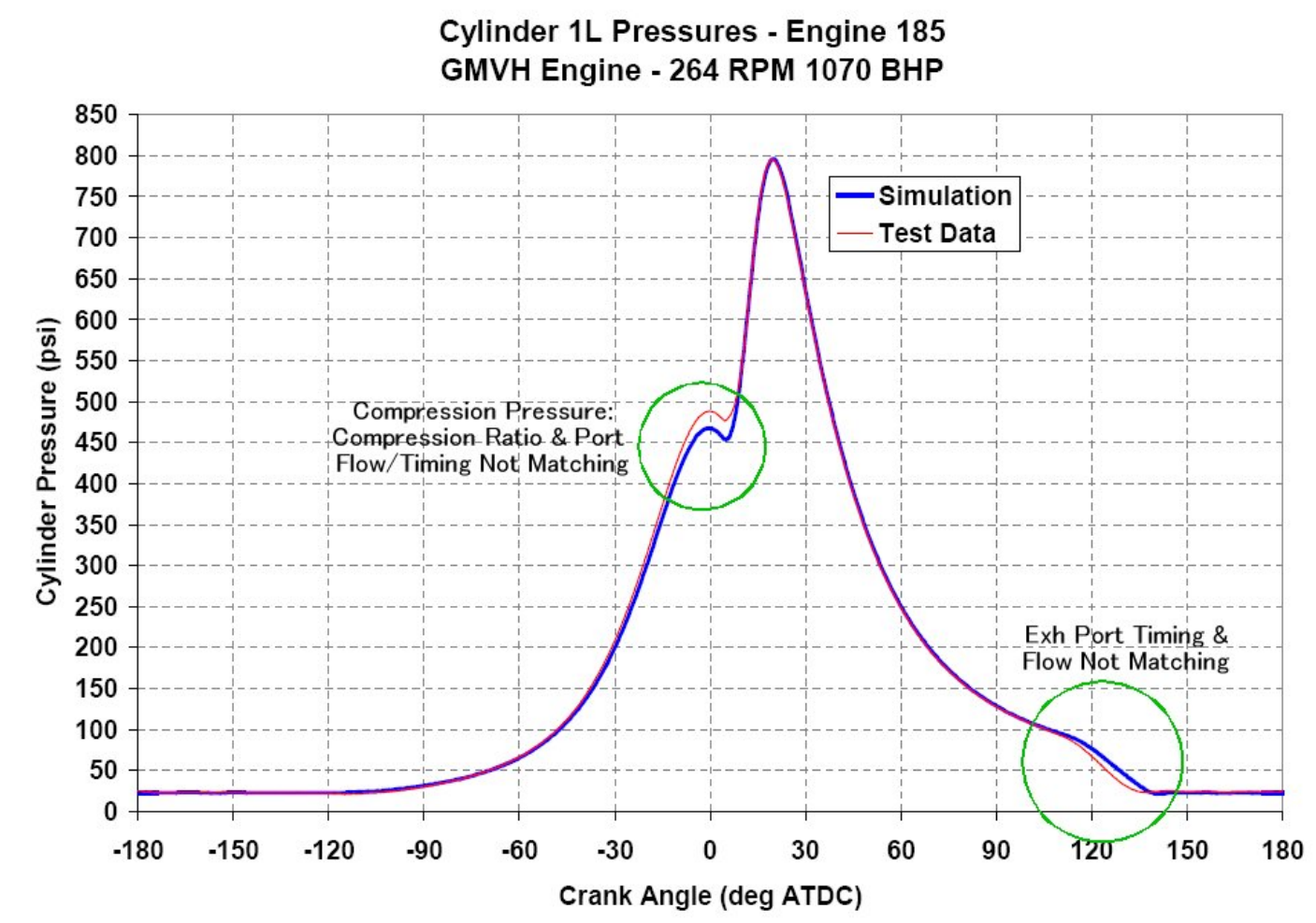

Figure 5-54. Initial Simulation to Measurement Comparison - Cylinder 1L Pressure

Intake Manifold Pressures - Engine 185

GMVH Engine - 264 RPM 1070 BHP

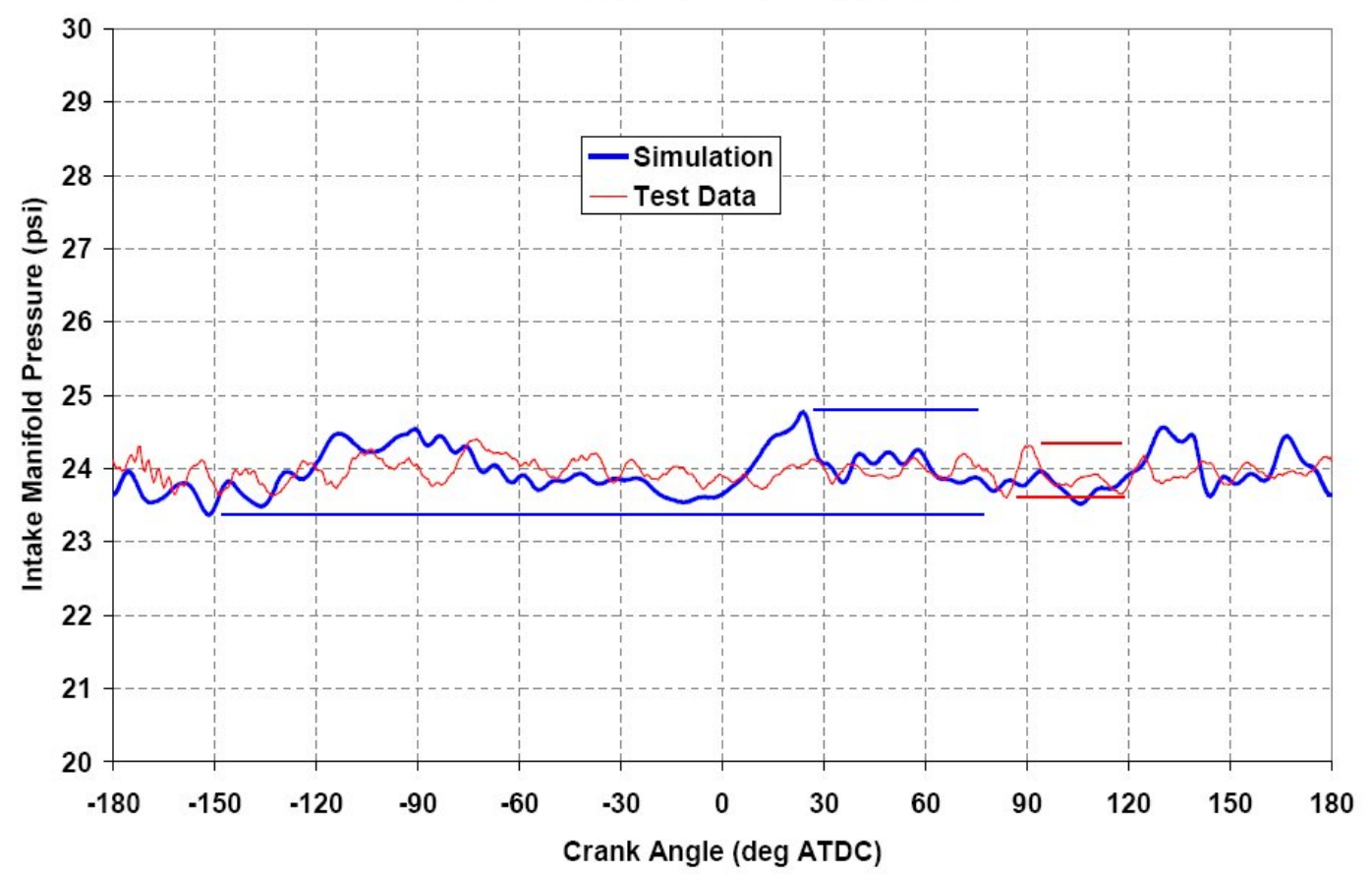

Figure 5-55. Initial Simulation to Measurement Comparison - Intake Manifold Pressure 


\section{Exhaust Manifold Pressures - Engine 185 \\ GMVH Engine - 264 RPM 1070 BHP}

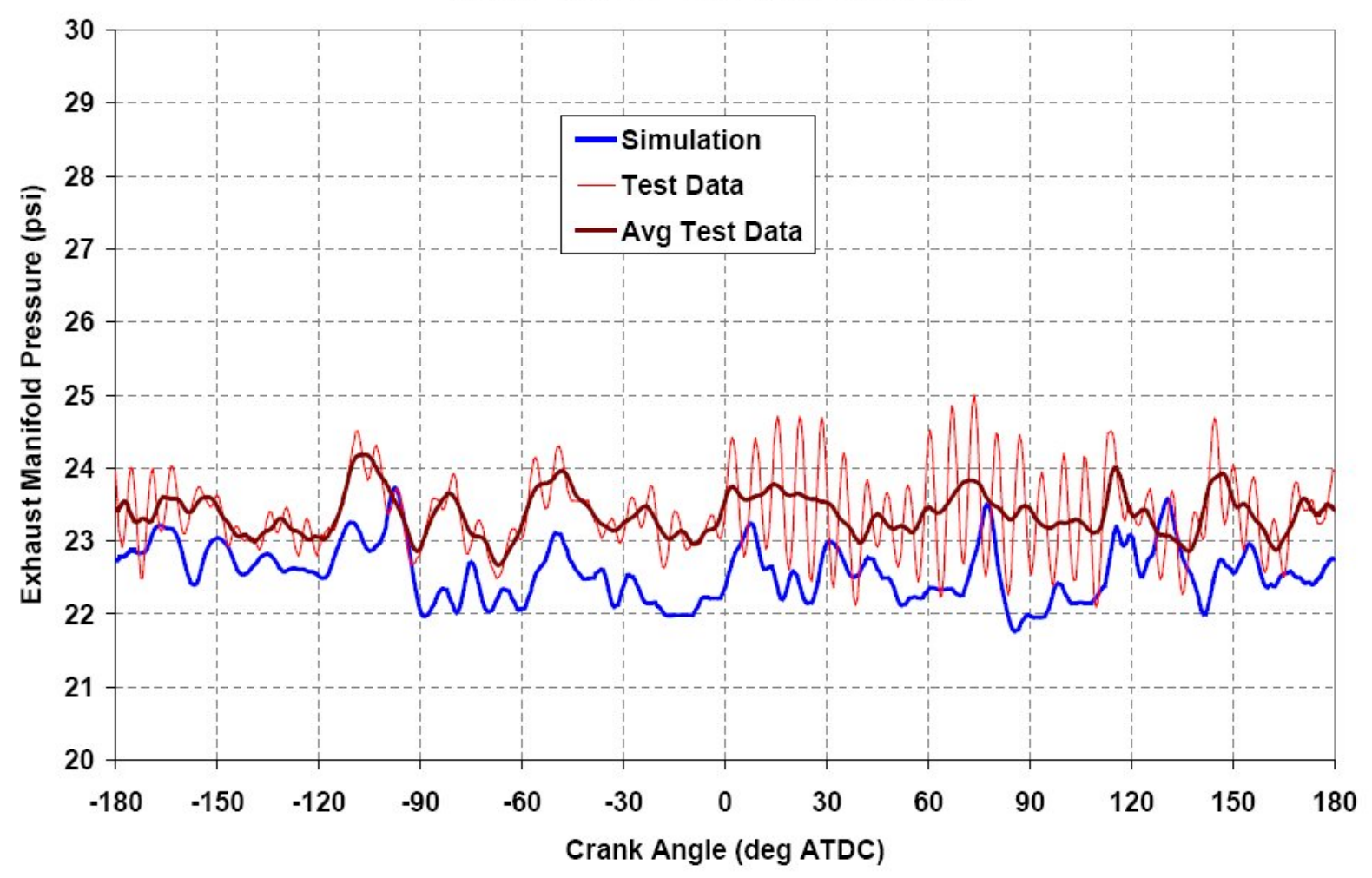

Figure 5-56. Initial Simulation to Measurement Comparison - Exhaust Manifold Pressure

Results of the geometric analysis and port flow testing were analyzed and incorporated into the GMVH-6 model. The base air chest geometry was also added to the model. A second iteration of tuning heat transfer and flow coefficients in various junctions was then performed. Simulation results now matched measurements much closer and to a level felt satisfactory to deem validation complete. A comparison of the cylinder pressure match with revised geometry is shown in Figure 5-57. Comparisons of the inlet and exhaust runner dynamic pressures, as well as cylinder pressure, are shown in Figure 5-58. The simulated inlet and exhaust pressures are shown in Figure 5-58 to now match very well in both amplitude and phasing of the pulsations. Although cylinder pressure looks very well matched in Figure 5-57, the close-up view of cylinder pressure in the range of scavenging pressures shows some discrepancy between the start to finish of the scavenging event. It was believed that this discrepancy was due to thermal shock of the non-water cooled transducers used for cylinder pressure measurement. 


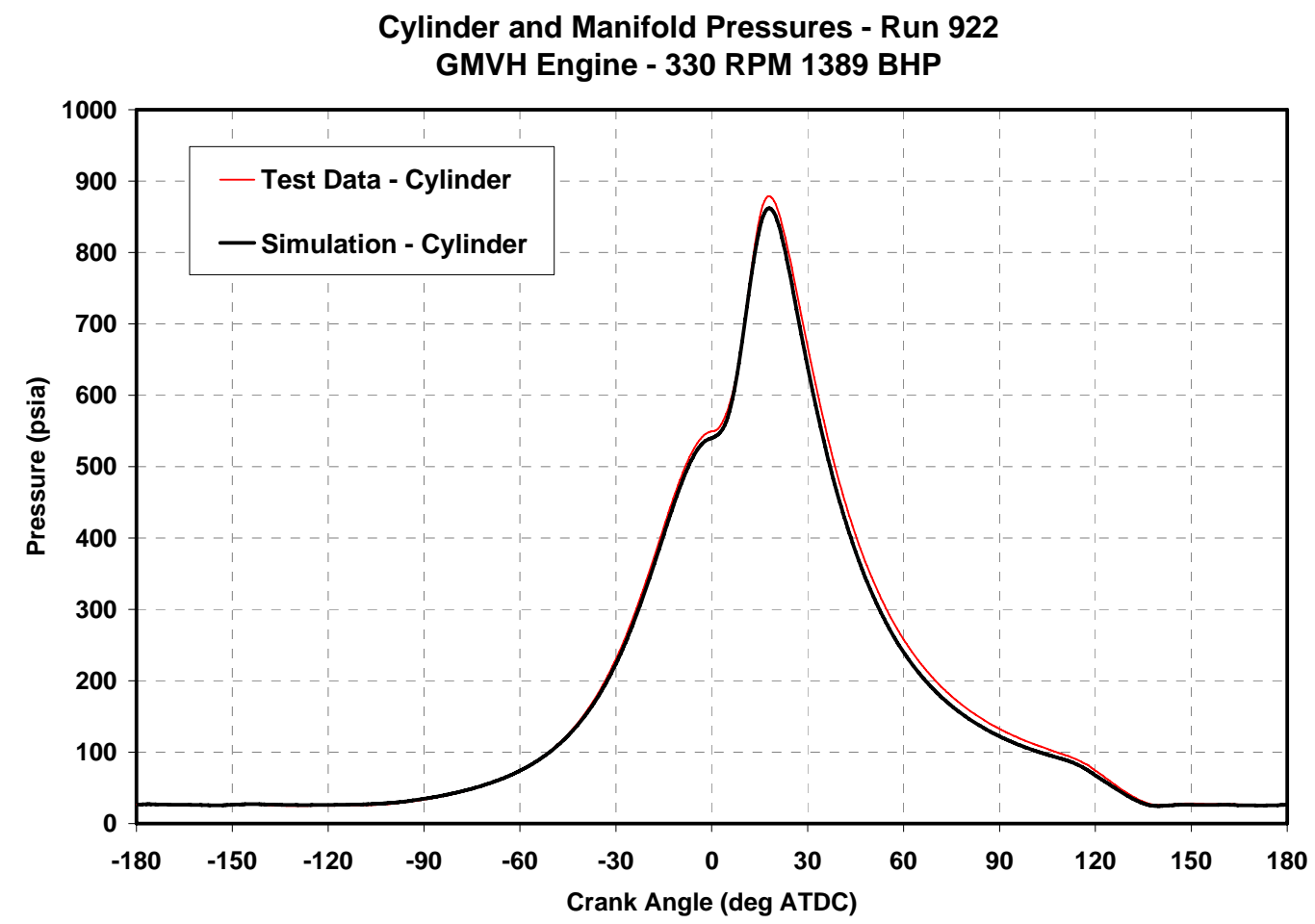

Figure 5-57. Revised Simulation to Measurement Comparison - Cylinder Pressure

Cylinder and Manifold Pressures - Run 922 GMVH Engine - 330 RPM 1389 BHP

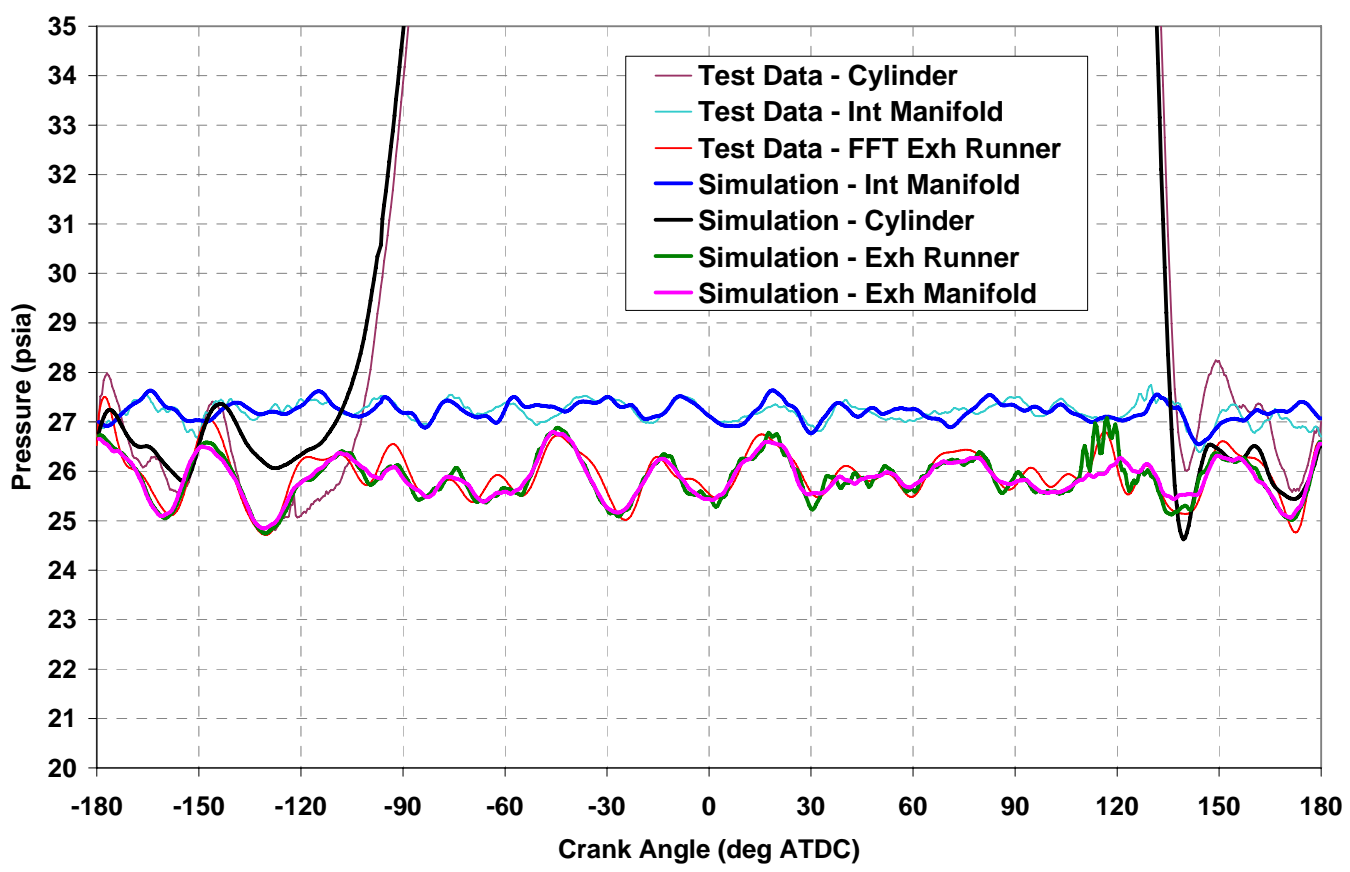

Figure 5-58. Revised Simulation to Measurement Comparison - Inlet, Exhaust, and Cylinder Pressure 


\subsubsection{IDentical Cylinder Model}

With the model validation achieved, the cylinder dimensional data was averaged to generate a model of the engine with identical cylinders. The identical cylinder model was validated to measurements of cylinder $1 \mathrm{~L}$ and used for investigation into manifold design and flow affects without the influence of geometric differences. The premise was that if the identical cylinder model showed similar variations in compression pressure, then the model would provide insight into the causes and could then be used to design manifold solutions. It was reasoned that mean geometric values should be used because the variation in actual geometric values was expected to be random among cylinders in field engines and may range more or less than those measured on the subject GMVH-6. Cylinder geometric variations exist due to manufacturing tolerances and may be more pronounced in field engines due to part mismatch. Therefore, the first analysis sought to investigate manifold affects with identical cylinders in the model to isolate their contribution to imbalance.

The correlation to performance in cylinder 1L was very good. However, this identical cylinder model did not predict the spread in compression pressures and showed only expected differences from bank-to-bank due to articulation and its affect of port timing. There was no indication from this model that the original manifold designs on the six cylinder engine, or dynamic flows with these designs, were causing any affect on compression pressure or trapped mass on a given bank. The cylinder $1 \mathrm{~L}$ to cylinder $3 \mathrm{~L}$ variation in the data was not observed in the simulation. Figure 5-59 shows the compression pressure at TDC from the identical cylinder simulation and corresponding engine measurements. Therefore, the initial conclusion was there is minimal manifold effect on breathing and that the geometric variations were dominating the variations seen in the data.

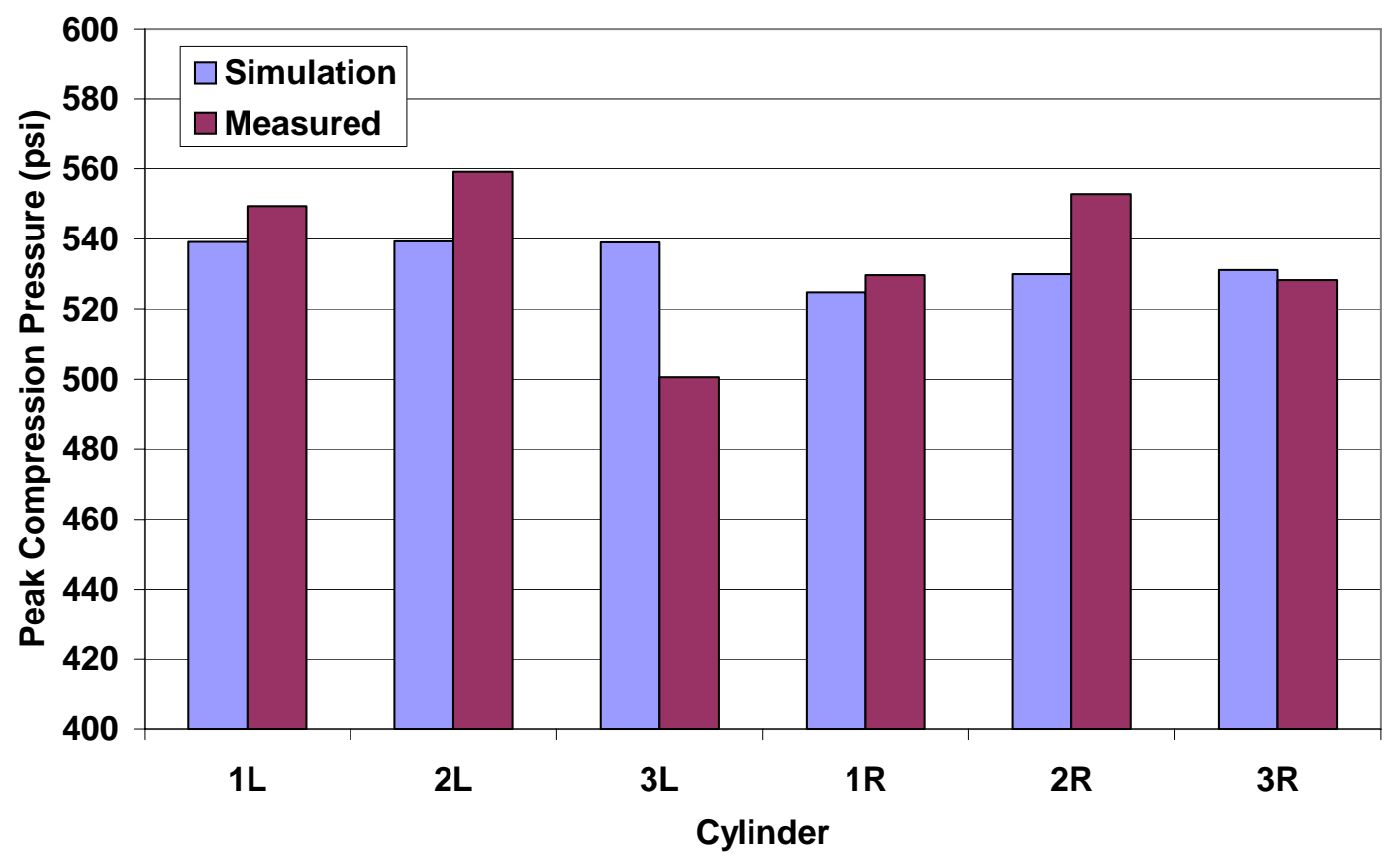

Figure 5-59. Identical Cylinder Simulation to Measurement Comparison - Cylinder Compression Pressure at TDC 


\subsubsection{Geometric Value Sensitivity Study}

Recall from Figure 5-9 that a difference of approximately 11 percent exists between cylinders $1 \mathrm{~L}$ and $3 \mathrm{~L}$ in measured compression pressures. To help quantify the contribution of geometric variation to this spread, a second version of the model was constructed to perform sensitivity studies of the significant geometric factors that may affect imbalance in either flow or compression pressure. The range of values used in the study simulated the minimum-maximum values measured during the geometric analysis.

The first parameters to be swept were intake and exhaust port opening heights (i.e. port timing), and the results are shown in Figure 5-60. The effect on compression pressure due to changes in intake port opening height was negligible. The effect on compression pressure due to changes in exhaust port opening height showed an approximate 2 percent change. A positive increase of 0.150 " in exhaust port opening height represents a 1-2 degree later closing of the port, matching the difference from cylinder $3 \mathrm{~L}$. The predicted change in compression pressure was approximately 2 percent with the full change in exhaust port opening height.

The next set of parameters swept with the model was the intake and exhaust port discharge coefficients. Figure 5-61 shows the results of a \pm 10 percent variation from nominal in the discharge coefficients. The predicted change in compression pressure from the minimum to maximum range simulated was approximately 0.6 percent for the intake and 1.1 percent for the exhaust. This range of affect was lower than expected with such a large variation in discharge coefficient.

The last parameter swept with the model was compression ratio. This was varied by changing the TDC clearance volume. Figure 5-62 shows the mechanical compression ratio (BDC to TDC swept volume) affect on compression pressure. The predicted change to compression pressure for 0.4 point change in compression ratio is 4.3 percent, which clearly is the dominant effect on compression pressure. This magnitude of change in compression pressure as a function of compression ratio was expected, and given the lesser affects from the previous parameters, this implies that using compression pressure as an indicator for trapped mass is not very accurate. 


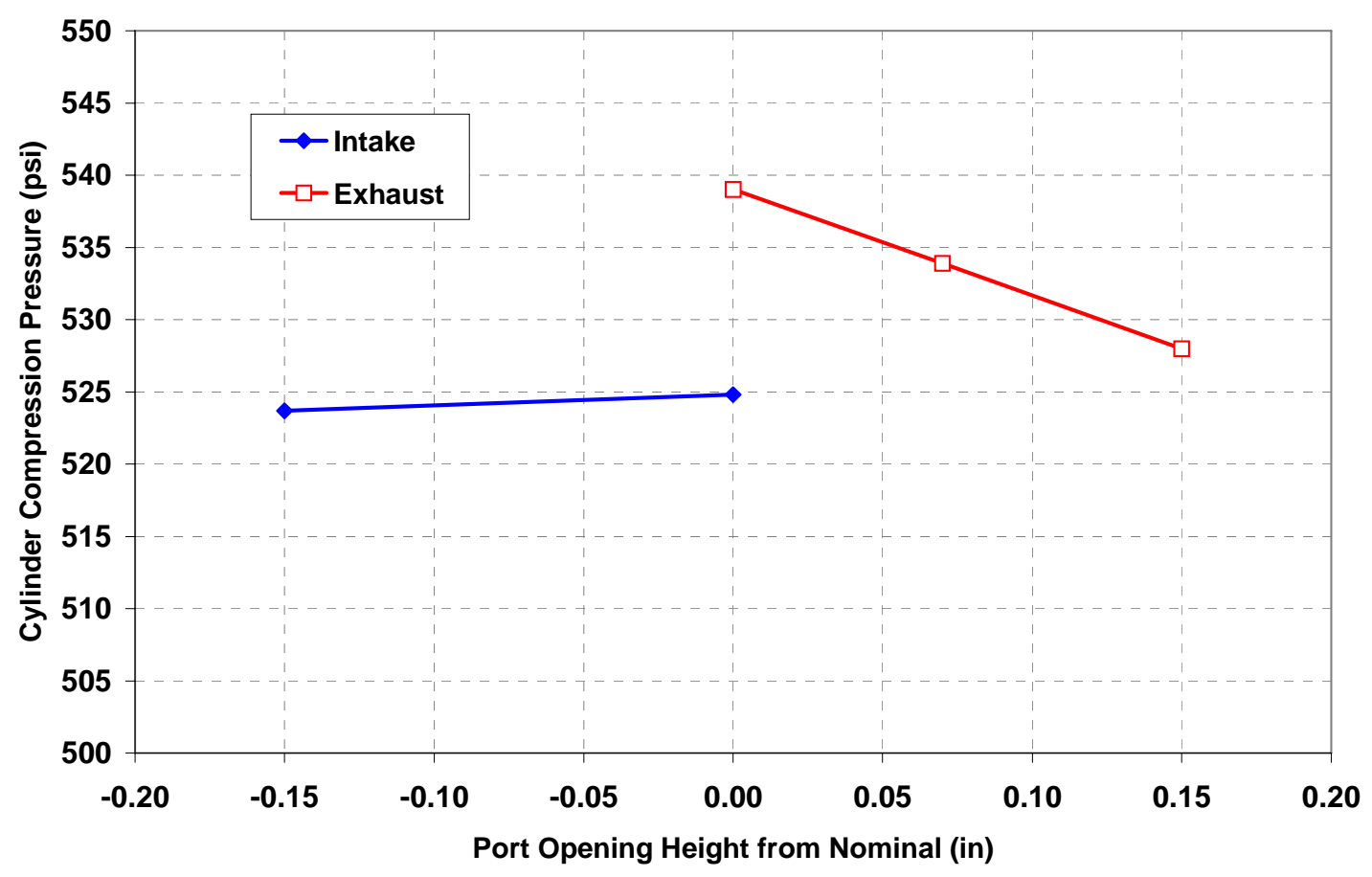

Figure 5-60. Simulation Predictions of Compression Pressure with Variation in Port Opening Height (Timing)

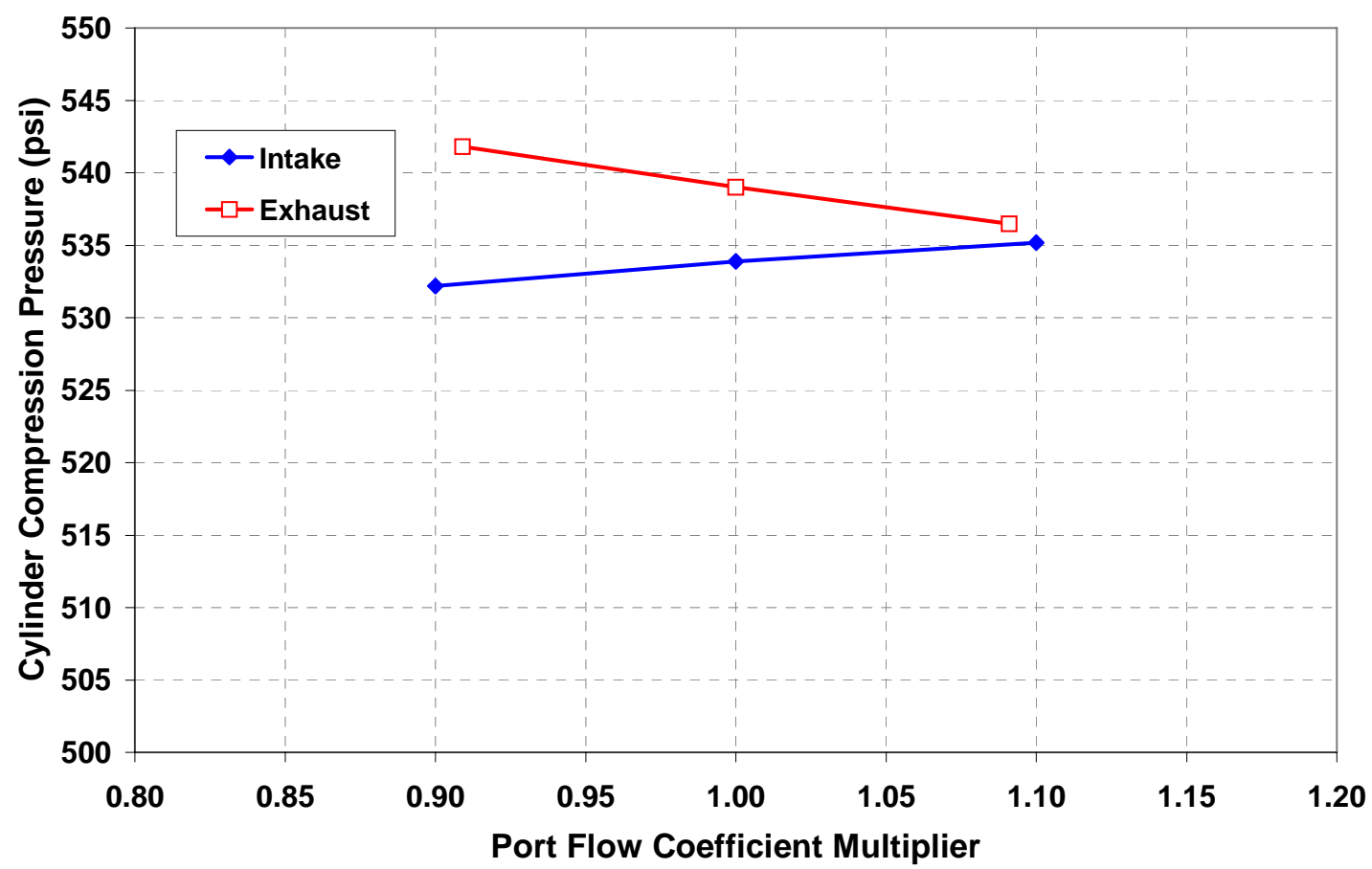

Figure 5-61. Simulation Predictions of Compression Pressure with Variation in Port Discharge Coefficient 


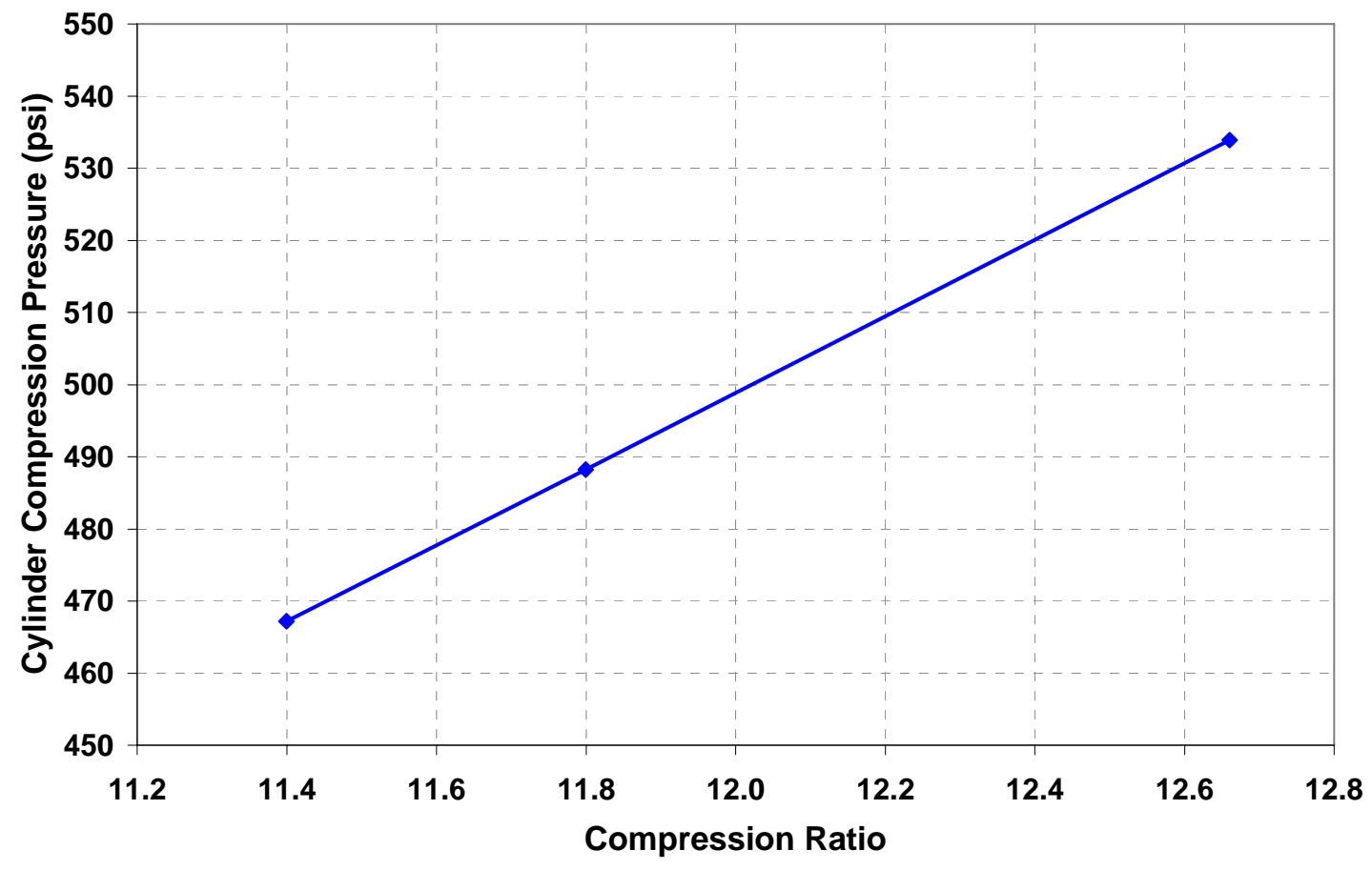

Figure 5-62. Simulation Predictions of Compression Pressure with Variation in Compression Ratio

The results of the model sensitivity study shows that geometric effects do account for a significant portion of the spread seen in the compression pressure. However, a summation of the simulated effects on compression pressure by the geometric variations matching those measured, only accounts for about 6 percent of the 10 percent difference between cylinders 1L and 3L. There is still approximately 4 percent of 1L-3L compression pressure spread unaccounted for. This discrepancy in accountability and experience with other field engines, where operation and data indicate variations in cylinder-to-cylinder air/fuel ratio, leads to the belief that there is still a breathing issue and likely related to the manifold designs. The Virtual 2-Stoke ${ }^{\circledR}$ program is a one-dimensional model, as is most other popular engine simulation models. One-dimensional models are very accurate with flow paths featuring relatively long lengths and small diameters. The GMVH engine, on the other hand, features flow path geometry consisting of large volumes and diameters with relatively short lengths. SwRI engineers suspect that the flow dynamics may not have been predicted accurately in certain regions of the system, and that three-dimensional modeling may be required for complex junctions and/or transitions. The Virtual 2-Stoke ${ }^{\circledR}$ program can be coupled to several available three-dimensional software packages. However, time and budget constraints have prevented further investigation into this scenario.

\subsection{GMVH-6 COMPONENT SWAP TESTING}

Upon completion of the geometric analysis, the engine was re-assembled. Power assemblies (cylinder, piston, rings, and connecting rod) were switched between cylinders 1L and $3 \mathrm{~L}$ during re-assembly to allow for quantification of the geometric variation affects on compression pressure. Cylinder 3L had the second lowest effective compression ratio, and cylinder $1 \mathrm{~L}$ the highest. Cylinder $3 \mathrm{~L}$ also had two of the five exhaust ports out of specification yielding a slight (1 to 1.5 degree) difference in port timing. In addition, cylinder 3L showed to 
have a slightly lower inlet discharge coefficient at low port opening positions. These cylinders were also on the same bank, which would avoid articulation affects complicating the comparison of pre and post switch data. As mentioned previously, the different casting number cylinder on $1 \mathrm{R}$ was replaced during re-assembly with a matching cylinder. This replacement also provided pre and post test data to investigate the affects of the low exhaust port discharge coefficient due to differing port shape. Prior analysis has shown that the geometric differences (compression ratio, port timing, and port flow coefficient) could account for as much as 50 to 60 percent of the difference in measured spread of compression pressure.

The engine was operated over a range of speeds and loads to generate curves similar to those in Figure 5-9. This new data with the swapped power assemblies is shown in Figure 5-63. The compression pressures from cylinder $1 \mathrm{~L}$ are lower as expected. However, the compression pressures from cylinder 3L increased only marginally. To better illustrate the effect on compression pressure from the component swap, compression pressure data from each cylinder at an air manifold pressure of $20 \mathrm{inHg}$ is plotted in Figure 5-64. This plot shows that the compression pressure for cylinder $1 \mathrm{~L}$ was reduced by approximately 5 percent, while the compression pressure for cylinder 3L increased approximately 1 percent. The change for cylinder 1R with the replacement cylinder was less than 1 percent, as seen in Figure 5-64.

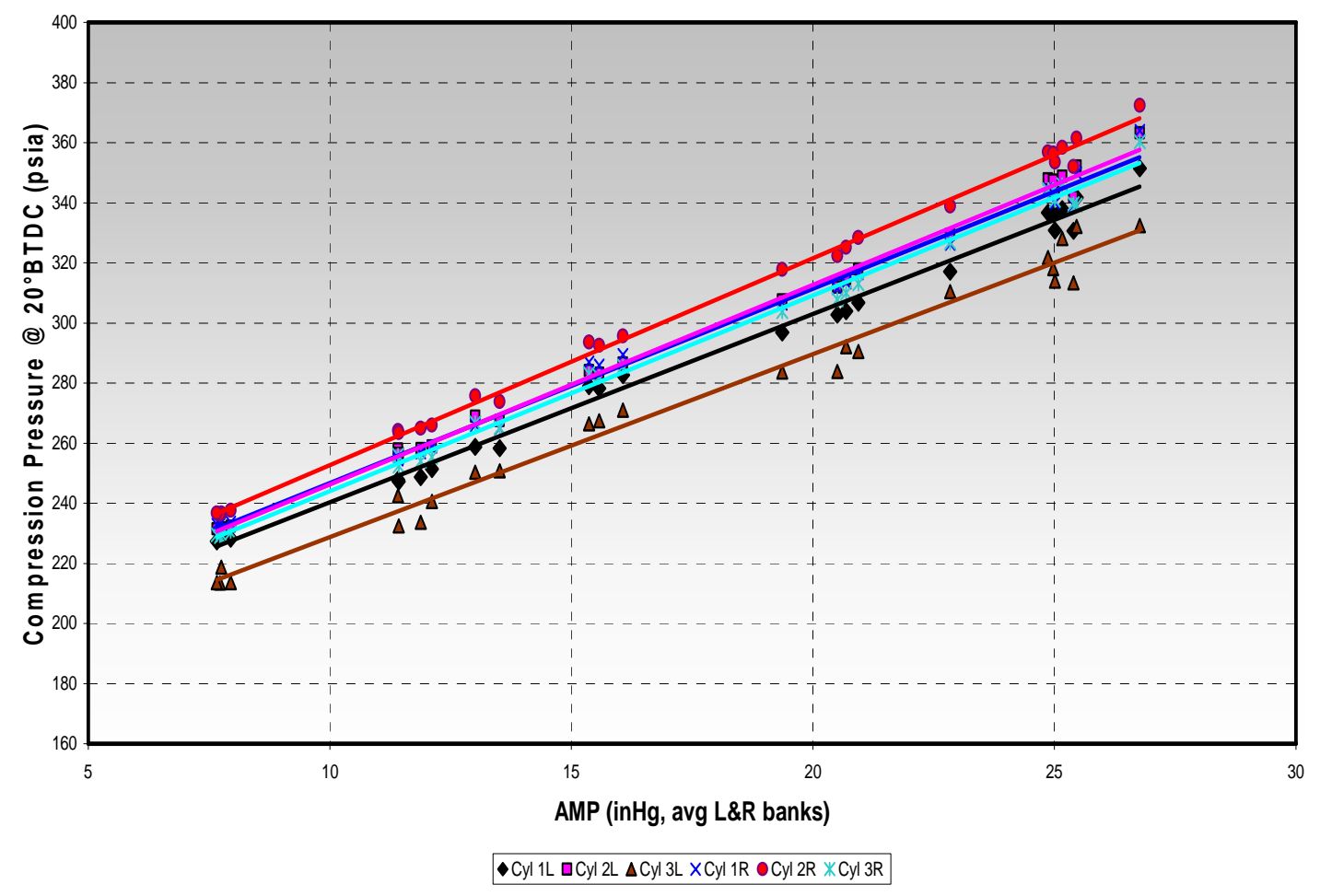

Figure 5-63. 100-Cycle Average Cylinder Pressures at 20 BTDC versus Air Manifold Pressure Post Power Assembly Swap 


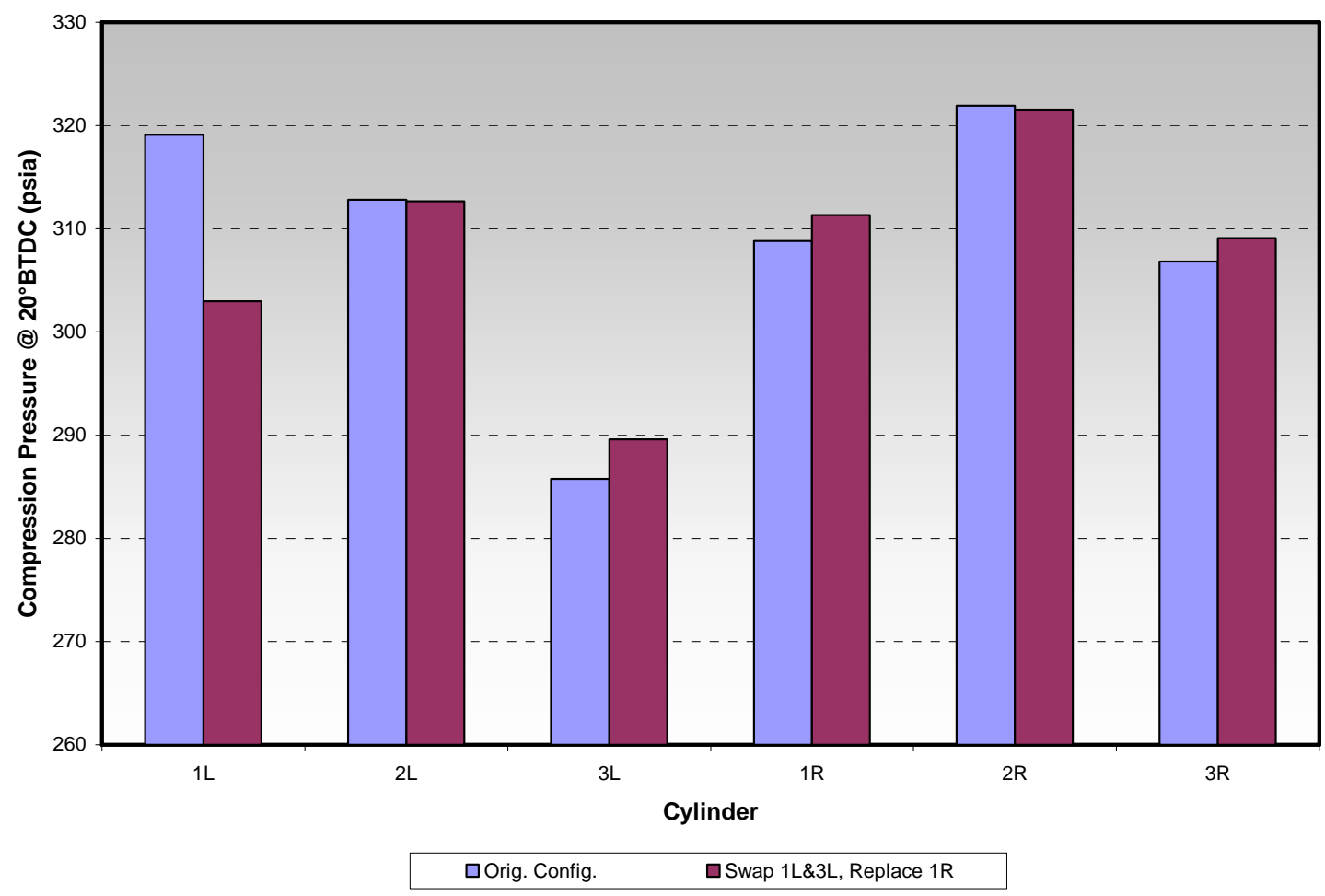

Figure 5-64. Cylinder Pressures at 20 BTDC for Air Manifold Pressure of $20 \mathrm{inHg}$ - Before and After Power Assembly Swap

The trends are as confusing as they are helpful. The effect on cylinder $1 \mathrm{~L}$ was closer to expectations, but the minimal change to cylinder 3L was not as expected. There is apparently still some phenomenon causing cylinder 3L to achieve the lower compression pressure. Further investigation will continue in the next task of the project, and detailed in the final report.

\subsection{DATA INTEGRITY}

Other tests have been performed to ensure data integrity. The measurements taken on the laboratory GMVH-6 were checked and re-checked. Sensors were calibrated frequently, replaced, and switched to ensure accurate readings. The data integrity tests included recalibrating the cylinder pressure transducers and swapping them between cylinders to ensure that sensor variance is not affecting the data. The calibration history of these sensors has shown repeatability within \pm 1 percent since initial installation. The data acquired before and after transducer swaps show results within \pm 1 percent. Therefore, cylinder pressure sensor calibration and repeatability could account for as much as 2 percent of the spread. 


\section{RESULTS AND DISCUSSION: CONCEPTUAL MANIFOLD DESIGNS}

At the beginning of this program, it was anticipated that a new manifold(s) design would be developed to correct dynamic flow problems and balance the air flow and trapped mass between cylinders. This focus changed somewhat after testing, geometric analysis, and simulation. Simulation and geometric analysis results indicated that a large portion of the perceived air imbalance, as deduced from cylinder pressure data, was caused by geometric variation. However, there is still a discrepancy between test data and analysis that has yet to be explained and felt to be due to flow dynamics that could be caused by current manifold designs. It was also thought that different engine models may have worse and more obvious flow dynamic problems than the even firing GMVH-6. Therefore, developing a methodology for analysis and design is valuable even if the solution for the GMVH-6 is nominal.

The GMVH-6 features an even $60^{\circ}$ firing interval, with each crankshaft throw coupled to a compressor. The exhaust manifold features a large diameter log, or plenum, connected to the cylinders at the bottom through runners. The exhaust manifold plenum features vertical support plates that effectively split the plenum at the runners, and are slightly longer than the width of the exhaust runners with an open volume between the cylinder pairs. Therefore, the exhaust from each cylinder passes through the runners into individual volumes that merge into common volumes between cylinders and at the turbocharger turbine entrance (see Figure 4-9 for model configuration). There are two intake manifolds, one for each bank, with are each comprised of a common log with rectangular runners to each cylinder airbox. The airbox in each cylinder is a volume that has connections to the intake runner, base air chest, and intake ports. The inlet air can pass through the airbox into either (or both) the base air chest or ports.

The exhaust ports are the last to close and the last to communicate with the combustion chamber during a cycle. Therefore, dynamics in the exhaust would seem to be more critical to scavenging than the intake side. Initial focus on conceptual manifold designs therefore focused on the exhaust. Though later, some of the focus switched to the intake side due to potential negative influences by having the intake manifolds and cylinder airboxes communicating through the base air chest. The resulting matrix of concepts for solution of the potential breathing issues involved a few different viewpoints on the solution. One viewpoint was that the concept should not only improve air balance but also provide improved performance. Another viewpoint was that the influence from one cylinder on another should be removed and each cylinder isolated. Yet another viewpoint was that if the original manifold designs are fine as they are, then develop retro-fit concepts to mitigate the geometric influences. The original viewpoint was to design modifications or a new concept to mitigate flow imbalance and achieve equal breathing among cylinders. Designing devices to address a particular cylinder's geometric variation was thought to be too cumbersome and not pursued, as the variation would be random, not easily quantified without disassembly for measurement, and change when engine components are replaced. Thus, a series of concepts were developed and are shown in a flowchart in Figure 6-1. 


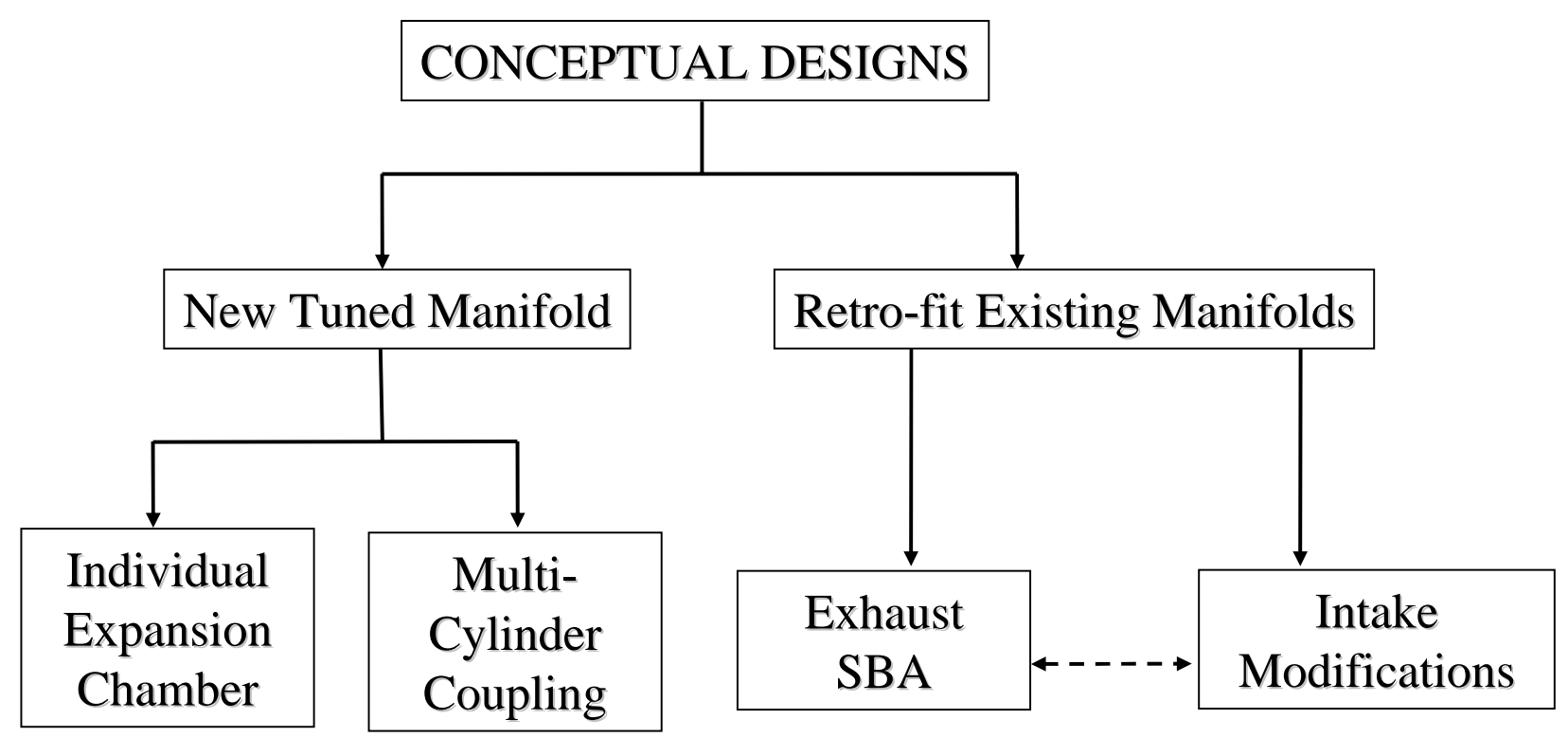

Figure 6-1. Flowchart of Current Conceptual Manifold Designs

\subsection{INDIVIDUAL TUNED EXPANSION CHAMBER CONCEPT}

The Individual Expansion Chamber concept involves the design and application of tuned expansion chambers for each cylinder. This concept would provide both cylinder isolation and could improve performance. Since this is a turbocharged engine, the individual expansion chambers would need to connect to a common plenum to maintain use of the constant pressure turbocharger. An expansion chamber is designed to first create a suction pulse that aids scavenge air flow, and then reflects a plugging pulse back to the exhaust ports at a time near port closing to supercharge or 'pack' fresh charge mass into the cylinder. This causes an increase in trapped mass that is typically utilized for increased power output. An excellent description and schematic of an expansion chamber for a single cylinder is provided by Dr. Gordon Blair in his text "Design and Simulation of Two Stroke Engines" ${ }^{[5]}$. This concept is most often applied to two-stroke performance or racing engines in applications such as motorcycles and snowmobiles. These applications are mostly single or two cylinder engines. An application specific to gas compression engines was a design produced by Cooper Compression for the $\mathrm{AJAX}^{\mathrm{TM}}$ engine family ${ }^{[6]}$. Example photographs of Individual Expansion Chamber manifolds are provided in Figure 6-2. 


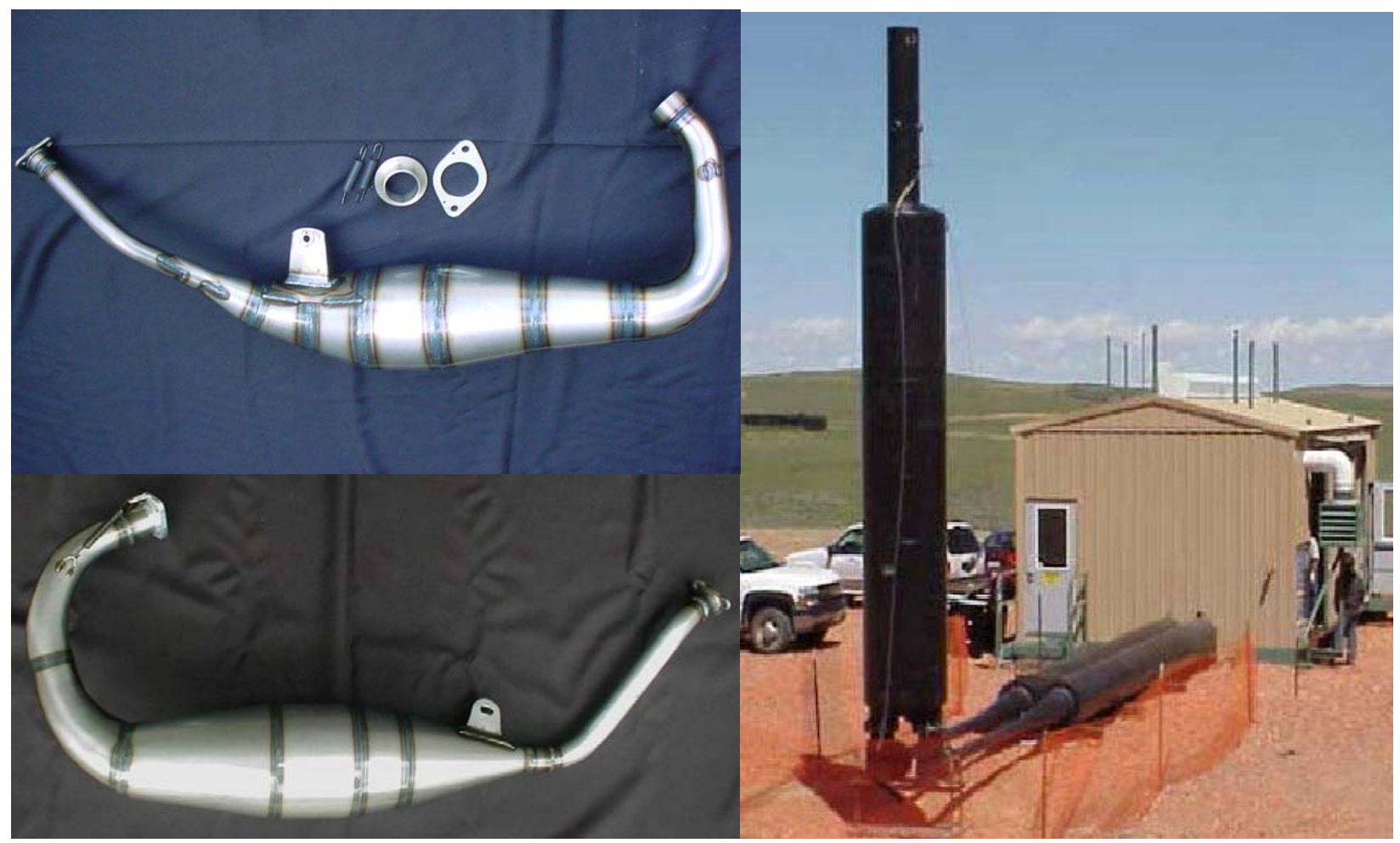

Figure 6-2. Photographs of Expansion Chambers (Motorcycle Application at Left \& AJAX ${ }^{\mathrm{TM}}$ Application on Right ${ }^{[4]}$ )

The design of an expansion chamber has been simplified by Dr. Blair and the equations from this text were utilized for an initial design of individual expansion chambers for the GMVH-6 engine. ${ }^{[5]}$ Figure 6-3 shows the various sections (lengths and diameters) specific to this design. The results of the initial design showed the overall length (LT) would be 60.2 feet and the major diameter (d4) would be 16.9 inches.

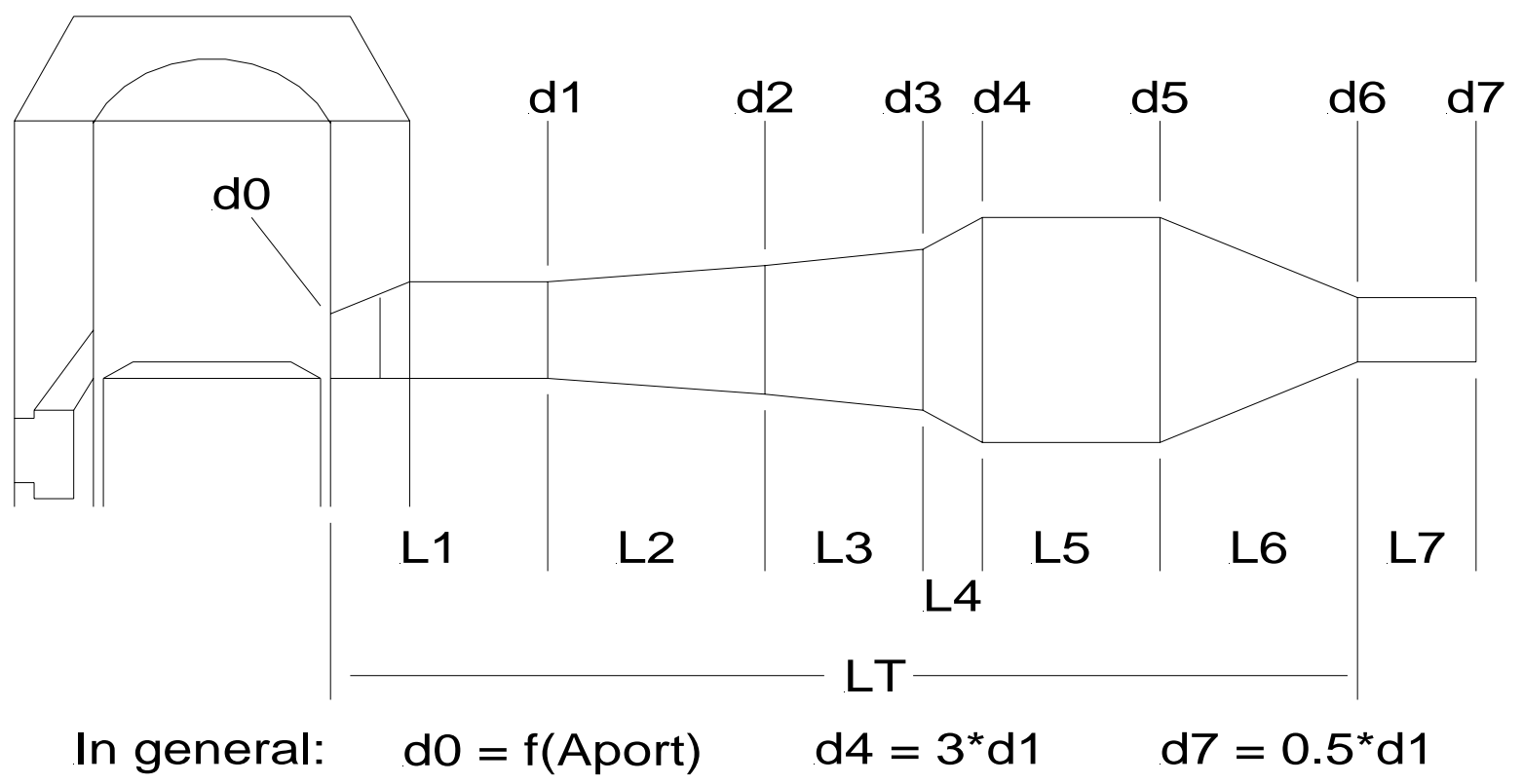

Figure 6-3. Design Parameters of an Individual Expansion Chamber Manifold 
The advantages of an Individual Expansion Chamber manifold for the GMVH-6 engine are as follows:

- Trapped mass increased for either leaner operation (if turbo-limited) or increased power.

- Isolation between cylinders from adverse dynamics caused by combustion instability would be achieved.

- Potential exists for tunable section to compensate for cylinder geometric variability, potentially allowing for balancing of cylinders in terms of trapped mass.

- Basic design is applicable to all two-stroke engines, more so for non-turbocharged engines.

The disadvantages of an Individual Expansion Chamber manifold for the GMVH-6 engine are as follows:

- Common plenum required to connect turbocharger to all expansion chamber outlets. Packaging would be extremely challenging, likely requiring off-engine turbocharger mounting.

- $\quad$ Size and complexity would create very expensive product.

- A tuned manifold has a very narrow operating band for efficient application. Performance may be worse than original manifold design at off-rated engine speed and load range.

The disadvantages for this concept outweigh the advantages, specifically in terms of cost and complexity. There was also concern that performance would be significantly degraded at operating conditions off-rated speed and load where the chambers would be tuned for maximum performance. Therefore, detailed design and optimization was not conducted for this concept.

\subsection{MULTI-CYLINDER COUPLING TUNED MANIFOLD CONCEPT}

The Multi-Cylinder Tuned Manifold concept follows the design for V-6 two-stroke engines typically used for outboard marine applications. This tuned manifold concept still utilizes a reflected pulse to supercharge the cylinder near port closure. The difference from the previous design is that this pulse is derived from another cylinder. The most attractive configuration would be three cylinders feeding into two plenums which then feed into one junction to the turbocharger. This configuration, called the 3-2-1 arrangement is depicted in Figure 6-4. This design would conveniently couple the cylinders by right bank and left bank due to the firing order and phasing inherent to the GMVH-6 design. 


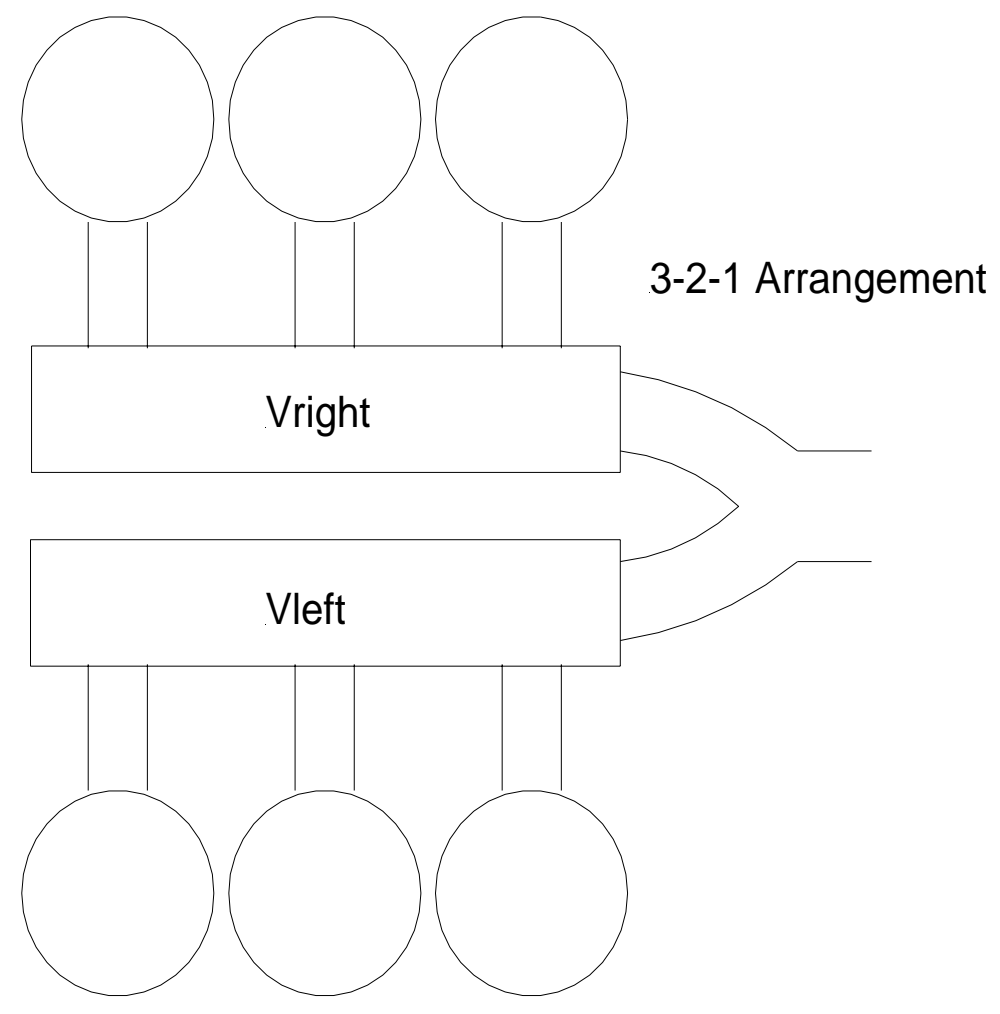

Figure 6-4. Multi-Cylinder Coupling Tuned Manifold Concept

As mentioned previously, cylinder firing occurs evenly, every 60 crank angle degrees in the GMVH-6. The phasing of blowdown events is shown in Figure 6-5. In this image, the coupling of the left and right bank cylinders can be seen. The design process would therefore focus on runner lengths and diameters to achieve the optimum timing of the pulse from one cylinder to the next (i.e. $1 \mathrm{~L}$ to $3 \mathrm{~L}$ to $2 \mathrm{~L}$ to $1 \mathrm{~L}$, etc.). 


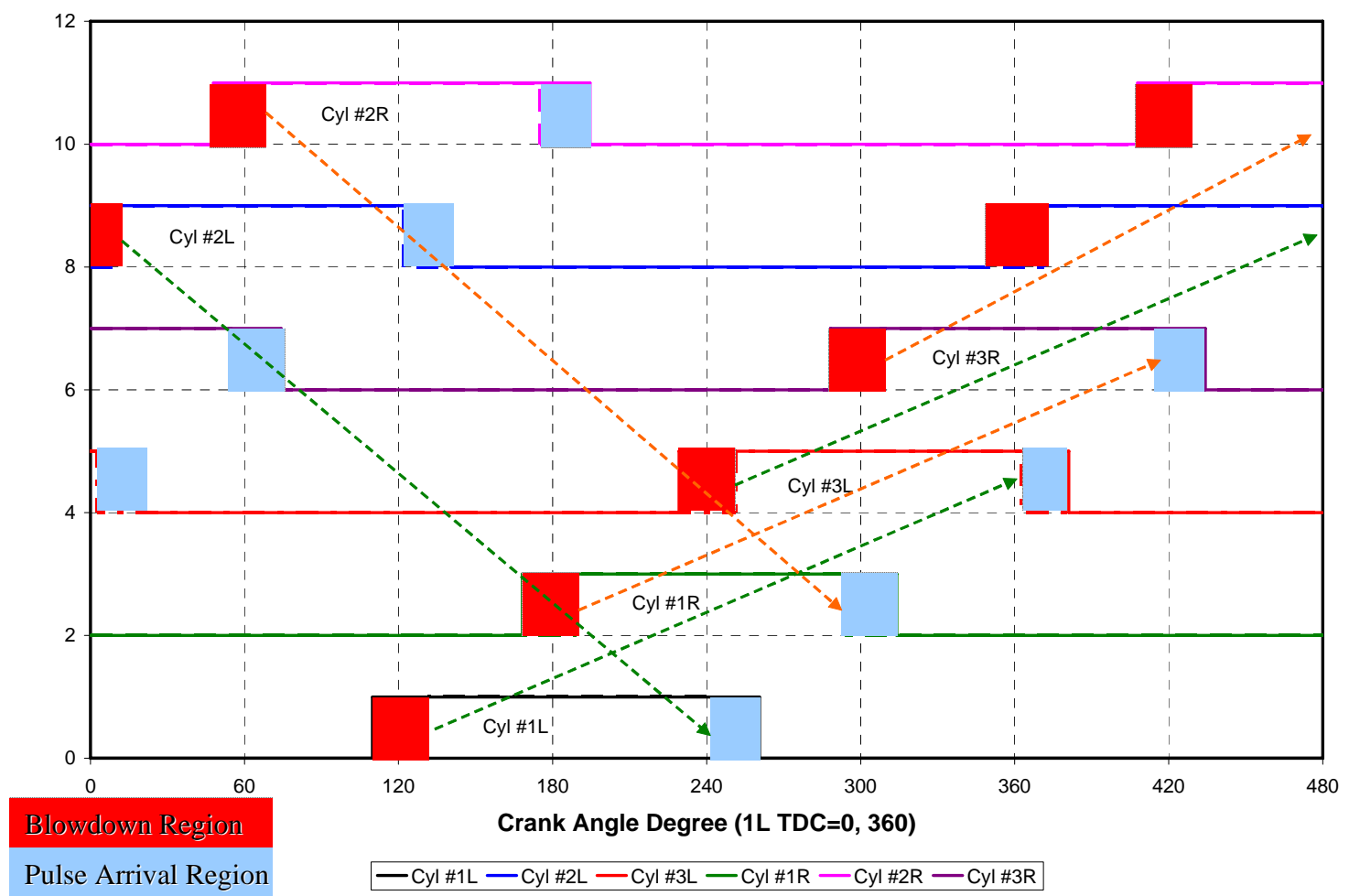

Figure 6-5. Phasing and Coupling of Cylinders on the GMVH-6 Engine

The design process for this concept utilized the Virtual 2-Stroke ${ }^{\circledR}$ software and the optimization process was conducted by Optimum Power Technology. The results of this process showed an expected increase in engine BMEP of approximately 4 percent at rated conditions (330rpm). The increase in BMEP is due to increased trapped mass and can be viewed as an ability to operate leaner at the same power output. The dimensions for this design are shown in Figure 6-6 for one bank (identical for opposing bank). The EMAN3 pipes from each bank would be coupled for a single EMAN4 pipe to the turbocharger. 


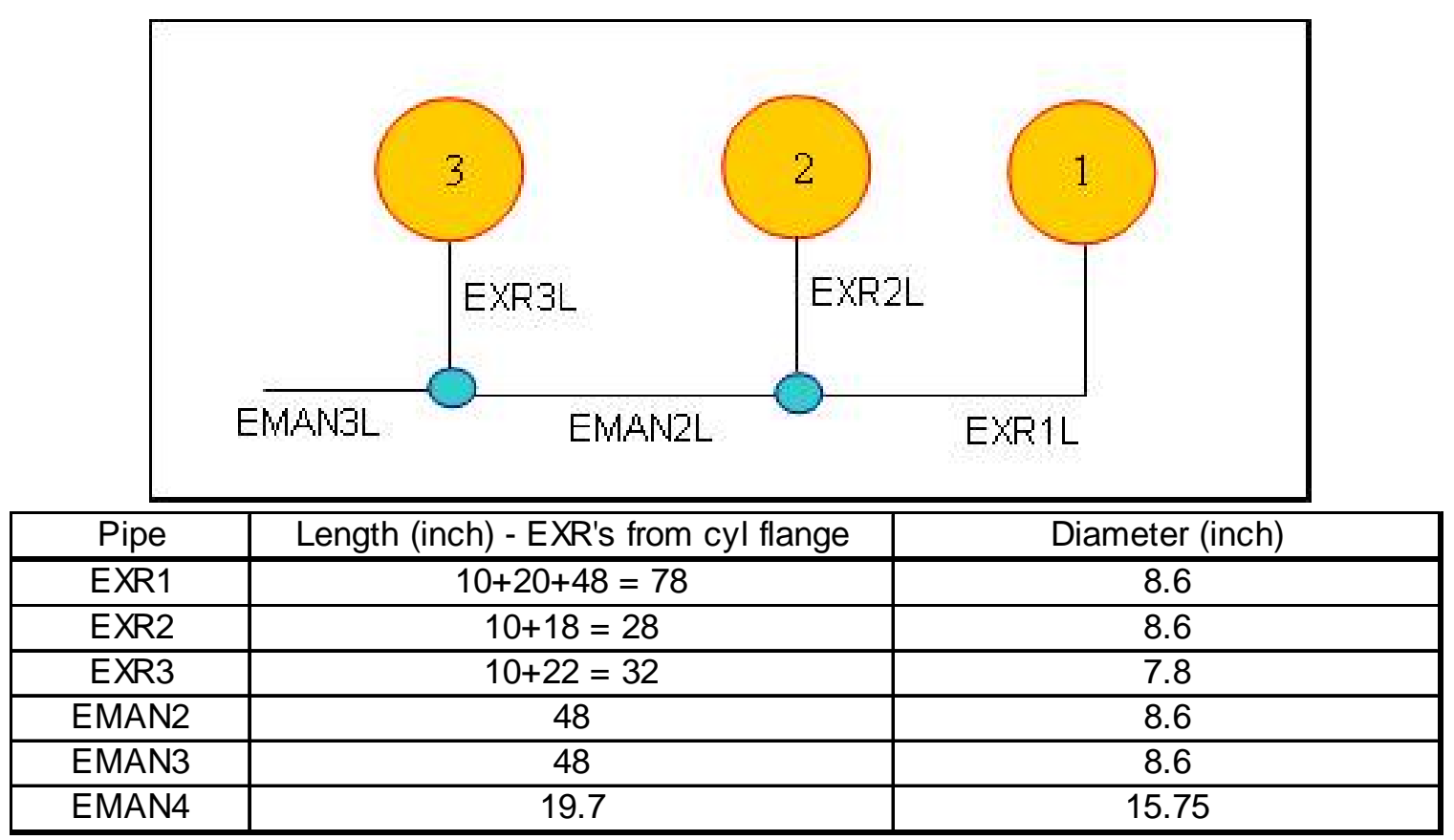

Figure 6-6. Dimensions for Optimized Multi-Cylinder Coupled Exhaust Manifold Concept

The advantages of the Multi-Cylinder Coupled exhaust manifold for the GMVH-6 engine are as follows:

- Trapped mass increased for either leaner operation (if turbo-limited) or increased power.

- Smaller size and dimensions than the Individual Expansion Chamber design.

- Potential exists for tunable section to compensate for cylinder variability, allowing for balancing of cylinders in terms of trapped mass.

- Basic design is more suited for turbocharged engines and should be applicable to all two-stroke engines, more so for Vee engines.

The disadvantages of the Multi-Cylinder Coupled exhaust manifold for the GMVH-6 engine are as follows:

- Completely new design would be an expensive product. Would likely require modification to turbocharger location/mounting, and in turn the compressor outlet pipes.

- Since pulse charging depends on a previously firing cylinder, the effect of a misfire in one cylinder would more greatly affect the next cylinder dependent on this pulse.

- Design seems applicable to V-6 engines. Design for in-line engines would be more complex in terms of packaging due to cylinder spacing.

- A tuned manifold has a narrow operating band for efficient application. Performance may be worse at off-rated engine speed and load range.

The disadvantages for this concept appear to outweigh the advantages, specifically in terms of cost and potential performance degradation with unstable combustion seen in most open chamber engines operating lean for low $\mathrm{NO}_{\mathrm{X}}$ emissions. There is also concern that performance would be degraded at operating conditions off-rated speed and load. 


\subsection{EXHAUST SIDE BRANCH ABSORBER (SBA)}

As mentioned in the discussion of the tuned manifold concepts, unstable combustion will affect the dynamic pressures and flows in the exhaust manifold and there is risk with a design that is dependant on these pulses. Therefore, a different approach was considered that would attempt to isolate the cylinders from the gas dynamics. One such approach was to incorporate a Side Branch Absorber (SBA) designed to dampen the specific frequency of pressure pulses caused by cylinder blowdown.

Data measured from the GMVH-6 for cylinder 1 Left is plotted in Figure 6-7. The incylinder, intake runner, and exhaust runner pressures versus crank angle are shown. Noted on this graph are the pulses in this one exhaust runner caused by the blowdown of all the other cylinders. Also seen on the exhaust runner pressure trace are higher frequency pulsations, specifically during the scavenging region.

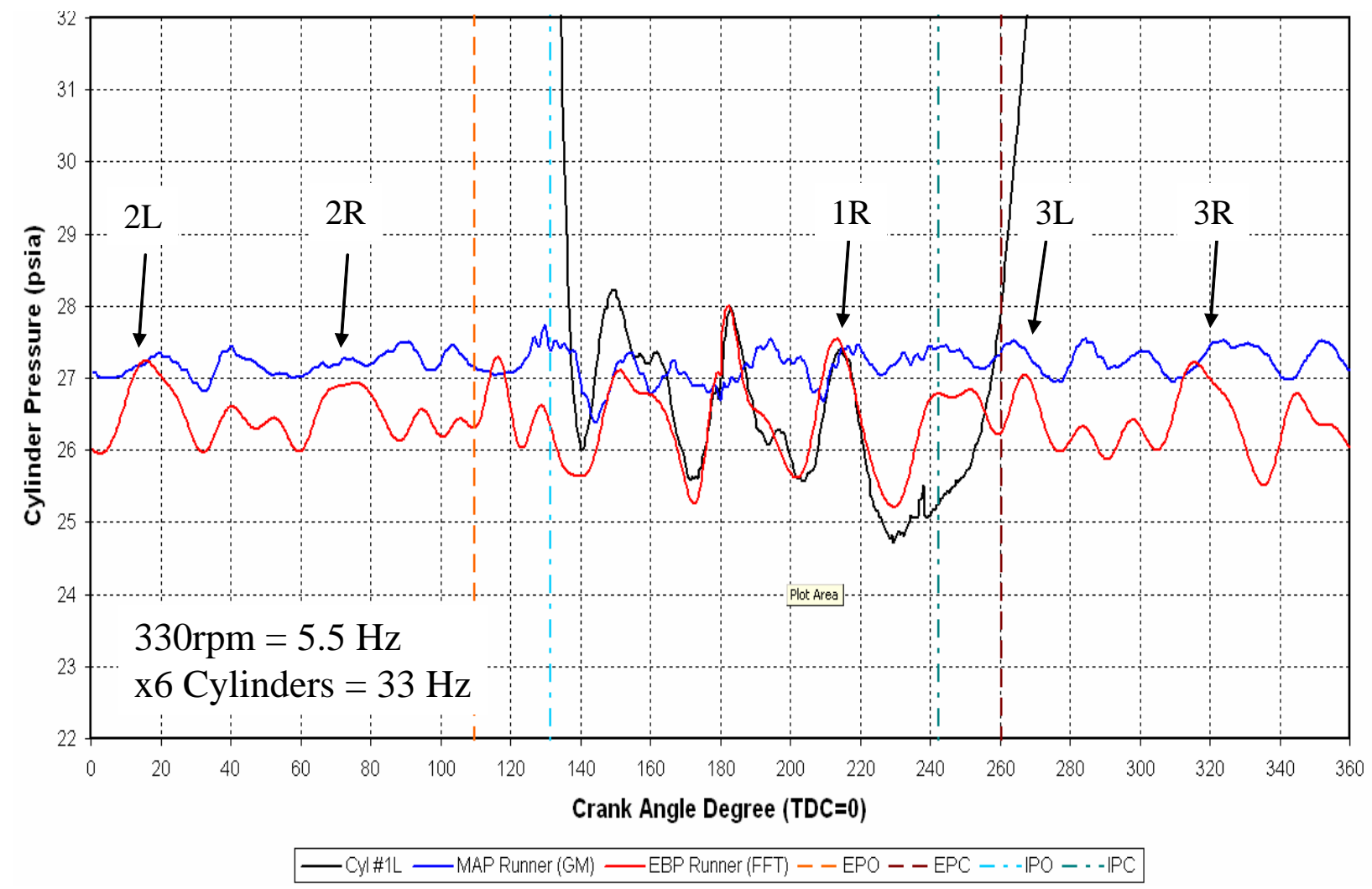

Figure 6-7. Dynamic Pressure Data Recorded on Cylinder 1L of the GMVH-6 Engine

An analysis on the exhaust dynamics was conducted with the SwRI developed IPPS model, which included derivation of the frequency modes and amplitudes of the measured exhaust pressures. Results of the data analysis are shown in Figure 6-8 for the left bank cylinders. The first mode of the length response of the exhaust chamber is seen in both the IPPS and engine data (near cylinders $1 \mathrm{~L}$ and 3L). The IPPS model predicted $64 \mathrm{~Hz}$ while the engine data showed 60 to $68 \mathrm{~Hz}$. The second mode of the response is seen at the center of the chamber (near cylinder 2 left). IPPS predicted $124 \mathrm{~Hz}$, and the engine data shows a response at approximately $132 \mathrm{~Hz}$. These results indicate that an SBA can be used to essentially eliminate the 1st mode of the response. Elimination of the pressure fluctuations during scavenging would 
be advantageous to increase scavenging and better isolate cylinders from each other for more consistent scavenging.

Acoustically, an SBA tries to create a velocity maximum at a point where a velocity minimum (pulsation maximum) exists. An SBA alters the acoustics such that the response associated with the frequency to which the SBA is tuned is "split" into two responses. The SBA design developed from IPPS modeling to address the exhaust dynamic pressure measurements is shown in Figure 6-9. The IPPS simulation results with the SBA incorporated are shown in Figure 6-10 for cylinder 1L.

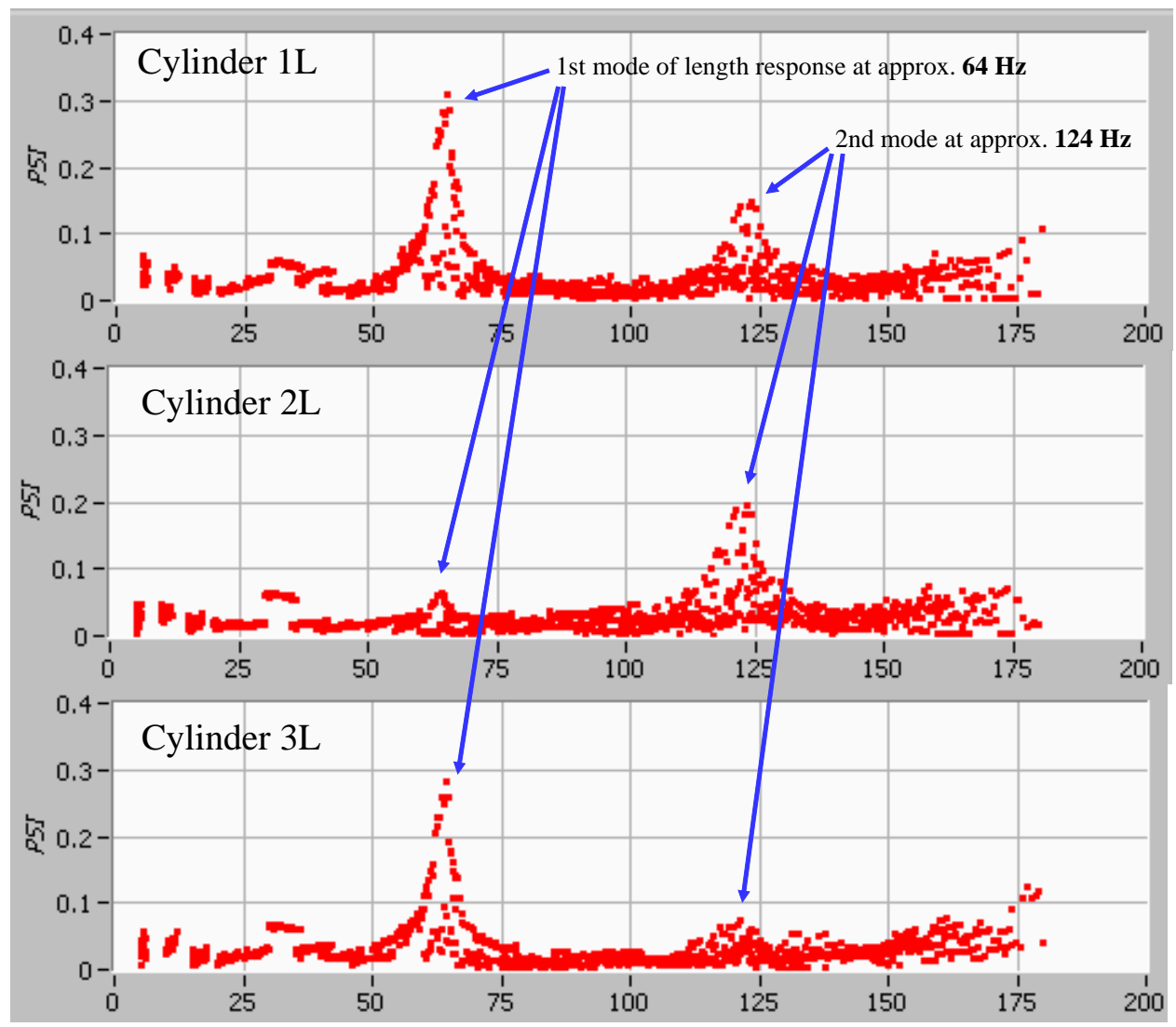

Figure 6-8. Frequency Analysis of Recorded Engine Data for Left Bank Cylinders 


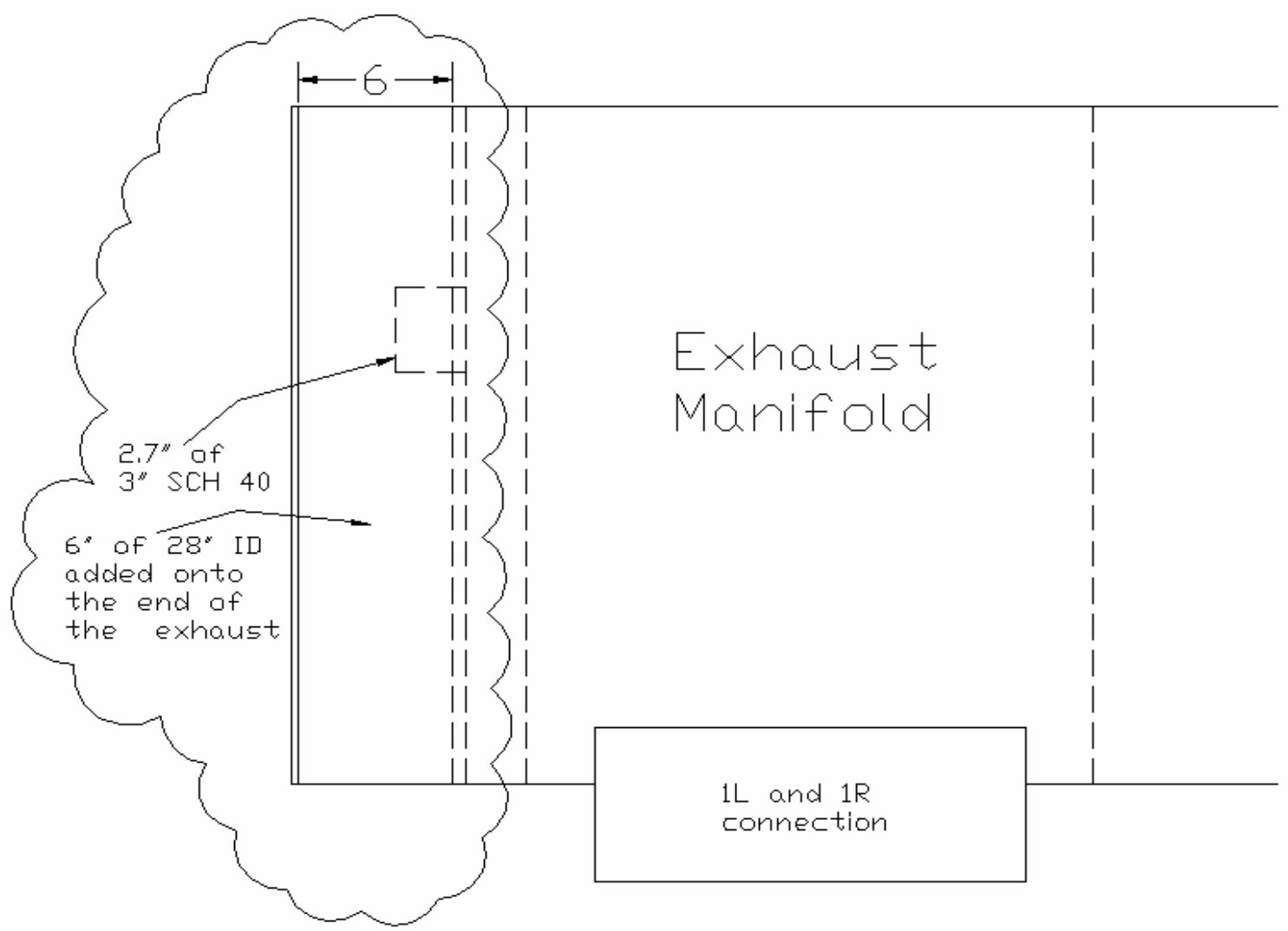

Figure 6-9. Conceptual Exhaust SBA Design for GMVH-6

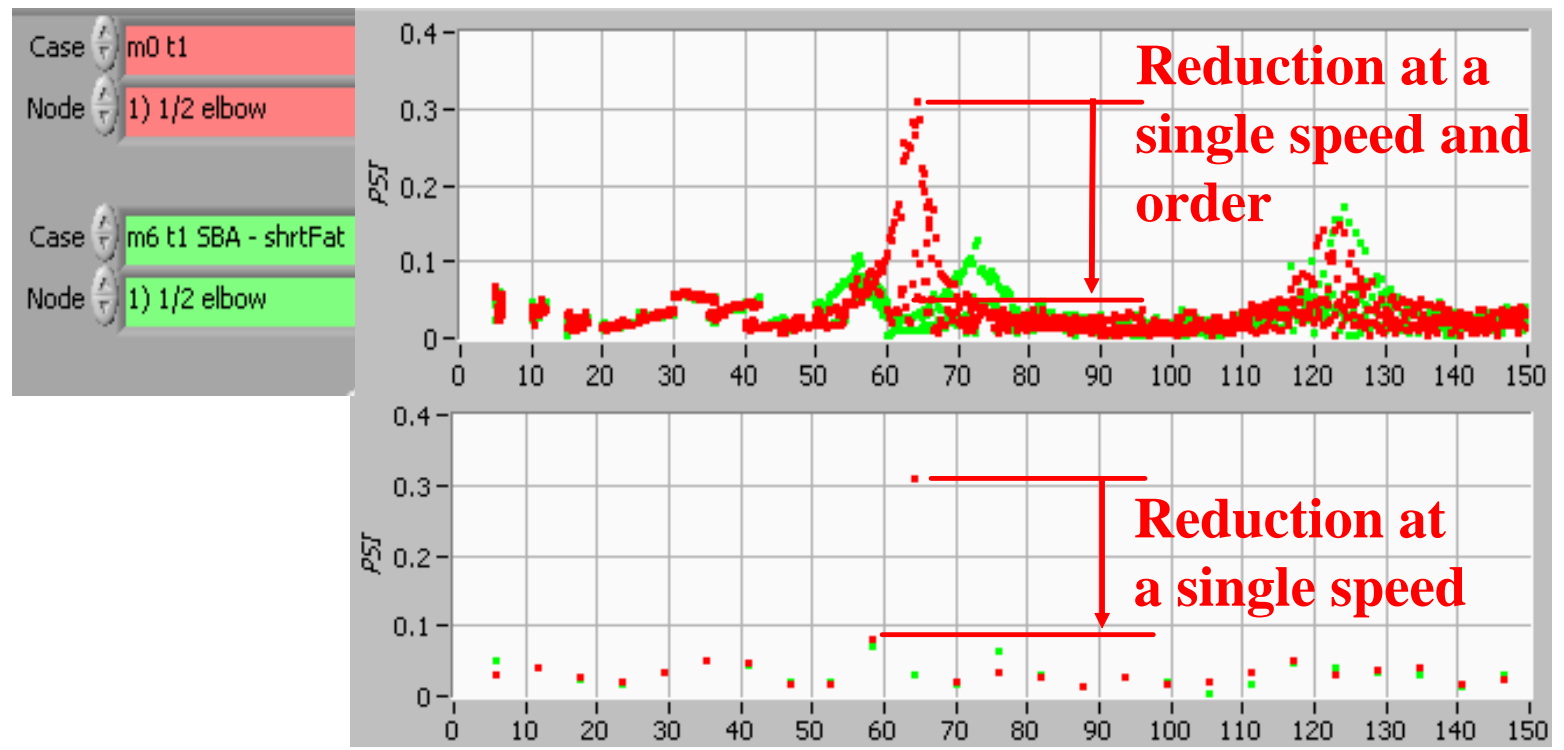

Figure 6-10. IPPS Model Results for SBA Concept

The advantages of the Exhaust SBA for the GMVH-6 engine are as follows:

- Cost-effective retro-fit of existing manifold.

- Concept design should provide better cylinder isolation for more consistent scavenging and combustion. 
- Some improvement in scavenging, and therefore performance, expected with pulsation attenuation.

- Can be designed to be tunable at different modes for best efficiency.

- Noise reduction would be expected as a side benefit.

The disadvantages of the Exhaust SBA for the GMVH-6 engine are negligible if the advantages can be achieved. If the mode changes at off-rated operating conditions, the SBA may become ineffective but will not alter engine performance from the original configuration. A more complex, but tunable design could be developed to address off-rated conditions.

The advantages for this concept make it very attractive. The next step was to conduct detailed analysis and optimization with the engine model. Initial modeling with the engine simulation showed only a small reduction in exhaust pulsations with the SBA. Iterations with SBA dimensions showed slight improvement in pulsation attenuation. It is currently uncertain if the engine model is accurately simulating the SBA. These devices have been designed and utilized in pipeline applications where they have successfully reduced resonant pulsations. SBA's are also used by the automotive industry on inlet air systems, such as late 1990's Chevrolet Pickups with V-8 engines. Therefore, more investigation was desired due to the costeffective potential and testing of the concept is in progress. A prototype SBA has been designed for easy changing of lengths and diameters, and with only minor modifications required on the engine. Demonstration testing will be conducted in the next task of this project.

\subsection{INTAKE MANIFOLD MODIFICATIONS}

The last concepts considered were modifications to the intake manifold. One of the intake concepts included blocking the base air chest to ensure all inlet air is derived from the intake manifold and then modifying the intake manifold volume to dampen the resulting pulsations that will occur. The second intake concept is a modification to the plenum entry where the manifold is connected to the aftercooler.

The base air chest is a legacy design in the GMV from earlier versions where scavenging was accomplished with either pistons or blowers. In these earlier designs, air was fed to each cylinder through the air chest. The GMVH design is turbocharged with external intake manifolds, but the base air chest was left active and connected to all cylinders. In actuality this air chest provides excellent dampening of intake pulsations. However, the air being fed into and out of this air chest undoubtedly is heated due to the very large surface area at or near oil temperatures. A concept was derived based on this to block the base air chest and reduce the actual air temperature entering the cylinder.

The first analysis was to determine what percentage of the total mass flow entering each cylinder is fed from the air chest. The engine simulation model was utilized for this analysis and results shown in Figure 6-11, where the instantaneous mass air flow from the air chest (plenum) and intake manifold runner is plotted with cylinder pressure. An integration of these traces shows that approximately 33 percent of the total mass air flow comes from the air chest, with the remainder coming from the intake manifold. This portion of the total mass flow was felt significant enough that eliminating the air chest flow would cause a significant reduction in inlet temperature. Simulation has shown that the air temperature entering the ports is approximately $20^{\circ} \mathrm{F}$ hotter than the air in the intake manifold log. A reduction in inlet air temperature would provide reduction in both $\mathrm{NO}_{\mathrm{X}}$ emissions and the tendency to knock. Prior test data from lean- 
burn natural gas engines indicates that a $10^{\circ} \mathrm{F}$ drop in inlet air temperature could achieve approximately $0.2 \mathrm{~g} / \mathrm{bhp}-\mathrm{hr} \mathrm{NO}_{\mathrm{X}}$ reduction in the GMVH-6. While not a significant reduction in total $\mathrm{NO}_{\mathrm{X}}$, an engine bordering on meeting permit levels would benefit in terms of efficiency with this amount of cushion or margin from the limit.

GMVH Simulation - Cyl 1L

330 rpm 100\% Load - Identical Cylinders

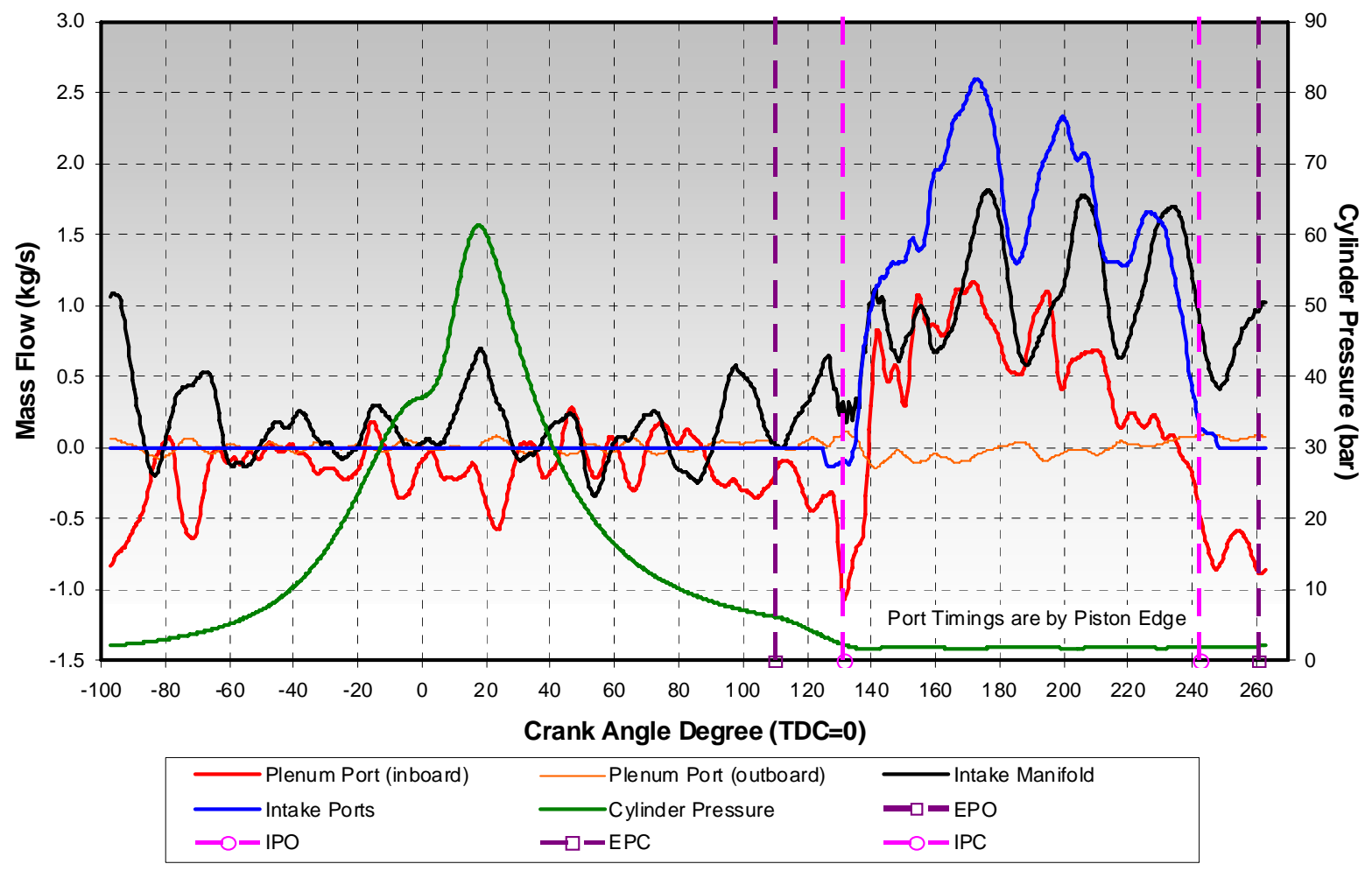

Figure 6-11. Simulated Mass Air Flow from Base Plenum, Intake Manifold, and Through the Intake Ports

The next step in this analysis was to re-design the intake manifold to prevent the pulsations that will occur with the elimination of the base plenum. Earlier simulations with the base plenum not incorporated into the model were used to derive the expected pulsation amplitude and frequency. The IPPS model was then utilized to determine if this pulsation was resonant and could be addressed with an SBA or if simple enlargement of the volume is required. The pulsation was determined to not be resonant and therefore the additional volume required for the intake manifold was derived. With the new intake volume determined, the engine simulation model was utilized to determine the potential temperature reduction with this concept.

The simulation results showed a disappointing reduction of only $4^{\circ} \mathrm{F}$. This reduction is not felt sufficient to justify the cost of removing each power cylinder and capping the base plenum with special gaskets. An alternative approach was to reduce the large volume (large surface area) inside each cylinder's airbox, which is suspected to still cause significant air heating even with the base plenum disconnected. This alternative, however, would require a new cylinder casting and would become even more costly. 
The next concept for intake manifold modification was not derived from simulation, but rather engineering judgment. The intake manifolds on each bank are composed of a log with runners branching perpendicular to each cylinder. The entrance to each log is connected via bolted flange to a transitional duct on the aftercooler. The issues are with the bolted flange which is internal to the manifold log, and the short transitional duct from the aftercooler. The transitional duct does not appear optimum for flow and the internal flange in the manifold log creates an orifice that is very close to the first cylinders' (3L and 3R) runners. A photograph and sketch of the left bank intake manifold and aftercooler duct are shown in Figure 6-12. The orifice created by the internal flange is likely creating a vena-contracta that may be restricting flow to the first cylinder runner. Cylinders 3L and 3R are the two lowest cylinders in terms of compression pressure as seen in Figure 5-9.
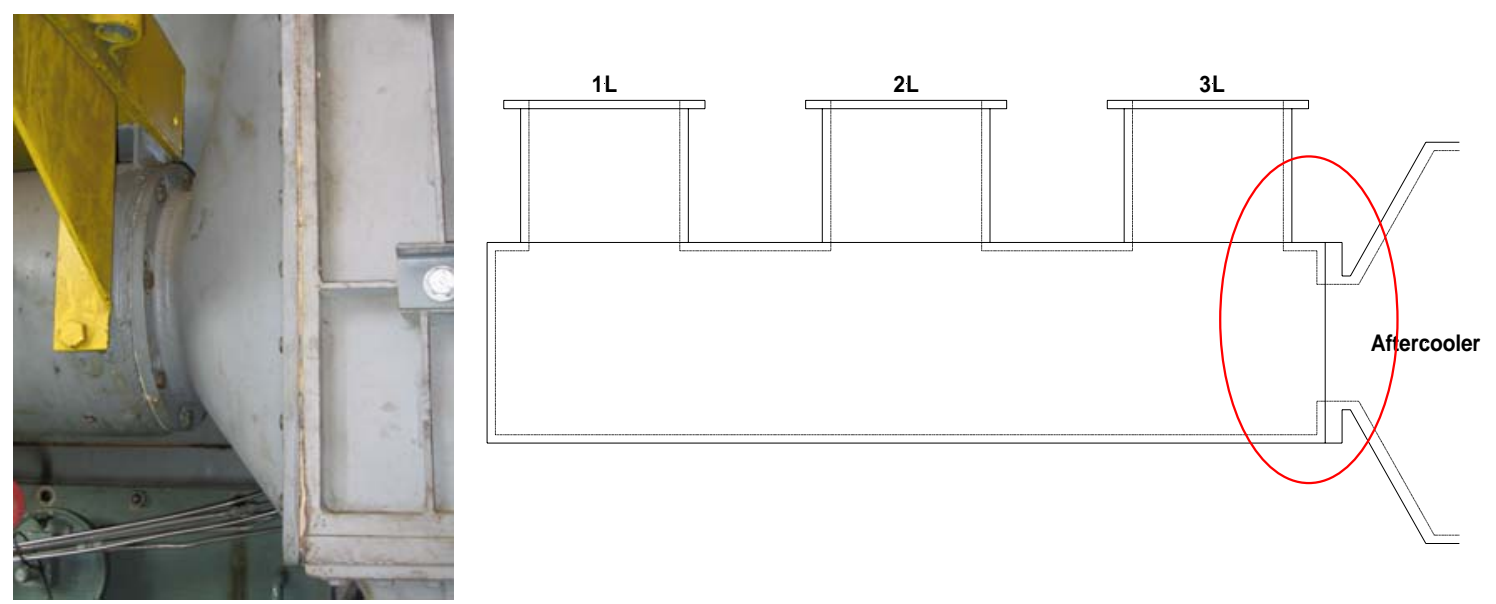

Figure 6-12. Photograph and Sketch of Intake Manifold Showing Region of Concern for Flow Disturbance and Restriction

If the vena-contracta is creating a flow structure that limits the flow to the first cylinders, then those cylinders will likely draw more air from the base air chest and may not trap as much total mass as the other cylinders. The air from the base is hotter than from the intake manifold air. This theory could explain the difference between measured data and simulation with geometric affects, which still cannot predict completely the spread in compression pressures. The flow phenomena suggested at the intake manifold entrance is highly dependent on the threedimensional geometry. It is therefore suspected that a one-dimensional model may not completely capture the affects. The affect can either be simulated with a three-dimensional CFD program, or testing on the engine can determine if the suspected flow disturbance is significant in affecting the flow.

The engine test planned to address this suspicion is to add thermocouples in the base plenum access doors and probes in the inlet runners of cylinders $1 \mathrm{~L}$ and 3L. The thermocouples will provide the needed temperature measurement of base plenum air and the probes will provide relative measurement of the dynamic air flow entering these cylinders. A significant reduction in air flow or velocity in cylinder 3L compared to cylinder $1 \mathrm{~L}$ would validate that the intake manifold design is affecting flow, and therefore trapped mass, among the cylinders.

The design concept would then involve removing the internal flange, possibly lengthening the intake log, adding an external flange, and possibly lengthening the aftercooler duct. The flange on the aftercooler duct will need to be redesigned for a larger bolt pattern 
matching the new external flange on the intake manifold log. This modification would also require a new mount design for the aftercoolers and modified turbocharger compressor outlet pipes.

The advantages of the Intake Entrance Modification for the GMVH-6 engine are as follows:

- Cost-effective retro-fit of existing manifold, compared to new exhaust manifold.

- Concept design should provide better cylinder air balance. With cooler, denser charge to end cylinders. Potential for better air/fuel ratio balance.

- Can be coupled with and compliment exhaust manifold modifications.

The disadvantages of the Intake Entrance Modification are as follows:

- Potentially will affect only two of six cylinders, and performance gain would need to be determined for cost-effectiveness. However, on some engines one poor performing cylinder (i.e. knocking or misfiring) would affect the overall engine performance if global spark timing and/or air/fuel ratio adjustment is required to compensate.

Additional testing is planned in the next task of this project. This testing will focus on quantifying any difference in actual flow from the intake manifold into the cylinders on a given bank. If the test results indicate a flow discrepancy, then design considerations to alleviate the flow imbalance will be determined. 


\section{CONCLUSIONS}

This on-going project began with the presumption that flow variations and/or dynamic pulsations due to manifold design were causing the measured spread in compression pressure and therefore causing deviations in the scavenging and resulting trapped mass. A spread in trapped air mass, and therefore trapped air/fuel ratio, would lead to undesirable results such as lower efficiency, higher $\mathrm{NO}_{\mathrm{X}}$ production, increased crankshaft stress, increased vibration, and reduced operating margins from detonation and misfire. To add credence to the air imbalance theory, various field tests have shown the sensitivity of one or two cylinders per engine to adjustments in global air/fuel ratio. This sensitivity indicates that these cylinders are operating at or near the misfire or knock thresholds, which implies differences in trapped air/fuel ratio.

To further investigate and develop solutions, the Cooper Compression laboratory GMVH-6 engine was used for testing and the Virtual 2-Stroke ${ }^{\circledR}$ software was used for simulation and design. Through the course of the project thus far, several conclusions have been made and areas for further research have been identified. The conclusions thus far are as follows:

- $\quad$ The GMVH-6 test engine has exhibited an 11 percent difference in compression pressure between the highest and lowest cylinder. A spread of 10 percent was consistently measured between cylinders $1 \mathrm{~L}$ and $3 \mathrm{~L}$, which are on the same bank and experience the same articulation effect.

- $\quad$ The GMVH-6 test engine was disassembled and the geometric variances were quantified. Cylinder 3L, which has the lowest compression pressure, was found to have a 0.3 point lower effective compression ratio, 2 of 5 exhaust ports opening earlier and closing later by 1-1.5 degrees, and lower inlet port discharge coefficient at low port opening positions. These variations all trend with the lower compression pressure. Conversely, cylinder $2 \mathrm{R}$ has the highest compression pressure but was found to have the lowest effective compression ratio. Cylinder $1 \mathrm{R}$ was found to be a different casting than the other five cylinders and exhibited several differences in port geometry and exhaust flow coefficient. Cylinders 1L and 3L were swapped and cylinder 1R replaced during re-assembly to allow further testing of geometric effects.

- A one-dimensional simulation model was constructed for the GMVH-6 engine using Virtual 2-Stroke ${ }^{\circledR}$ software. The model was validated to measured data from cylinder 1L and used for analysis and design. Results of a model with identical cylinders, matching the mean values from geometric analysis, showed only a contribution from articulation on the compression pressures and no adverse effects of the original manifold designs. The model was used for sensitivity studies of the geometric variations and found they account for approximately 50 to 60 percent of the compression pressure spread. The remaining discrepancy between the measured spread and that contributed to by geometric variances is being investigated in the next task.

- Several manifold concepts were developed. Design and simulation was conducted for each concept and several were eliminated due to cost-benefit predictions. Testing of the exhaust SBA concept is planned and additional measurements are being acquired to validate theories of the intake manifold entrance design issue.

Additional tasks remaining on the project are the testing and analysis mentioned above and conducting validation testing. Since the geometric variations have shown to be a significant 
factor, measurement techniques and procedures will be developed to aid diagnosis of mismatched components and identify components out of specification. 


\section{REFERENCES}

1. Heywood, John and Sher, Eran, The Two-Stroke Cycle Engine, Taylor \& Francis, 1999.

2. Heywood, John, Internal Combustion Engine Fundamentals, McGraw-Hill Publishing Company, 1988.

3. Taylor, C.F., The Internal Combustion Engine in Theory and Practice, Vol. $1,2^{\text {nd }}$ ED., MIT Press, 1985.

4. Blair, G.P., The Basic Design of Two-Stroke Engines, SAE International, 1990.

5. Blair, G.P., Design and Simulation of Two-Stroke Engines, SAE International, 1996.

6. Chrisman, B.M. and Bartos, J.C., "Development and Testing of an Expansion Chamber for the Reduction of $\mathrm{NO}_{\mathrm{X}}$ Emissions in a Two-Stroke Lean Burn Gas Engine," Gas Machinery Conference, 2004. 